NASA CR-159578

DOUGLAS REPORT NO, MDC J7733

NASA-CR-159578

19800001895

An Efficient User-Oriented Method for Calculating Compressible Flow In and About Three-Dimensional InLets

JOHN L. HESS

DUN-POK Mack

Norbert 0. Stockman (NASA Lewis Research Center)

Douglas Aircraft Company

McDonne11 Douglas Corporation

Long Beach, Ca. 90808

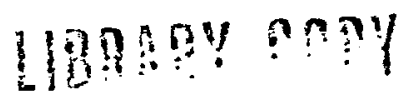

Contract NAS3-21135

Apri 1979

DCT 3 ins:

LAMLi.

$E R$

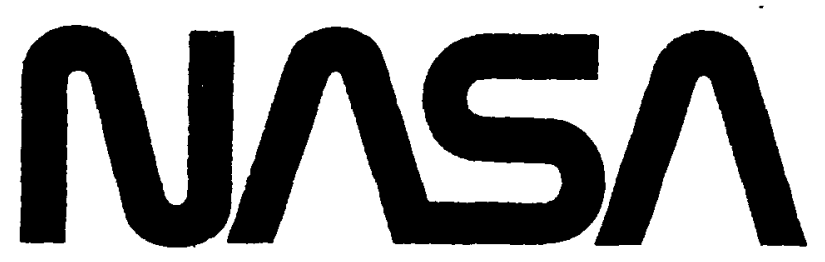


31176001895698 
NASA CR-159578

Report No. MDC 38497

\title{
AN EFFICIENT USER-ORIENTED METHOD FOR CALCULATING COMPRESSIBLE FLOW IN AND ABOUT. THREE-DIMENSIONAL INLETS
}

\author{
by \\ John L. Hess \\ Dun-Pok Mack \\ Norbert 0 . Stockman \\ (NASA Lewis Research Center)
}

APRIL 1979

prepared under

CONTRACT NO. NAS3-21135 
NOTE

The requirements of NASA Policy Directive NPD 2220.4 (Sept. 14, 1970) regarding the use of SI Units have been waived in accordance with the provisions of paragraph 5D of that Directive by the Director of Lewis Research Center. 


\subsection{ABSTRACT}

This method uses a panel method to calculate incompressible flow about arbitrary three-dimensional inlets with or without centerbodies for four fundamental flow conditions: unit onset flows paraliel to each of the coordinate axes plus static operation. The computing time is scarcely longer than for a single solution. A linear superposition of these solutions quite rigorously gives incompressible flow about the inlet for any angle of attack, angle of yaw, and mass flow rate. Compressibility is accounted for by applying a we11-proven correction to the incompressible flow. Since the computing times for the combination and the compressibility correction are smal1, flows at a large number of inlet operating conditions are obtained rather cheaply. Geometric input is aided by an automatic generating program. A number of graphical output features are provided to aid the user, including surface streamline tracing and automatic generation of curves of constant pressure, Mach number, and flow inclination at selected inlet cross sections. This report describes the inlet method, including the use of the program and presents illustrative results. 


\subsection{TABLE OF CONTENTS}

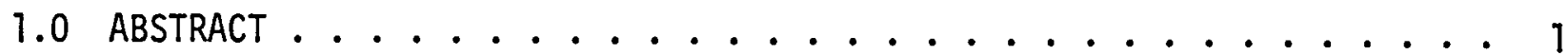

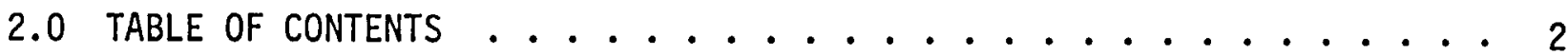

3.0 GENERAL DESCRIPTION OF THE METHOD ............. 5

3.1 The Panel Method ............... 5

3.2 The Technique of Superposition of Fundamental Solutions . . . . 6

3.3 The Compressibility Correction. . . . . . . . . . . 10

3.4 Geometric Specification of the Inlet .......... 12

3.5 symmetry ..................... 12

3.6 Graphical Output Options .............. 13

4.0 GENERAL REQUIREMENTS OF THE GEOMETRIC INPUT .......... 15

5.0 OVERALL OPERATION OF THE PROGRAM ............... 17

6.0 PROCEDURE FOR NONSYMMETRIC CASES . . . . . . . . . . 19

6.1 Basic Potential-Flow Program . . . . . . . . . . 19

6.2 Cross Sections and Control Station ............ 20

6.3 Combination Program ................ 20

7.0 PROCEDURE FOR SYMMETRIC CASES .............. 22

7.1 Input and Geometric Output ............... 22

7.2 Basic Potential-Flow Program . . . . . . . . . . 22

7.3 Cross Sections and Control Stations ............ 23

7.4 Combination Program ............... 23

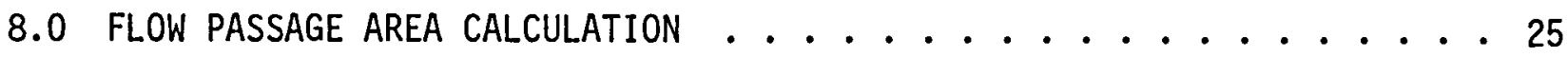

8.1 Organization of the Input ........... 26

8.2 Intersection Program $\ldots \ldots \ldots 27$

8.3 Initial Centerline Point. . . . . . . . . . . 27

8.4 Interior and Exterior Points of the Intet ........ 27

8.5 Initial flow Passage Area ............. 28

8.6 Successive Flow Passage Areas . . . . . . . . . . 29

8.7 Possibilities for the Centerbody ............. 29

8.8 Arc Length Tables. Interpolation for Flow Passage Area at Interior Control Points . . . . . . . . . . . . . 31

8.9 Flow Passage Areas at Exterior Control Points of the Inlet . . 32 
8.10 Flow Passage Areas at Exterior Control Points of the Centerbody . 34

8.11 Flow Passage Areas for Off-Body Points . . . . . . . . 35

9.0 CROSS-SECTION AND CONTROL STATION PROGRAM ........... 36

9.1 Input . . . . . . . . . . . . . . 36

$9.2 \mathrm{~N}$-Line Intersections and Flow Passage Area ....... 36

9.3 Cross-Section $\mathrm{N}$-Lines . . . . . . . . . . . 37

9.3.1 No Centerbody ............... 37

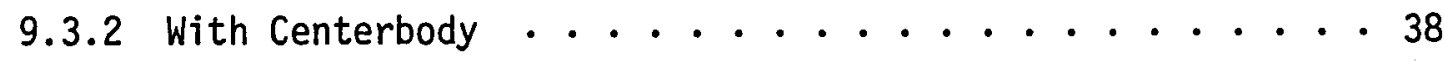

9.4 Cross-Section Panels and Control Points . . . . . . . . 39

9.5 Flow Calculation . . . . . . . . . . . . . . 42

10.0 COMBINATION PROGRAM INPUT AND PRELIMINARY CALCULATIONS . . . . 44

10.1 Incompressible Option . . . . . . . . . . . . 44

10.2 Freestream Conditions . . . . . . . . . . . . . 4 44

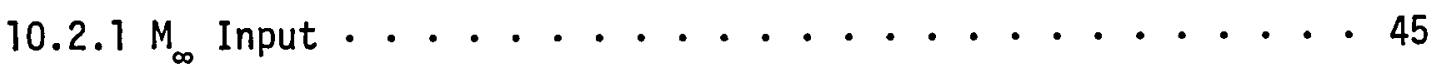

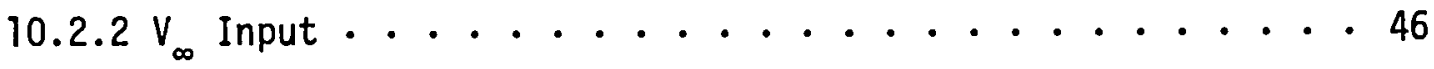

10.2.3 Additional Freestream Quantities . . . . . . . 46

10.2.4 Summary .................. . . 47

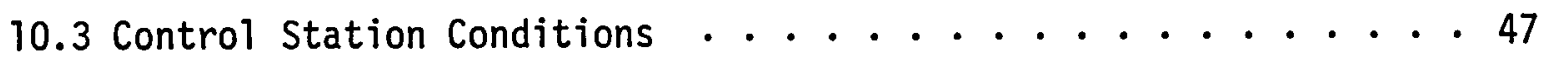

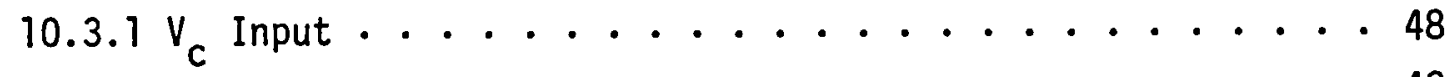

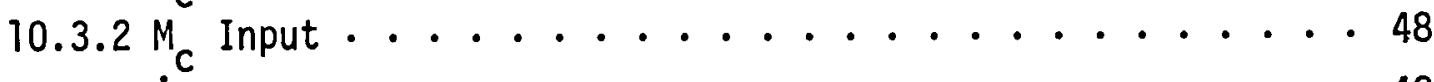

$10.3 .3 \mathrm{w}$ Input . . . . . . . . . . . . 48

10.3.4 Additional Control Station Quantities ...... 48

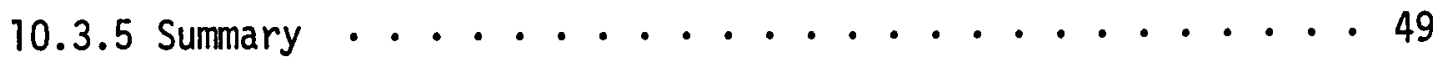

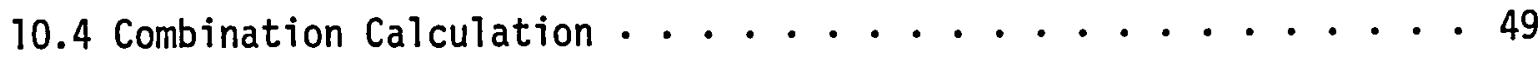

10.5 Compressibility Correction . . . . . . . . . . 4 49

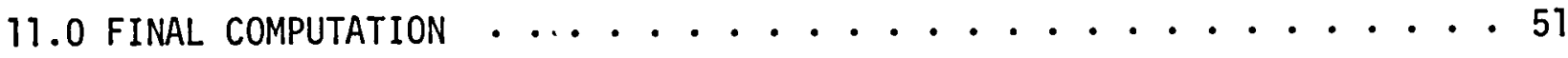

11.1 Incompressible Option .............. 51

11.2 Basic Compressible Calculation ............. . 51

11.3 Additional Output Quantities Pertaining to a Cross Section as a

Whole..................... 52

11.4 An Example Comparing Calculated Results with Experimental Data. 53

12.0 INPUT TO THE PROGRAM ................. 55

12.1 Types of Execution ................ 55

12.2 The Various Input Cards . . . . . . . . . . 55

12.3 Specific Input Card Formats . . . . . . . . . 56 
13.0 INPUT TO THE GEOMETRY PACKAGE. . . . . . . . . . . . 66

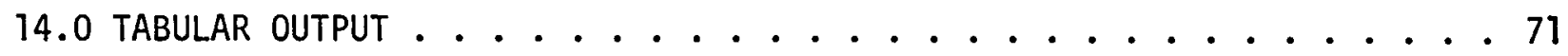

14.1 Basic Body Geometry . . . . . . . . . . . . . . 71

14.2 Fundamental Solution Output .............. 71

14.3 Cross-Section Control Data ............. . . 72

14.4 Cross-Section Panel Geometry ............. . 72

14.5 Cross-Section flux . . . . . . . . . . . . 73

14.6 Incompressible Combination Output ........... . 73

14.7 Compressible Combination Output . . . . . . . . . . . . 74

14.8 Error Messages . . . . . . . . . . . . . . . 74

15.0 EXAMPLES OF GRAPHICAL OUTPUT ............. 80

15.1 Surface Streamlines ................ 80

15.2 Equi-Value Contours in a Cross Section .......... 82

16.0 ACKNOWLEDGMENT . . . . . . . . . . . . . . . . 85

17.0 PRINCIPAL NOTATION . . . . . . . . . . . . 86

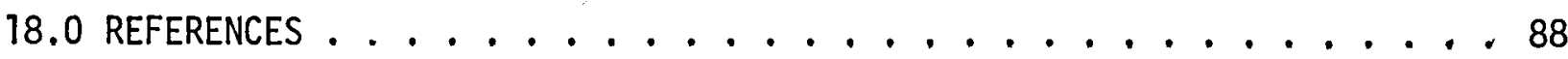

APPENDIX A. OVERLAY STRUCTURE . . . . . . . . . . . . . . 89

APPENDIX B. EXTERNAL UNITS USED IN THE PROGRAM ............ 90

APPENDIX C. SAMPLE INPUT AND OUTPUT FOR A SMALL PANEL NUMBER TEST CASE. . . 93 


\subsection{GENERAL DESCRIPTION OF THE METHOD}

The computer program that has been constructed for analyzing flow in and about the forward portions of nonaxisymmetric engine inlets applies to nonround inlets, inlets with curved centerlines, and scoop inlets. The range of operating conditions to which the method is applicable is essentially unrestricted except that the flow at large distances must be subsonic with respect to the inlet. Generally speaking, the present method may be considered a generalization of that of Stockman (Ref. 1), which is restricted to axisymmetric geometries. No attempt has been made to develop new physical or mathematical theories. Instead, well-proven computational techniques have been assembled in a new way. The main criterion used in assembling this method has been numerical efficiency with special emphasis on the case where solutions for a fairly large number of distinct operating conditions for a given geometry are desired. A second major consideration has been to assure maximum utility for users of the procedure. This has been accomplished by providing a geometry generating program to facilitate input and certain graphical output options to display the calculated flow quantities in a manner shown by experience to be usefur.

\subsection{The Panel Method}

The basic calculational tool is a panel method for calculating inviscid incompressible lifting flow about arbitrary configurations (Ref. 2). In recent years the use of panel methods has grown to the point where at least the simpler, older versions are now standard aerodynamic design tools. Moreover, the literature on panel methods has increased in a similar degree. Accordingly, details of the panel method are not given here, but only some aspects that are particularly important for the present application are discussed.

The body about which flow is to be calculated is input to the computer by means of the coordinates of a set of points lying on the body surface. These points are used to form a large number of quadrilateral "panels," which form the discrete representation of the body. An example is shown in Figure 4 . On each panel there is a surface source distribution whose strength is initially unknown. The calculational procedure forms a large full matrix that represents the 
aerodynamic influences of the panel sources on each other. A matrix equation is then solved, which expresses the condition that the total flow about the body must have zero normal velocity at one point of each panel. That is, the source strengths on the panels are adjusted to cancel the normal components of whatever onset flow or flow environment is incident to the body. Each right side of the linear equations corresponds to a particular onset flow, and yields a complete set of panel source strengths and thus a complete flow about the body. The aerodynamic influence matrix depends only on the geometry of the body. If, as in the present program, a direct matrix solution is used, solutions for several flows about the body may be obtained in essentially the same computing time as a single solution.

Because panels are placed on the actual surface of the body, rather than on some interior surface, the method described above is applicable to arbitrary configurations with no restrictions to slender bodies or small flow perturbations. Moreover, the method is numerically exact in the sense that any degree of accuracy may be obtained by using a sufficiently large number of panels. The key calculational efficiency of a panel method, as opposed to, say, a finite-difference method, is that the former need not solve for the entire flow field, but can obtain the flow only on the surface if desired. Flow at off-body locations can then be generated only where it is of interest, e.g., at certain interior cross sections.

\subsection{The Technique of Superposition of Fundamental Solutions}

The basic panel-method calculational efficiency as described above is augmented in the inlet application by additional efficiencies arising from use of the technique of superposition of fundamental solutions to obtain flows at various inlet operating conditions. For a simple closed body in incompressible flow the operating condition is defined by the magnitude and direction of the flow at large distances. Thus there are three parameters: angles of attack and yaw, and velocity magnitude. An inlet, however, contains complicated internal machinery that controls the amount of fluid that enters the inlet. It is not possible or even desirable for the panel method to analyze this machinery in detail. Instead, its effect is lumped into a single parameter, mass flow through the inlet. Thus, in incompressible flow the operating condition of an inlet is defined by four parameters. In compressible flow there is a fifth parameter defining compressibility, e.g. sound speed or total temperature. 
To analyze the flow about the inlet, the forward portion of the inlet, which is the region where the flow is of interest, is artificially extended by means of a long afterbody with constant inner and outer cross sections, as shown in Figure $1(a)$. The afterbody is open at the downstream end. A forward location is selected by the user and the interior cross section there is designated the control station where mass flow is evaluated. Often the propeller plane or the compressor face is chosen as the control station. Four fundamental flow solutions are calculated. The first three are illustrated in Figure 1. Incompressible flow about the inlet with its extension is calculated by the panel method

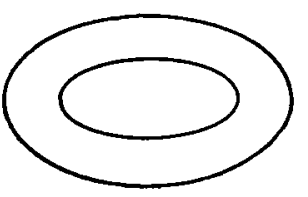

(a) Inlet geometry with afterbody.
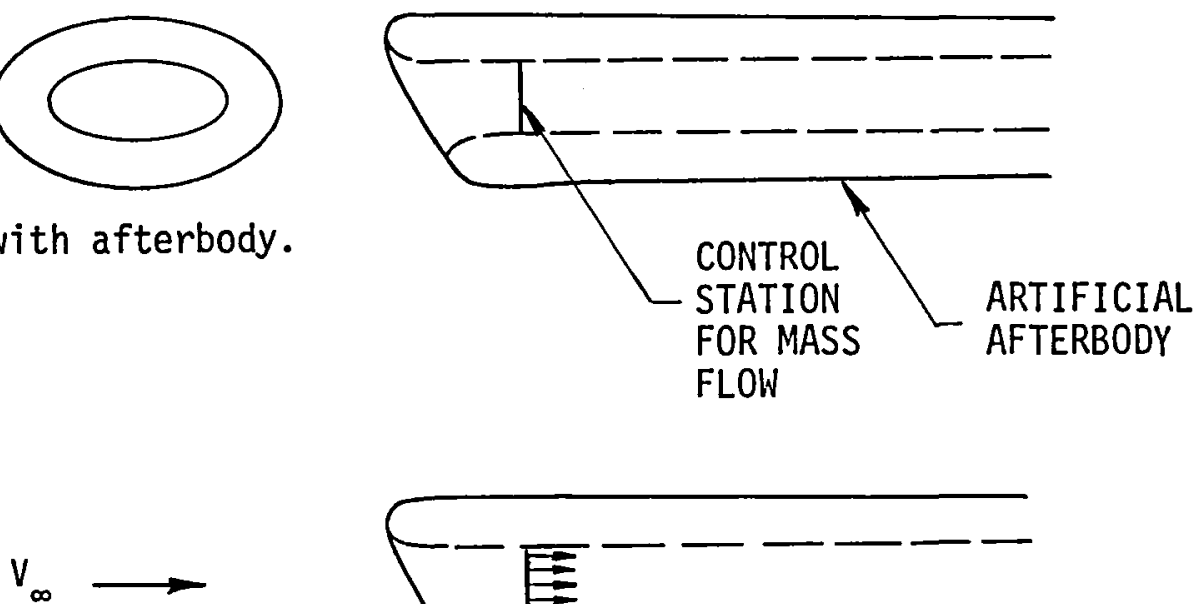

(b) Zero angle of attack and yaw
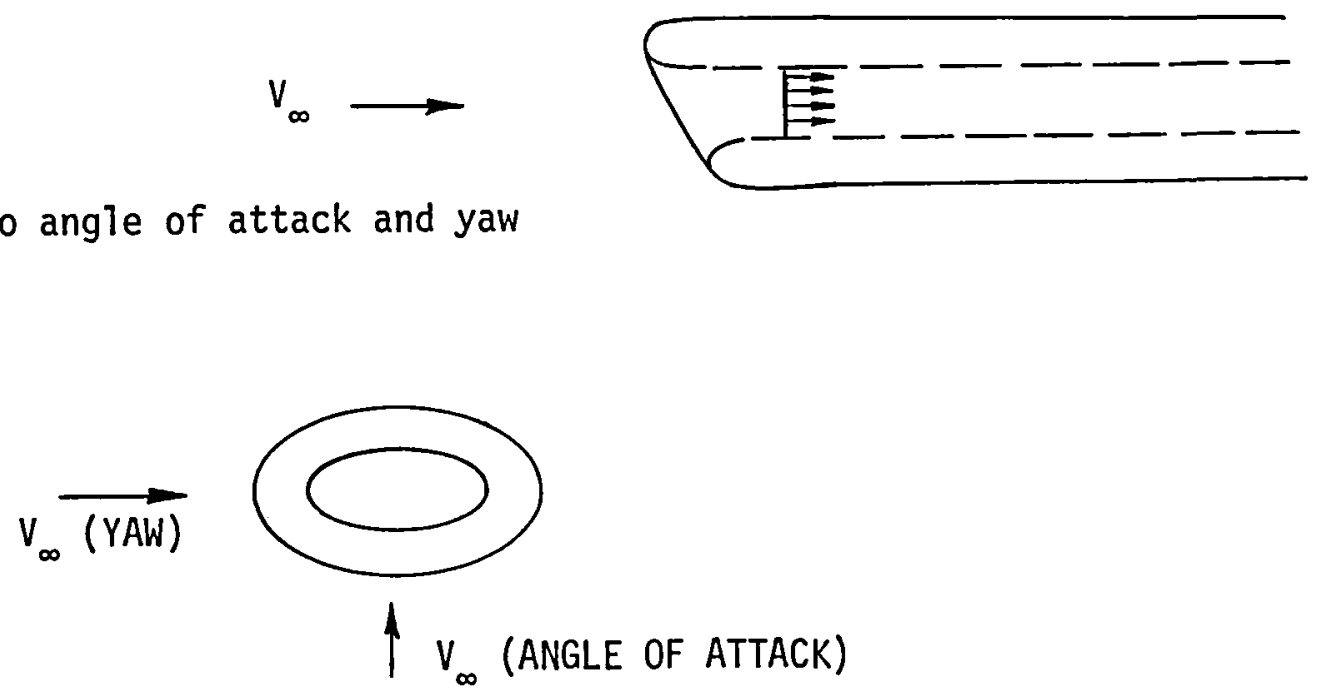

(c) Pure angle of attack and pure yaw

Figure 1. Three fundamental flow solutions for three-dimensional inlets. 
for three inciinations of the uniform onset flow at large distances: (1) $0^{0}$ angle of attack and yaw, (2) $90^{\circ}$ angle of attack with $0^{\circ}$ angle of yaw, and (3) $90^{\circ}$ angle of yaw with $0^{\circ}$ angle of attack. Mass flow for these three fundamental flows are evaluated at the control station. In general, these cannot be predicted in advance, but whatever values are computed simply must be accepted. Usually the mass flows for flows (2) and (3) are near zero. The above three fundamental flows may be linearly combined to give the flow about the inlet at any angle of attack and any angle of yaw, but the mass flow will always be nearly equal to that of flow (1). To control mass flow a fourth fundamental flow is required.

The fourth fundamental flow is the incompressible flow about the extended inlet in static operation, i.e., zero flow at large distance but a finite mass flow at the control station. This is obtained as illustrated in Figure 2 which also shows the $\mathrm{N}-\mathrm{lines}$ of input points and the lifting strips utilized by the panel method (Ref. 2). A known distribution of vorticity is placed on the panelled inlet surface in such a way that closed vortex lines run around the inlet cross sections - both interior and exterior. (An axisymetric inlet has ring vorticity oriented exactly on the circular cross sections.) The vorticity strength is constant in the direction parallel to the long afterbody, i.e., in the axial or stream direction. The variation of vorticity strength circumfer. entially "around" the inlet, i.e., from one lifting strip to another, may be specified by the user if he desires, but the strength is normaliy taken constant which is definitely the standard option. Possibly better results would be

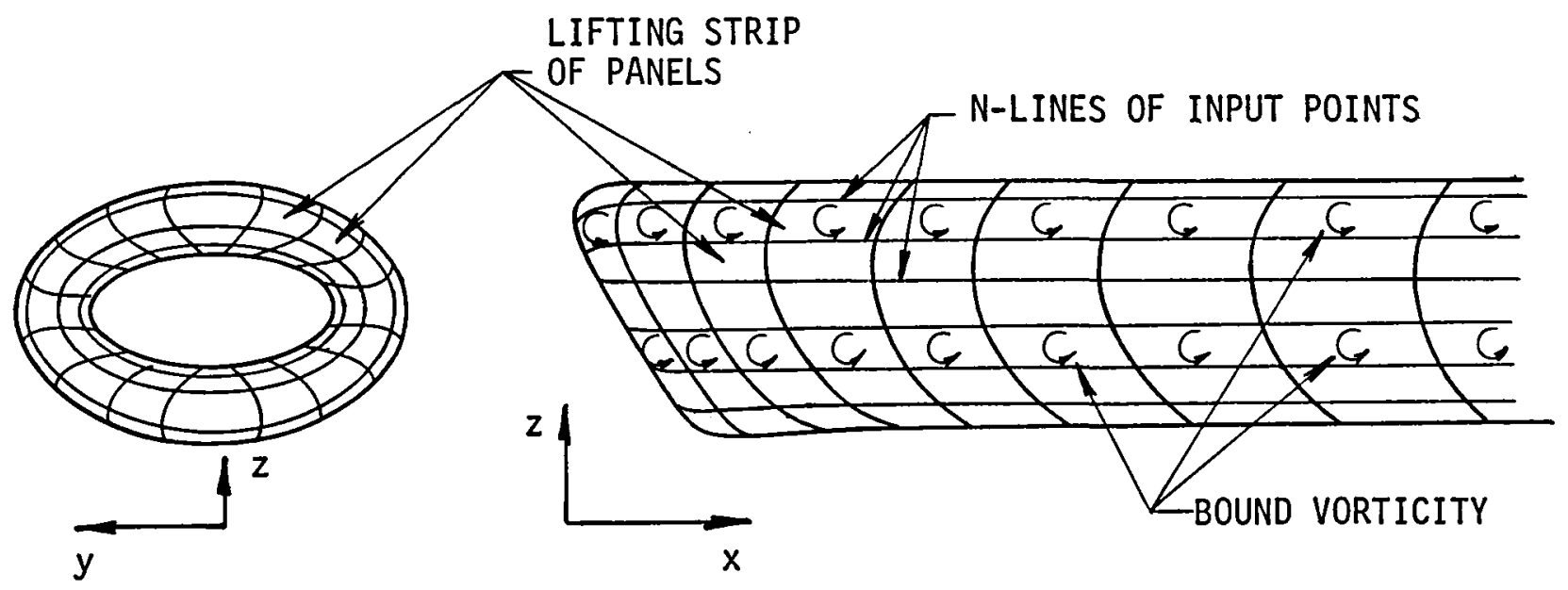

Figure 2. Use of surface vorticity to obtain a solution for a three-dimensional inlet in static operation. 
obtained for an unusual inlet geometry using a "circumferential1y" varying vorticity strength, but this is up to the user to determine. In any case, the normal velocity on the inlet surface due to the vorticity distribution is not zero, and source distributions on the panels are also required. The vorticity field provides one more onset flow to the inlet and one more right side of the normal-velocity matrix equations. The resulting solution is a fourth flow about the inlet. It can be shown that for a sufficiently long afterbody this flow represents the inlet in static operation. There is a constant uniform flow interior to the inlet at a sufficient distance from the entrance. On the exterior surface the flow velocity falls to zero with increasing distance from the entrance, as indeed it does in all directions in the fluid.

Thus the same mechanism, i.e. vorticity, that is used to produce lift in reference 2 is used here to regulate mass flow. In the lifting application, the vorticity strengths on the lifting strips are determined by the Kutta condition. In the inlet application the distribution of vorticity is prescribed and the total strength is adjusted to give the desired mass flow.

The four fundamental flow solutions may be linearly combined to give the incompressible flow about the inlet at any operating condition. Specifically, the four combination constants are determined so as to yield any prescribed values of: (a) angle of attack, (b) angle of yaw, (c) freestream velocity, and (d) mass flow at the control station. For incompressible potential flow the validity of this superposition is not approximate but is exact. The computational effort required to perform the combination for a particular set of operating conditions is a small fraction of that required for the original panel-method calculation. Thus solutions for large numbers of operating conditions may be obtained quite cheaply. In the inlet program provision has been made for permanent storage of the four fundamental flow solutions, so that additional solutions may be obtained easily at future times. Not only may additional operating conditions be specified, but the location of the control station may be changed, and additional interior cross sections may be designated where it is desired to know the flow field. 
Since the computing time for the panel method is much less than that required for a finite-difference solution even for a single operating condition, it is estimated that if several operating conditions are of interest, the present program is faster than a finite-difference method by two orders of magnitude. This numerical efficiency is realized because the main flow calculation of the present program is incompressible. Thus the practicality of this program depends, in an essential way, on the availability of an accurate and general compressibility correction that may be applied a posteriori. That is, it is crucial that a means be available for obtaining compressible flow about an inlet from the incompressible flow about the same inlet, as opposed to, say, a stretched version of the inlet.

\subsection{The Compressibility Correction}

The compressibility correction used in the present program is that of Leiblein and Stockman (Ref. 3). The mathematical details are contained in the references and will not be repeated here. However, a general description of the procedure appears to warrant inclusion.

The Leiblein-Stockman compressibility correction is a correlation based on empirical observation. The correlation was deduced from a comparison of exact solutions for the compressible and incompressible flows in a turbine stator passage. Strictly, the correction applies to internal flows, but it has been extended to external flows as well.

Physically, the correction consists of one-dimensional compressible flow in the predominant flow direction. Specifically, the compressible total-tostatic density ratio is obtained from one-dimensional flow considerations. This requires only the flow passage area, the inlet mass flow, and the total temperature. This one-dimensional density ratio is then modified by the ratio of local incompressible velocity to the average incompressible velocity at that particular axial station. The local incompressible velocity is obtained at each point by combining the four fundamental flow solutions. The average incompressible velocity may be obtained either from the incompressible solution or from onedimensional incompressible flow. For points in the interior of the inlet, the 
key quantity in this correlation is the flow passage area, which is automaticaliy calculated by the program from the inlet geometry. At points on the exterior of the inlet an alternate procedure is employed.

of course the key issue determining the validity of using a compressibility correction of this sort is how well it predicts compressible flow as obtained experimentally. The Leiblein-Stockman correction is exceptionally well verified in this regard (Refs. $1,3,4$ ). Indeed it appears to have attained the status of a routine procedure. While all previous work has been done with round inlets, excellent comparisons with experiment have been obtained at large angles of attack - at least $75^{\circ}$ - where the flow is essentially three-dimensional in nature. Rather than repeat the comparisons contained in the references, a new comparison is presented here. Figure 3 compares calculated and experimental static-to-total

$$
\alpha=75^{\circ}, \quad M_{T H}=0.603
$$

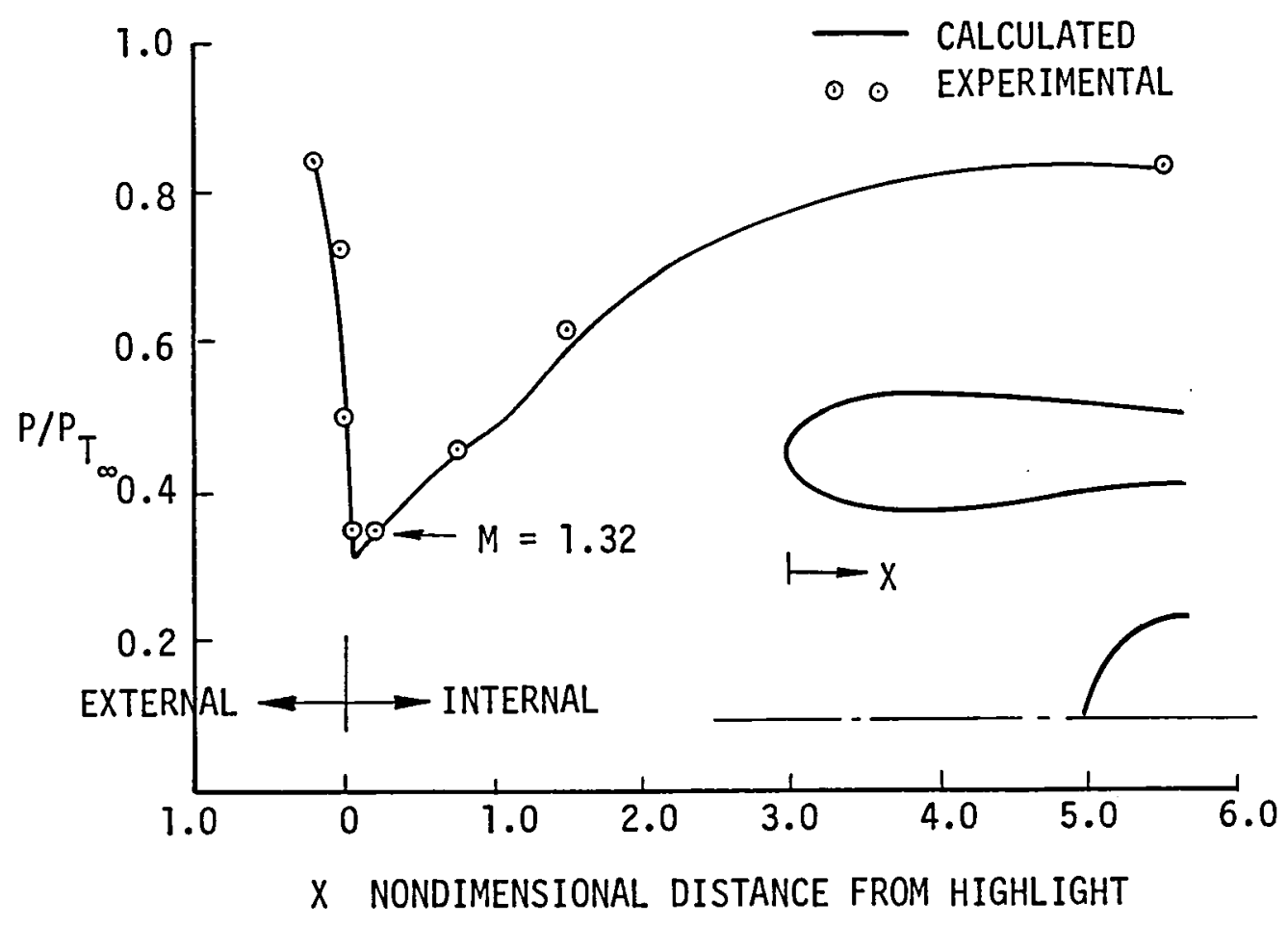

Figure 3. Comparison of calculated and experimental static-to-total pressure ratio distributions on the windward side of an inlet operating condition at which the flow is supercritical. 
pressure ratios on the surface of an inlet at 750 angle of attack. The agreement is excellent even at the pressure peak where the local Mach number is 1.32. This illustrates the validity of the compressibility correction for shock-free flows with significant supersonic regions.

\subsection{Geometric Specification of the Inlet}

For good accuracy the surface of the inlet must be specified by a rather large number of points - larger than is needed for purely external flows. To minimize the effort required of the user of the inlet program, a geometry package has been incorporated into it. This geometry package has a wide range of capabilities and is applicable to a much larger class of problems than inlets (Refs. 6, 7). In the present application the geometry package allows the user to input a relatively small number of points defining the inlet and centerbody. Moreover, extreme care in distributing the points need not be taken. The routine enriches the point number and redistributes the points according to one of a number of algorithms. Graphical output of the points allows the user to approve the distribution before proceeding with the relatively expensive flow calculation. Alternatively, the user may elect to enrich the point number and continue to complete the flow calculation in a single computer run. An example of the use of the geometry package is shown in Figure 4 , which presents the input point distribution and the enriched distribution for a typical case.

\subsection{Symmetry}

It is anticipated that most inlets will have a plane of symmetry. Accordingly, provision has been made to take advantage of this condition to reduce both computing time and the amount of required input data. One half the body is defined by points, and the reflected half is accounted for internally. There are two aerodynamic influence matrices - one matrix for flows where the values of the source densities on symmetrically located panels are equal and another matrix for flows where these values are equal and of opposite sign. Of the four fundamental flow solutions, all use the first matrix except that corresponding to pure yaw, which uses the second. Here pure yaw is defined as a freestream perpendicuiar to the inlet's symmetry plane. 


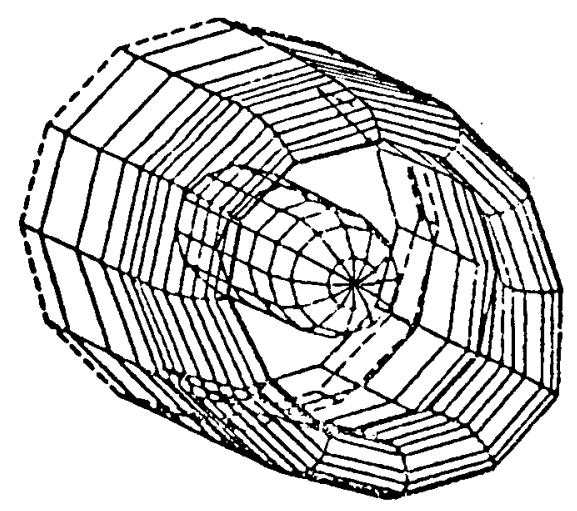

INPUT DISTRIBUTION

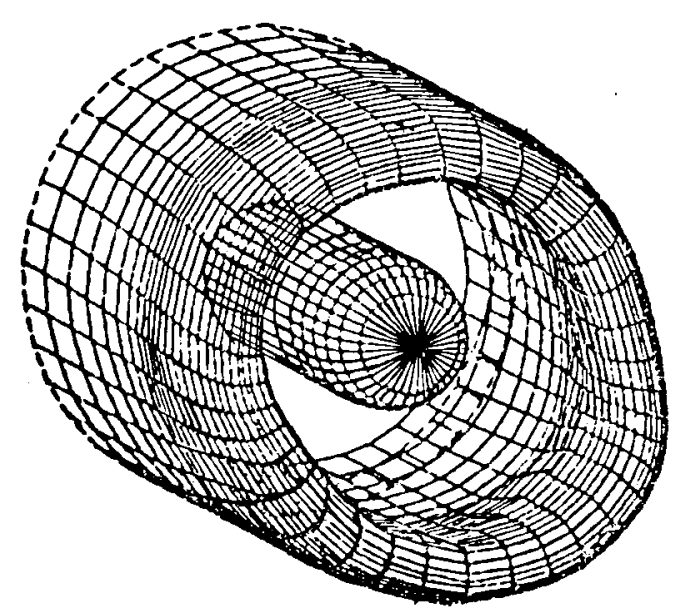

ENRICHED DISTRIBUTION

Figure 4. Use of the geometry package to obtain input data for the inlet program.

Even though only half the inlet is input, probably most users prefer graphical output for the complete inlet. Therefore, this has been made the standard option, both for the inlet geometry (Fig. 4) and the calculated flow results. Results for the other half of the inlet are generated internally, including cases with yaw where the combined numerical values are not symetric.

\subsection{Graphical Output Options}

The main tabular output of the inlet program consists of local flow properties, e.g., velocity, pressure, Mach number, etc., at one point of each of the panels on the inlet's surface and at points on sections across the interior of the inlet. To aid the user in evaluating this rather formidable amount of data, two graphical output options have been provided. These are the surface streamline option and the cross-section option.

The user may specify a set of points on the surface of the inlet and/or its centerbody through which streamlines are to be constructed. The program calculates these streamlines - in both upstream and downstream directions if desired. It then graphically displays the streamline trajectories against the panel representation of the inlet. Viewing angles may be specified by the user, and a number of angles may be input simultaneously. Either orthographic (parallel) projection or perspective projection may be selected. A second type of graph is also generated by this option, namely conventional two-variable Cartesian 
plots of pressure, Mach number, and flow angles versus distance along each streamline.

An interior cross section of the inlet is defined by a point and a vector. The program defines a plane through the point whose normal is the given vector, calculates the region of this plane bounded by its intersection with the interior of the inlet and the centerbody, and automatically distributes field points throughout this region. For any inlet operating condition, flow is calculated at the field points, and an interpolation procedure defines curves of constant value of various flow quantities: pressure, Mach number, flow angle. A user may specify several cross sections if he desires. The particular routine used for constructing contours of equal value is quite general. In particular a contour of some particular value may consist of more than one disjoint portion. 


\subsection{GENERAL REQUIREMENTS OF THE GEOMETRIC INPUT}

The present program has been built around that of references 2 and 5 , which is designed for lifting wings and wing-fuselages. The geometric input requirements reflect this ancestry. Moreover, to prevent the logic of the Flow Passage Area Calculation from growing too complicated, certain restrictions on the complexity of the inlet calculation have been assumed.

The inlet program is designed for configurations of the type illustrated in Figure 4: a single isolated cowl or inlet either with or without a single disjoint centerbody. Additional surfaces such as slats, vanes, or additional inlets (say an inlet within an inlet) will cause the logic of the Flow Passage Area Calculation and, probably also the Cross Section Calculation, to fail.

In the logical scheme of the lifting panel method the inlet (cowl) is a lifting body on which surface vorticity is placed, and the centerbody is a nonlifting body which has no vorticity. Both bodies are specified to the computer by means of coordinates of a set of points that define their surfaces. These points are organized by means of so-called $\mathrm{N}-1$ ines, as indicated in Figure 2 and described in reference 2. Basically, an N-Tine is a curve in the body surface connecting successive input points. Thus points are input $\mathrm{N}-\mathrm{l}$ ine by $\mathrm{N}-\mathrm{line}$. In the inlet program the $\mathrm{N}-\mathrm{l}$ ines are not cross sections at a given axial station but rather are curves at a given circumferential location that traverse the bodies in the axial or streamwise direction.

Specifically, the first point of each $\mathrm{N}-\mathrm{line}$ lies at the most aft (downstream) location of the extended afterbody (Figures 2 and 4). Moreover this point is on the interior surface of the inlet. Successive input points on the $\mathrm{N}-\mathrm{line}$ proceed forward (upstream) along the interior of the inlet, go around the $1 \mathrm{ip}$, and then proceed aft (downstream) along the exterior surface to the end of the afterbody. The last input on the $\mathrm{N}-\mathrm{l}$ ine is a so-called wake point. It is assumed that at the aft end of the afterbody the inlet centerline is straight. The direction from the second-to-last point on an N-Tine to the last (wake) point should be parallel to the local centerline direction. On the centerbody the first point on each $\mathrm{N}-\mathrm{l}$ ine is at the nose and successive points proceed aft (downstream) to the end of the afterbody. Thus, inlet $\mathrm{N}-\mathrm{l}$ ines both begin and 
end at the end of the afterbody, while centerbody $\mathrm{N}-\mathrm{l}$ ines begin at the front and proceed to the rear. The order of input of $\mathrm{N}-\mathrm{lines}$ on both the inlet and the centerbody is clockwise as viewed by an observer at upstream infinity.

Every $\mathrm{N}-\mathrm{l}$ ine on the inlet must have the same number of points. Every $\mathrm{N}-\mathrm{l}$ ine on the centerbody also must have the same number of points, but this number may be different from that of the inlet $\mathrm{N}-\mathrm{Tines}$. It is required, however, that both the inlet and the centerbody have the same number of $\mathrm{N}-1$ ines.

If one plane of symmetry is utilized, this must be the $y=0$ plane, and points must be input in the plane to obtain a closed surface. Thus the first and last $\mathrm{N}-\mathrm{l}$ ines of both the inlet and the centerbody must $\mathrm{lie}$ in the $y=0$ plane.

In all cases the Geometry Package of references 6 and 7, which has been incorporated into the inlet program, is available to aid in preparing geometric input data. 


\subsection{OVERALL OPERATION OF THE PROGRAM}

There are basically two main modes of operation of the inlet program. The first begins with the geometric input data and produces the Fundamental Solutions of Sections 3.2 and 6.0. This is the time-consuming portion of the calculation. Its logical structure is illustrated in Figure 5 . Once the fundamental solutions have been generated, they can be saved indefinitely to produce flow solutions at any future time. Thus the expensive part of the calculation need only be done once for each inlet configuration. The second mode of operation begins with values of the physical quantities that define an inlet operating condition and produces a complete flow solution for that condition. It is illustrated in Figure 6 , particularly $6 \mathrm{c}$. The first two parts of Figure 6 illustrate the Flow Passage Area and Cross Section Calculations that are performed at the same time. It is possible to run the program all the way through both modes in a single computer run, but this probabiy will not be the standard mode of operation. In any event several sets of operating conditions may be input simultaneously.

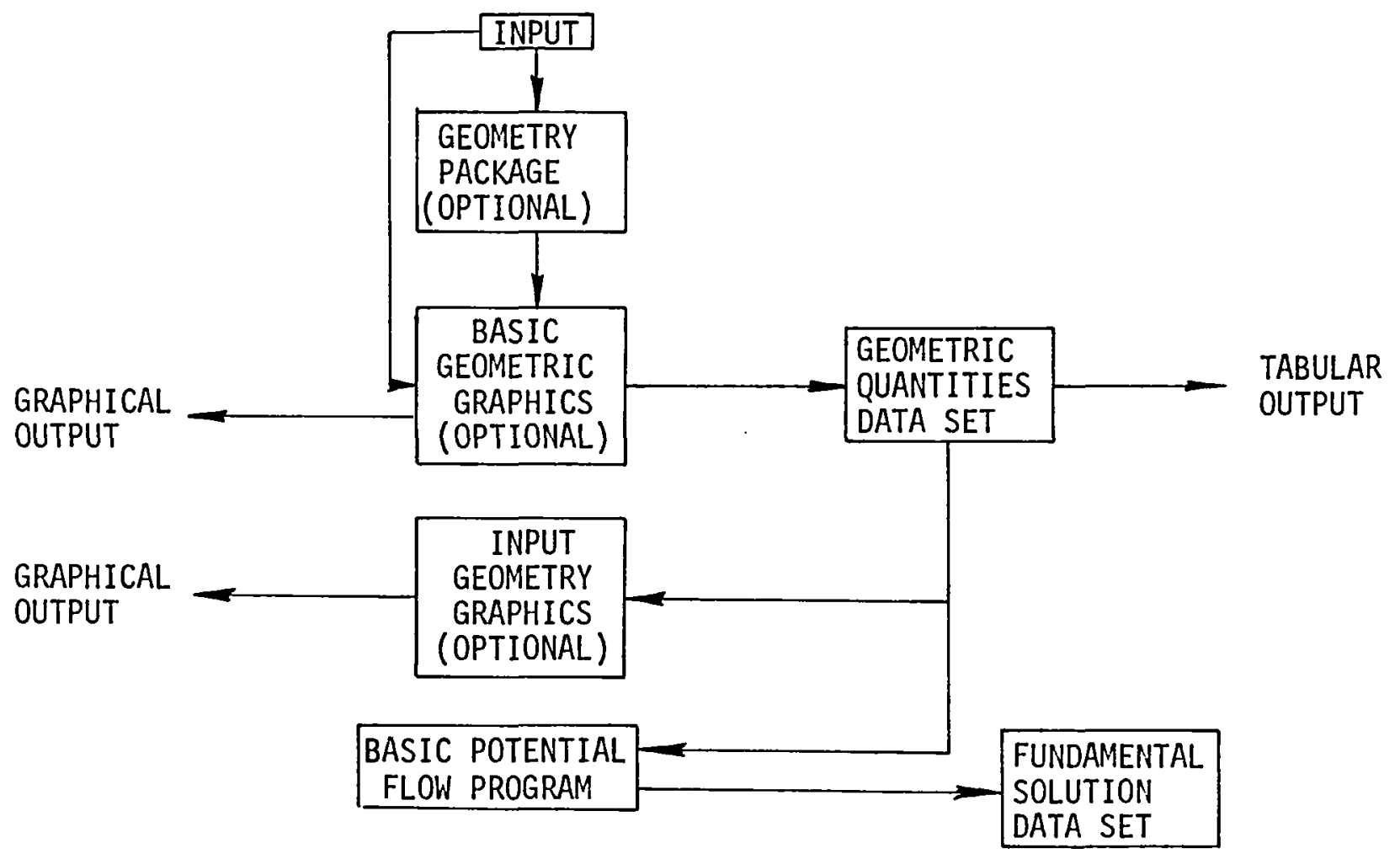

Figure 5. Logic of generating the fundamental flow solutions. 


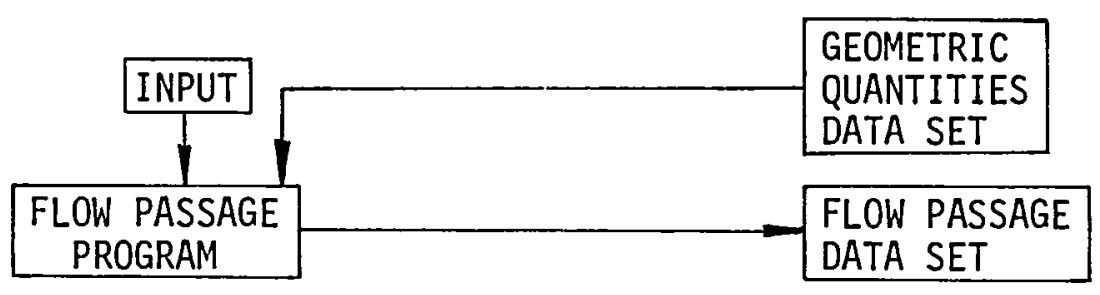

(a) Flow Passage Program

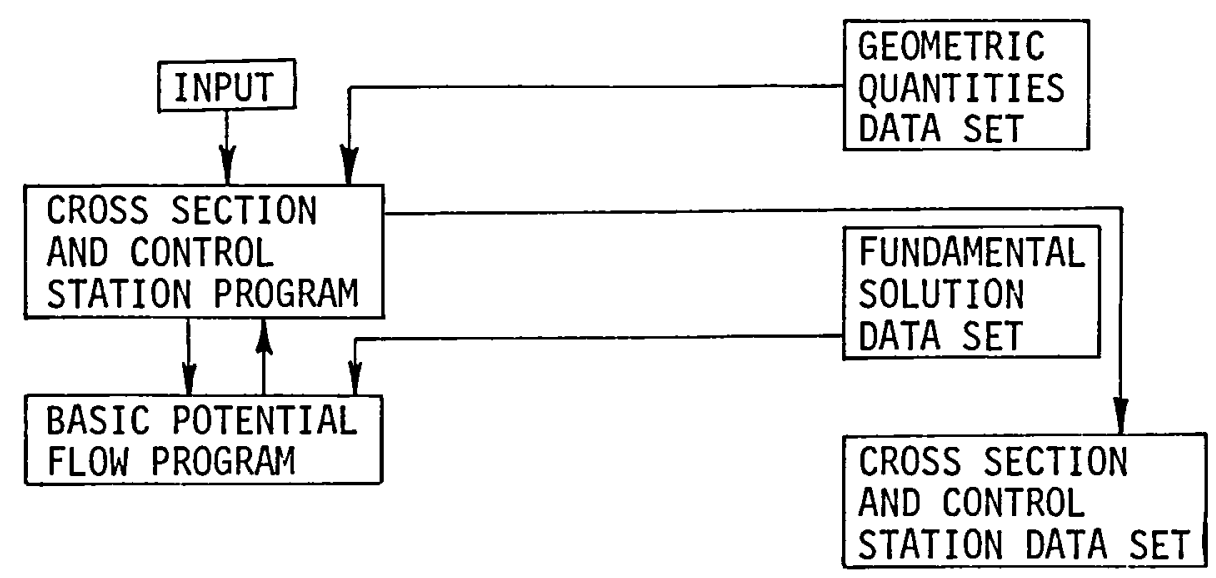

(b) Cross-Section and Control Station Program

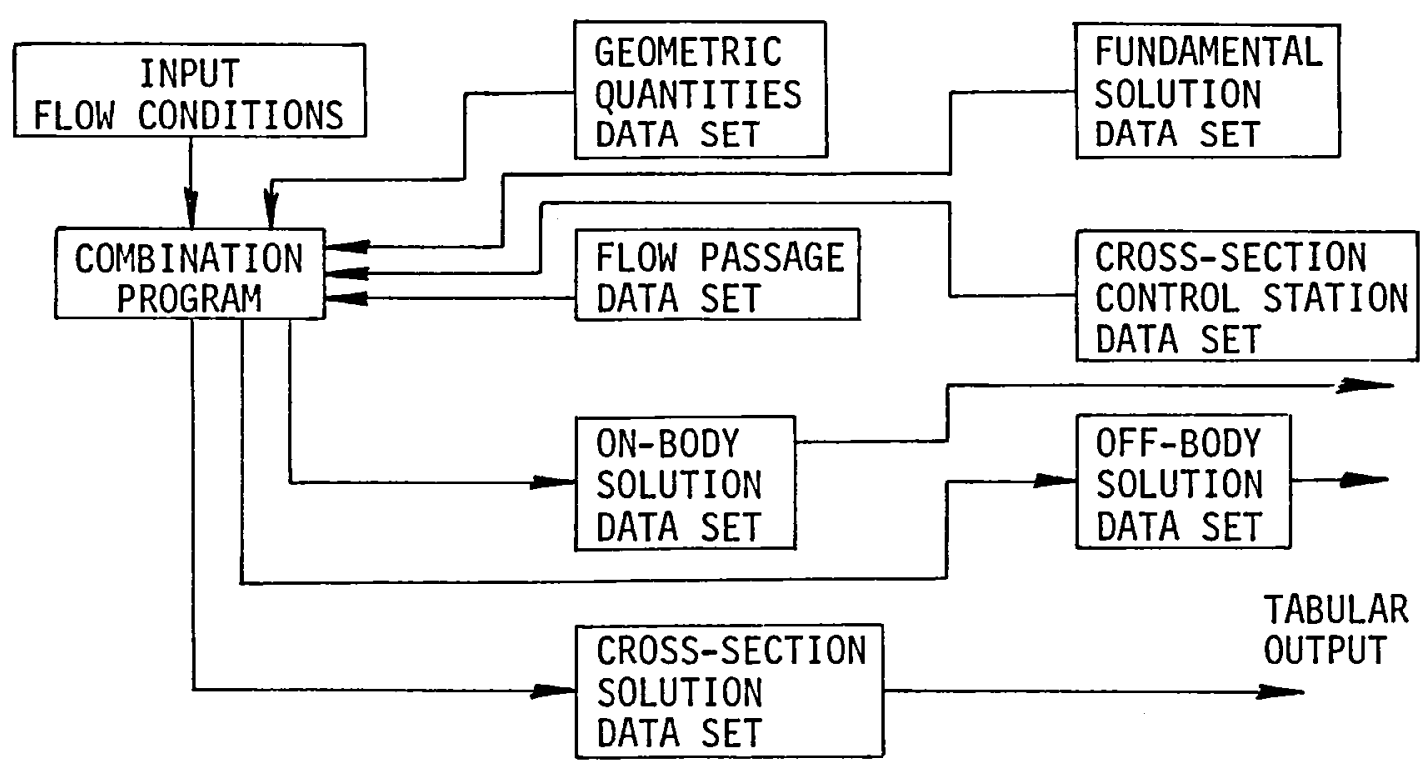

(c) Combination Program

Figure 6. Logic of calculating flow at a specified inlet operating condition from the fundamental flow solutions. 


\subsection{PROCEDURE FOR NONSYMMETRIC CASES}

\subsection{Basic Potential-Flow Program}

This program is very similar to the ordinary lifting panel method of reference 2. It differs: (1) in replacing the Kutta condition by a mass flow condition, (2) in the procedure for cases with symmetry, and (3) in the computation and storage of individual flow solutions.

Solutions are obtained for three uniform onset flows, one parallel to each coordinate axis. Thus the flow components are: $(1,0,0),(0,0,1)$ and $(0,1,0)$. A solution is also obtained corresponding to a uniform vorticity on each lifting strip. If there is no symmetry, all solutions use the same matrices $\vec{V}_{i j}$ and $A_{i j}$, representing velocity at the $i$ th control point due to a unit source density on the $j$ th panel (see reference 2 for detailed definitions).

Source density solutions are obtained for the three uniform and $L$ nonuniform vorticity onset flows, where $L$ is the number of lifting strips. These last are denoted $\sigma_{j}^{(k)}, j=1,2, \ldots, N, k=1,2, \ldots, L$.

The $L$ sets of source densities for the vorticity solutions are combined into a single set by assigning the relative vorticity strengths $B^{(k)}$, $k=1,2, \ldots, L$. There are two options:

1. Constant option: $A 11$ the vorticity strengths $B^{(k)}$ are simply set equal to unity.

2. Input option: $A$ set of $L$ numbers $B^{(k)}$ are input.

In either case the sets of $\sigma$ are combined by the formula:

$$
\sigma_{j}(s)=\sum_{k=1}^{L} B^{(k)} \sigma_{j}(k), \quad j=1,2, \ldots, N
$$

where the subscript $j$ denotes values on the $j$ th panel and $N$ is the total number of panels. This set $\sigma_{j}^{(s)}$ is denoted the static solution. There are thus four sets of source densities and four onset flow velocities: one for each of the three uniform flows and one for the static solution. The onset flow velocity at the ith control point for the static case is given by 


$$
\underset{\substack{\text { io } \\ \text { (s) }}}{\vec{L}}=\sum_{k=1}^{L} B(k) \vec{v}_{\substack{\text { io } \\ \text { (k) }}}^{(k)}
$$

where the $\vec{v}_{i 0}^{(k)}$ are the onset flows for the individual strip vorticity solutions.

These source densities and onset flow velocities are used with the influence coefficient matrices in the usual way to obtain on-body and off-body velocities. The new feature is that this is done for all four individual flows. These velocity distributions, and source densities for the individual flows form the fundamental solution data set. After these solutions have been stored, the matrices $\vec{V}_{i j}$ and $A_{i j}$ are destroyed.

\subsection{Cross Sections and Control Station}

The cross section and control station program furnishes sets of off-body points to the program. Say there are $C$ cross sections specified, each with $P$ points. Moreover, each cross section has its own normal vector. Velocities at each of the CP off-body points are calculated for each of the four onset flows. For each point this involves calculating a new row of the $\vec{v}_{i j}$ matrix including the vorticity onset flows, and then performing summations of the form

$$
\vec{v}_{i}^{(f)}=\sum_{j=1}^{N} \vec{v}_{i j} \sigma_{j}^{(f)}+\vec{v}_{i 0}^{(f)}
$$

using the source densities $\sigma_{j}^{(f)}$ and onset flows $\vec{v}_{i 0}^{(f)}$ from the fundamental solution data set. The complete set of: off-body points, flow velocities, boundary points (where the cross-section intersects the on-body $\mathrm{N}$-lines), areas, normal vectors and mass flows at each cross section comprise the cross section and control station data set. The areas and mass flows are obtained by numerical integration. One particular cross section is specified as the control station, and data for it are used in the combination program.

\subsection{Combination Program (Excluding Mach Number)}

To obtain an incompressible combined solution, the basic input consists of: angle of attack $\alpha$, angle of yaw $\beta$, freestream velocity $V_{\infty}$ and mass flow 
$Q$ at the control station. The combined velocity (or source density) formula is

$$
\vec{v}_{i}=V_{\infty}\left[\cos \alpha \cos \beta \vec{V}_{i}^{(100)}+\sin \alpha \vec{V}_{i}^{(001)}+\cos \alpha \sin \beta \vec{V}_{i}^{(010)}\right]+B \vec{V}_{i}^{(s)}
$$

The $V_{j}$ 's on the right are the individual fundamental solutions. The single constant $B$ is evaluated from the mass flow $Q$ at the control station by

$$
B Q(s)=Q-V_{\infty}\left[\cos \alpha \cos \beta Q(100)+\sin \alpha Q^{(001)}+\cos \alpha \sin \beta Q(010)\right]
$$

where the $Q$ 's are the individual mass flows from the control station data set.

After an incompressible combined velocity has been calculated as above, a compressibility correction is applied if a nonzero Mach number has been specified. The flow passage program calculates a flow passage area for every on-body and cross-section point. For each point this area is used together with the incompressible velocity in a compressibility correction program to yield compressible velocity and pressure. A normal output is accomplished for each Mach number. These calculations are discussed in subsequent sections. 


\subsection{PROCEDURE FOR SYMMETRIC CASES}

The symmetry procedure for inlets differs in two important respects from the symmetry procedures for an ordinary lifting case: the use of two flow matrices and the generation of twice the usual amount of output. This section refers to the nonsymmetric description (Section 6.0) for all portions of the calculation that are similar.

\subsection{Input and Geometric Output}

As is done in the ordinary lifting panel method of reference 2, only the half-body for which $y \geq 0$ is input, and the tabular output of control points, etc., i.e., the basic geometric quantities, is for the half-body. However, the graphical output (if any) is for the complete body, so before entering the graphics program the other half of the body is generated by reflection. Each reflected panel is obtained from a basic (input) panel by changing the signs of five geometric quantities (reference 2). Each input section has its corresponding reflected section. Thus there is twice as much geometry entering the graphics program as was input.

\subsection{Basic Potential-Flow Program}

The major change here is that two complete $\vec{v}_{i j}$ and $A_{i j}$ are calculated and stored: one calculated by the procedure for a plus symmetry plane and one for a minus symmetry plane. These correspond, respectively, to flows that are symmetric and antisymmetric about the symmetry plane. These are calculated together. After a $\vec{v}_{i j}$ has been calculated for both a panel and its reflection, the two influences are added to get the influence appropriate to a plus symmetry plane and subtracted to obtain the influence appropriate to a minus plane. Both are saved in different places, so that finally the plus and minus $\vec{V}_{i j}$ and $A_{i j}$ matrices are stored separately. All matrices are of order $N$, where $N$ is the number of input panels (half the body).

The vorticity onset flows are calculated by the procedure appropriate to a plus symmetry plane only. They are summed in the manner of Section 6.1 to obtain a static onset flow. 
The fundamental flow solutions, source density and velocity, are obtained in the usual way using the plus matrix for all flows except the uniform onset flow $(0,1,0)$ which corresponds to pure yaw and using the minus matrix for that one flow. In particular, the plus matrix is used for the two uniform onset flows $(1,0,0)$ and $(0,0,1)$ and for the static onset flow. Each flow solution is only for the half-body that was input, i.e. $N$ on-body points and off-body points having $y \geq 0$.

\subsection{Cross-Sections and Control Stations}

Off-body points, normal vectors and boundary points are calculated as in the nonsymmetric case but only for $y \geq 0$. When calculating velocity influences from the $\vec{v}_{i j}$ matrices both plus and minus influences must be caiculated. The minus influences (matrix row) are used with the solution for the flow $(0,1,0)$ and the plus influences for all other fundamental solutions. The cross-section and control station data set is generated in the usual way, except the computed areas are doubled, and mass flows $Q_{k}$ are doubled except for the $(0,1,0)$ solution where the mass flow is set equal to zero.

\subsection{Combination Program (Excluding Mach Number)}

The combination constant $B$ is determined as in the nonsymmetric case, equation (5). The combined incompressible velocity is obtained from the fundamental flow solutions by equation (4) for the control points of the input $(y \geq 0)$ panels. Another complete set of output is produced for the control points of the reflected panels. The geometry of the reflected panel is obtained by changing cer.tain signs. In particular the reflected control point coordinates are $x_{0},-y_{0}$, $z_{0}$ and the normal vector is $\eta_{x},-n_{y}, n_{z}$, where the unsigned quantities are for the input panel.

The velocity components at the reflected control point are obtained from equation (4) using the same fundamental flow components but with certain sign changes. These changes are 


\begin{tabular}{l|l|l} 
& $\begin{array}{l}\text { Solution } \\
\text { for }(010)\end{array}$ & $\begin{array}{l}\text { All other } \\
\text { Solutions }\end{array}$ \\
\hline $\begin{array}{l}\text { Sign(s) } \\
\text { Changed }\end{array}$ & $\begin{array}{l}\text { x-component } \\
z \text {-component }\end{array}$ & $y$-component
\end{tabular}

This holds for off-body points as well.

The flow passage program must be altered to reflect symmetry and to compute flow passage area for both basic (input) and reflected panels. The flow passage area corresponding to the control point of a reflected panel is set equal to the flow passage area corresponding to the associated basic panel. Compressible velocities and pressures are then computed for both basic and reflected panels in the same way as for a nonsymmetric case.

Thus, there is twice as much output as for a nonsymmetric case having the same number of input points. 


\subsection{FLOW PASSAGE AREA CALCULATION}

The compressibility correction of reference 3 requires a flow passage area to be associated with each point where compressible velocities are to be computed. At points interior to an axisymmetric inlet (either on or off the surface), the proper choice of such an area is straightforward. It is the area of the circular cross section of the interior of the inlet at the axial location of the point in question. The area may be constructed geometrically by passing a plane through the point in question normal to the axis of symmetry of the inlet and then finding the intersection of this plane with the interior surface of the inlet. If a centerbody is present, its intersection with the plane is also computed. The flow passage area is then the area contained within the closed curve defining the inlet intersection minus the area contained with the closed curve defining the centerbody intersection.

Determination of the flow passage area for interior points of a threedimensional inlet is also straightforward and indeed can be accomplished by essentially the above procedure provided: (1) the inlet (and centerbody) has a straight centerline and (2) the inlet highlight lies in a plane perpendicular to the centerline. In such cases the centerline plays the role of the symmetry axis in the construction of the previous paragraph. However, for general threedimensional inlets, e.g., inlets with curved centerlines or scoop inlets, the proper definition of the flow passage area is not obvious. In constructing the present program it was decided that the program would automatically calculate flow passage areas for all interior points and that this calculation would be entirely geometrical. To accomplish this it was necessary to assume that the inlet highlight lies approximately in a plane, although the orientation of this plane is arbitrary. The centerline of the inlet is defined by the user who inputs a set of centerline points.

At points exterior to the inlet (either on or off the surface) the concept of flow passage area becomes less significant and its definition somewhat arbitrary. Nevertheless, flow passage areas have been defined for points on the surface in a manner that has yielded reasonable compressible velocities in a limited number of preliminary cases. The program automatically calculates these areas. Selection of flow passage areas for exterior off-body points is currently an unsolved problem. 
The remaining subsections of Section 8.0 present the details of the flow passage area calculation.

\subsection{Organization of the Input}

The restrictions on the body geometry and the order of input are set forth in Section 4.0. The result is a configuration as shown in Figure 7. Specifically, there is one inlet (1ifting body) and either one or no centerbody (nonlifting body). The $\mathrm{N}-\mathrm{l}$ ines on the inlet are input from lower surface "trailing edge" to leading edge to upper surface "trailing edge." In this context the lower surface is inside the inlet, and the upper surface is outside. Thus, for example, the top of the inlet - both inside and outside - is a single $\mathrm{N}-1$ ine, and the bottom - both inside and outside - is a different $\mathrm{N}-\mathrm{line}$, as shown in Figure 7. All $\mathrm{N}-\mathrm{l}$ ines on the centerbody (if any) are assumed to start at a certain "initial point" and to proceed downstream. Thus, in particular, the top and bottom of the centerbody are different $\mathrm{N}$-7ines.

The centerline of the inlet is input as a set of points and normal vectors beginning with a certain initial point and continuing downstream (Figure 7). While normally the input centerline corresponds to the physical centerline, it need not. The input centerline is a device for calculating flow passage areas. In particular, the initial centerline point and vector define the inlet lip or highlight.

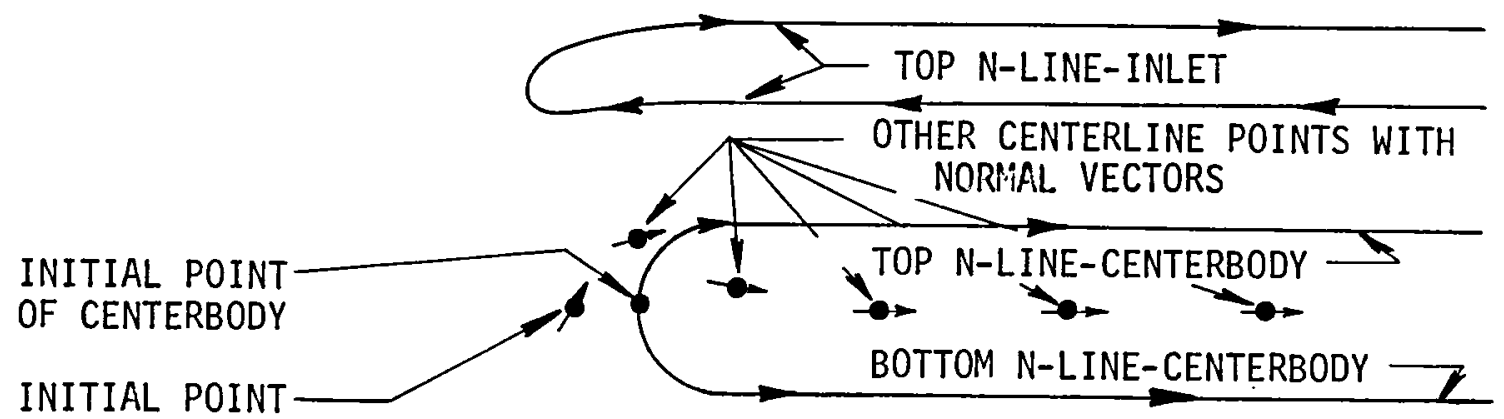

OF CENTERLINE

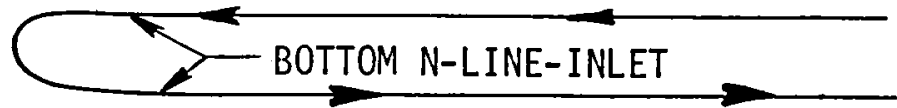

Figure 7. Input to the program including the centerline points used to calculate flow passage areas. 


\subsection{Intersection Program}

The basic calculational unit is a subroutine that takes a segmented line ( $\mathrm{N}-\mathrm{Tine})$ and finds the point of intersection with a plane: the coordinates of the intersection and the number of the segment it is on. The plane is defined by a point and a normal vector. The routine also has the capability of computing the area bounded by a set of intersection points obtained for several $N-$ Tines.

\subsection{Initial Centerline Point}

The initial centerline point and its vector are key input quantities. Together they define a plane whose intersection curve with the inlet defines inside and outside. More specifically, this plane should intersect the panels on each side (interior and exterior) of the inlet highlight. This is easy to arrange if the inlet has a highlight that lies in a plane all around the inlet. The plane of the initial centerline point then is parallel and slightly downstream. If the inlet highlight is not plane, the plane of the initial centerline point should be as near the highlight as possible and should intersect the inlet all the way around. More specifically the plane defined by the initial centerline point and its normal vector must have exactly two intersection points on each $\mathrm{N}$ - Tine of the inlet, otherwise the calculation ceases with an error message. For the centerbody there is either one intersection point on each $\mathrm{N}-1$ ine or there are no intersection points on any $\mathrm{N}-1$ ine. The Intersection Program calculates the plane's intersection points with all $\mathrm{N}-1$ ines.

\subsection{Interior and Exterior Points of the Inlet}

Points on all $\mathrm{N}-1$ ines are classified as either interior or exterior and a designation must be added to the data describing each control point. On the inlet for each $\mathrm{N}-\mathrm{line}$ the one of the two intersection points that is closer to the initial centerline point is designated an interior $\mathrm{N}-\mathrm{line}$ point. Inen, on the strip of panels adjacent (following) the N-line, the control point of the panel adjacent to the segment containing the closer intersection point is designated the "last interior control point." (If the k-th segment of the $\mathrm{N}$-line contains the intersection point, the control point of the $k$-th element 
of the strip is the desired one.) It and a11 preceeding control points of the strip are labelled interior. All succeeding control points of the strip are labelled exterior.

If there are no intersection points with the $\mathrm{N}-\mathrm{lines}$ of the centerbody, then all control points of the centerbody are labelled interior. If there is an intersection point on one segment of each $\mathrm{N}-\mathrm{l}$ ine of the centerbody, the control point of the panel adjacent to that segment is denoted the "first interior control point." It and all succeeding control points of the strip are labelled interior. All preceeding control points are labelled exterior.

\subsection{Initial Flow Passage Area}

For the inlet, the interior intersection points (interior $\mathrm{N}-\mathrm{T}$ ine points) are collected into one list and the exterior intersection points into another list. (These last are the intersection points on each $\mathrm{N}-1$ ine further from the centerline point.) Using the intersection program, areas are computed for both these sets of points: the interior area $A_{j}$ and the exterior $A_{e}$. If there are intersection points of the plane with the centerbody, the area enclosed by these points is called $A_{C}$. Define

$$
\begin{aligned}
& A_{F P}=A_{j}-A_{c} \\
& A_{F P}^{*}=A_{e}-A_{c}
\end{aligned}
$$

If there are no intersection points with the centerbody then

$$
\begin{aligned}
& A_{F P}=A_{i} \\
& A_{F P}^{*}=A_{e}
\end{aligned}
$$

Next arc lengths are computed along $\mathrm{N}-1$ ines from the initial point to the intersection points: the interior and the exterior points on each $\mathrm{N}-\mathrm{line}$ of the inlet and the point (if any) on each $\mathrm{N}-\mathrm{l}$ ine of the centerbody. For a segment containing an intersection, the arc length up to the first point of that segment is given by the method of reference 2. The additional arc length to be added to get the arc length of the intersection point is found by computing the usual straightline distance between the intersection and the first point of the segment. 
The area $A_{F P}^{*}$ is associated with the arc lengths corresponding to the exterior intersection for all N-lines of the inlet. The area $A_{F P}$ is associated with the arc lengths corresponding to the interior intersection for all $\mathrm{N}-1$ ines of the inlet and also for all $\mathrm{N}-1$ ines of the centerbody, if any.

\subsection{Successive Flow Passage Areas}

The procedure of Sections $8.3,8.4,8.5$ above is repeated for all of the imput centerline points. A plane is passed through each centerline point having its normal vector identical with the centerline tangent vector. Interior and exterior intersection points are found on each $\mathrm{N}-\mathrm{l}$ ine of the inlet and a single intersection point on each $\mathrm{N}-\mathrm{l}$ ine of the center body (if applicable). The areas $A_{F P}$ and $A_{F P}^{*}$ are calculated from $(6)$ or (7) and associated with the arc lengths corresponding to the intersections (interior and exterior) on the inlet $\mathrm{N}-\mathrm{lines}$ and the centerbody $\mathrm{N}-1$ ines as described in Section 8.5. Thus, tables of area versus arc length are constructed (Section 8.8).

\subsection{Possibilities for the Centerbody}

(a)

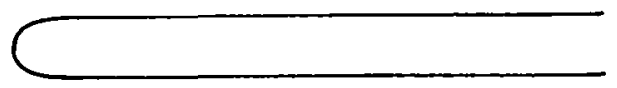

(c)

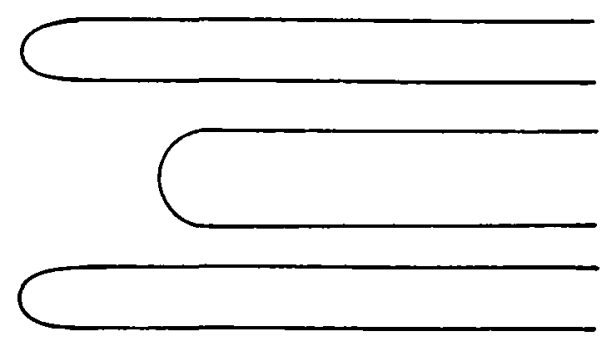

(b)

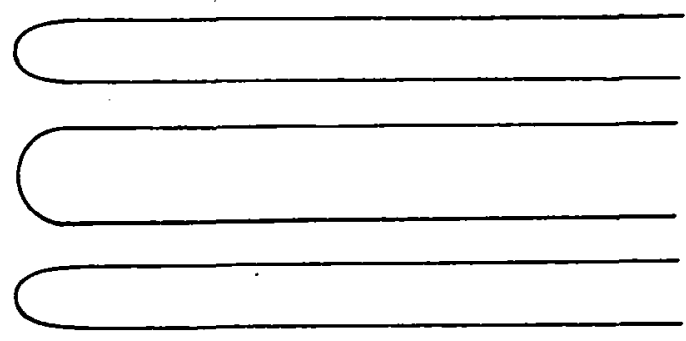

(d)

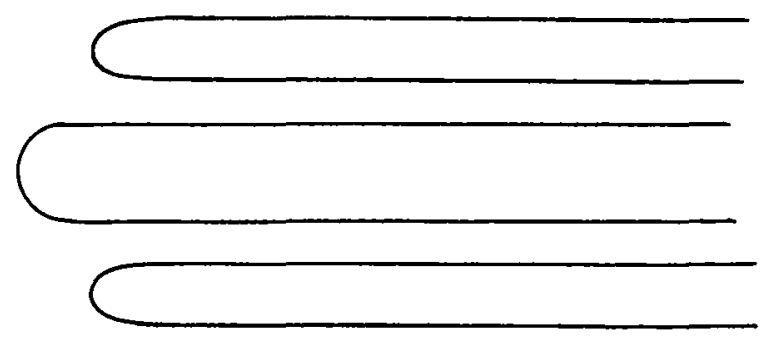

Figure 8. Possibilities of the centerbody. 
There are four possibilities for the location of the centerbody, some of which require slightly different logic.

a. No Centerbody: This case is identified by input flag. Equation (7) is used for all points of the inlet, and, of course, no area table is constructed for the centerbody.

b. Centerbody Abreast of Inlet Highlight: This case is identified by the fact that the intersections of the centerbody $\mathrm{N}$-Tines with the initial centerline plane occur on the first segments of those N-lines. Equations (6) are used for all intersection points, and a table of area versus arc length is prepared for each $\mathrm{N}-\mathrm{line}$ of the centerbody using the areas of (6). Tables for the centerbody have the same length as those for the inlet $\mathrm{N}-\mathrm{l}$ ines except for the one additional exterior intersection on each of the latter (Section 8.8).

c. Centerbody Downstream of Inlet Highlight: This case is identified by the fact that there are no intersection points of the initial centerline plane with any of the $\mathrm{N}-\mathrm{lines}$ of the centerbody, but there is a centerbody. This situation may exist for the first several centerline points. Eventually, a centerline point is reached that is the first whose plane intersects the centerbody. Call this the centerbody point (not necessarily the same as the initial centerbody point where the $\mathrm{N}-1$ ines start). Equations (7) are used for the intersections corresponding to the centerline points preceeding the centerbody point. Equations (6) are used for the intersections corresponding to the centerbody point and all succeeding points. It is only for the latter cases that there are intersections on the centerbody. Tables of area versus arc length are prepared for all $\mathrm{N}$-lines on the inlet and the centerbody, but the centerbody tables are shorter, because their entries begin with the centerbody point, while those of the inlet begin with the initial centerline point.

d. Centerbody Upstream of Inlet Highlight: This case is characterized by the fact that there are intersections of the $\mathrm{N}-\mathrm{lines}$ with the initial centerline $\mathrm{plane}$, and these are not on the first segments of the centerbody $\mathrm{N}-\mathrm{lines}$. Just as in (b), equation (6) is used to compute areas for all interior intersections on both inlet and centerbody $\mathrm{N}$-lines, but now there are additional expressions to assign values of flow passage area at points of the centerbody upstream of the inlet lip (Section 8.10). 
8.8 Arc Length Tables. Interpolation for Flow Passage Areas at Interior Control Points

When the various tasks of Sections 8.3 or 8.7 have been accomplished, flow passage areas $A_{F P}$ have been associated with the arc lengths corresponding to interior intersection points on both inlet and centerbody $\mathrm{N}-\mathrm{lines}$. For each $\mathrm{N}-\mathrm{l}$ ine a table of area $\mathrm{A}_{\mathrm{FP}}$ versus arc length can be constructed.

For each inlet $\mathrm{N}-\mathrm{line}$, the first entry in the table is the area $\mathrm{AFP}_{\mathrm{FP}}^{*}$ associated with the exterior intersection for the initial centerline point. The second entry is the area $A_{F P}$ associated with the interior intersection for the initial centerline point. Successive entries are the areas $A_{F P}$ for the interior intersections for the successive centerline points, i.e.,

$\begin{array}{ccc}\text { Entry } & \begin{array}{c}\text { Associated } \\ \text { Arc Length }\end{array} & \text { Area } \\ 1 & \mathrm{~S}_{1} & A_{F P}^{*} \text { (ext. Initial centerline point) } \\ 2 & \mathrm{~S}_{2} & A_{F P} \text { (int. initial centerline point) } \\ 3 & \mathrm{~S}_{3} & A_{F P} \text { (int. 2nd centerline point) } \\ 4 & \mathrm{~S}_{4} & A_{F P} \text { (int. 3rd centerline point) } \\ \cdot & & \\ \cdot & & \\ \text { Last } & \mathrm{S}_{\text {LAST }} & A_{F P} \text { (int. last centerline point) }\end{array}$

Notice this table is in decreasing magnitude of arc length.

For each centerbody $\mathrm{N}$-line the first entry is the area $A_{F P}$ associated with the first intersection point. This is obtained from the initial centerline point in cases $b$ and $d$ of Section 8.7, but from some other centerline point in case $c$. Successive entries are the areas $A_{F P}$ for successive centerline points. This table is in increasing magnitude of arc length.

Interpolation in arc length is performed in the above tables to obtain flow passage areas at the midpoints of the segments of each $\mathrm{N}-1$ ine. 
Once the above has been accomplished, the flow passage areas for the control points must be obtained. This is obtained by averaging the areas for the midpoints on the two segments bounding the panel on . which the midpoint is located. Specifically, the area to be associated with the control point of the $k$-th panel of a strip is obtained by averaging the areas associated with the midpoints of the $k$-th segments of the two successive $\mathrm{N}-\mathrm{l}$ ines bordering the strip.

The above procedure is used to obtain flow passage areas $A_{F P}$ at the interior control points of the inlet and the centerbody body. The exterior control points require special handling.

\subsection{Flow Passage Areas at Exterior Control Points on the Inlet}

The area A Ap defined in Section 8.5 is not really a flow passage area but is merely a geometric area. It is used to obtain flow passage areas at exterior control points. As mentioned above, the definition of such an area is somewhat arbitrary, but the one adopted has given encouraging results. It is important to emphasize that even if the results at exterior points should turn out less accurate than desired, it would not affect the accuracy of interior points, for which the compressibility correction has been thoroughly verified in a large number of cases.

Initially the $A_{\mathrm{FP}}^{\star}$ are handled in a manner similar to the internal flow passage areas $A_{F P}$ to obtain a value of $A_{F P}^{*}$ at each exterior control point. Additionally, however, two special values of $A_{F P}^{*}$ are needed: an initial value $A_{0}$ near the inlet highlight and a final value $A_{L}$ far downstream on the afterbody.

Key quantities for this computation come from the intersection with the $\mathrm{N}-\mathrm{Tines}$ of the inlet with the plane for the initial centerline point. For each $\mathrm{N}-\mathrm{Tine}$ there are the coordinates $\mathrm{x}_{i}, \mathrm{y}_{\mathbf{i}}, \mathrm{z}_{\mathbf{i}}$ of the intersection point (interior) and the flow passage area $A_{F P}$. All four of these quantities are averaged between successive $\mathrm{N}-\mathrm{l}$ ines (a two-point average to produce an initial point $\left(x_{0}, y_{0}, z_{0}\right)$ and an initial area $A_{0}$ for the strip of panels lying between the two $\mathrm{N}-\mathrm{lines}$ in question). Further, the coordinates of the last intersection 
on each $\mathrm{N}-\mathrm{Tine}$ (from the last centerline point) are averaged between successive $\mathrm{N}$-lines to produce coordinates $x_{L}, y_{L}, z_{L}$ of the last point on the strip lying between the two $\mathrm{N}-\mathrm{lines}$, and a similar average of areas $\mathrm{A}_{\mathrm{FP}}^{*}$ gives the final area $A_{L}$.

Also needed are the exterior geometric areas A $A_{F P}^{*}$ for the exterior control points. These are obtained by interpolation in a manner similar to that described above for interior control points. For each $\mathrm{N}-\mathrm{line}$ a table of area versus arc length is constructed for the intersection points. The first entry in the table is the area $A_{F P}$ corresponding to the interior intersection for the initial centerline point. The second entry is the area $A_{F P}^{*}$ associated with the exterior intersection for the initial centerline point. Successive entries are the areas A $A_{F P}^{*}$ for the exterior intersections for successive centerline points, i.e.,

$\begin{array}{ccl}\text { Entry } & \text { Arc Length } & \text { Area } \\ 1 & \mathrm{~S}_{1} & A_{F P} \text { (int. initial centerline point) } \\ 2 & \mathrm{~S}_{2} & A_{\mathrm{FP}}^{*} \text { (ext. initial centerline point) } \\ 3 & \mathrm{~S}_{3} & A_{F P}^{*} \text { (ext. 2nd centerline point) } \\ 4 & \mathrm{~S}_{4} & A_{F P}^{*} \text { (ext. 3rd centerline point) } \\ \cdot & & \\ \cdot & & \\ \text { Last } & S_{\text {LAST }} & A_{F P}^{*} \text { (ext. last centerline point) }\end{array}$

The table is in increasing magnitude of arc length.

Interpolation in arc length is performed in the above table to obtain areas $A_{F P}^{*}$ at the midpoints of the segments of each $\mathrm{N}$-line, whose arc length is calculated in the manner described in Section 8.8. These midpoint areas are averaged between successive $\mathrm{N}-\mathrm{lines}$ to obtain areas $A_{F P}^{*}$ at the exterior control points. 
The geometric area A Ap associated with each exterior control point, together with the control point coordinates $x, y, z$, is used to obtain the following linear dimensions needed to compute the exterior flow passage area.

$$
\begin{gathered}
y^{\prime}=\sqrt{(1 / \pi) A_{F P}^{\star}}, \quad R=\sqrt{\left(y^{\prime}\right)^{2}+\left(x-x_{0}\right)^{2}}, \quad D=\frac{\left(y^{\prime}-y_{0}^{\prime}\right)}{\left(y_{L}^{\prime}-y_{0}^{\prime}\right)} \\
y_{0}^{\prime}=\sqrt{(7 / \pi) A_{0}}, \quad y_{L}^{\prime}=\sqrt{(1 / \pi) A_{L}}
\end{gathered}
$$

Finally, the flow passage area associated with the control point for use with the compressibility correction is

$$
A_{F P}=[1+D] \pi R\left[R+x-x_{0}\right]
$$

Equation (9) gives a flow passage area that varies from a value near the inlet highlight that is approximately equal to the highlight disk area to an area far downstream that equals the surface area of a sphere centered at the highlight minus the final cross section of the inlet. This area distribution is approximately that through which the flow passes in the case of static operation.

\subsection{Flow Passage Areas at Exterior Control Points of the Centerbody}

The first step is to compute the cross-sectional area of the centerbody at selected "axial" locations. To do this, a set of centerline points upstream of the inlet highlight are input. These are used in the same way as centerline points as far as computing intersections and areas except that: (1) these points are input and used only in case $d$ of Section 8.7, and (2) intersections and areas are found only on the $\mathrm{N}-\mathrm{l}$ ines of the centerbody.

The resulting areas $A_{C}$ are interpolated in arc length to find areas at the control points in the same manner as in Section 8.8. Finally, the flow passage area to be saved with each exterior control point on the nonlifting centerbody is

$$
A_{F P}=A_{i}-A_{C}
$$


where $A_{j}$ is the area computed in Section 8.5 for the initial interior intersection. Comparing equation (6) (which applies here rather than (7)) and the definitions in Section 8.9 shows that

$$
A_{i}=A_{0}+A_{c} \quad \text { (initial centerline point) }
$$

The $A_{c}$ in (11) is that for the initial centerline point. The $A_{c}$ in (10) is that for the control point in question. Also, $A_{0}$ is defined in Section 8.9.

\subsection{Flow Passage Areas for Off-Body Points}

There are two types of off-body points: ordinary input off-body points and off-body points generated by the cross-section and control station program. The latter are always interior points, and the flow passage area is calculated by that program (Section 9.0). It is anticipated that all interior off-body points will be so generated. Thus, input off-body points will be exterior points. It is not clear at this time how the flow passage areas for such points should be defined, and this decision has been postponed. Thus input off-body points should not be used in compressible cases. 


\subsection{CROSS-SECTION AND CONTROL STATION PROGRAM}

In inlet applications it is not only the flow on the body that is of interest but also the flow at field points off the body, usually in the interior of the inlet. Most commonly, distributions of various flow quantities across some interior cross sections of the inlet are desired. Of course, off-body points could simply be input to the program, but this is tedious for the user. Instead, the program generates the required off-body points at each cross section. The user specifies the location and orientation of each cross section where flow calculation is required, and the program automatically distributes off-body points across the cross section. It is this last calculation that distinguishes a cross-section calculation from the flow passage area calculation of Section 8.0. One cross section is selected as the control station for the combination program and thus at least one cross section is required if a combined flow is to be computed. The remaining subsections of Section 9.0 give the details of the cross-section procedure.

\subsection{Input}

Each cross section is defined by a cross-section point and normal vector (six numbers) which are used in a manner very similar to the way a centerline point and its normal vector are used in the flow passage program (Figure 7 ). However, more calculations are required for a cross section. One additional input integer designates which cross section is to be used as the control station in the combination program. Another input integer specifies the number of "radial" segments to be used at each cross section. This latter number is denoted $r$.

\subsection{N-Line Intersections and Flow Passage Area}

The intersection program is used to find the intersection points of the $\mathrm{N}-1$ ines with the plane through the cross-section point whose normal vector is the input cross-section normal vector. On the $\mathrm{N}-\mathrm{l}$ ines of the inlet only the interior intersection points are needed. The exterior intersection points are discarded. If there are intersections with the $\mathrm{N}-\mathrm{lines}$ of the centerbody, these 
points are needed. The areas $A_{i}$ and $A_{c}$ (if any) are computed as in Section 8.5, and the flow passage area is computed from (6) or (7) as appropriate.

\subsection{Cross-Section $\mathrm{N}-\mathrm{T}$ ines}

Two situations must be distinguished: the case when there are intersections with the $\mathrm{N}-\mathrm{l}$ ines of the centerbody and the case when there are no such intersections.

9.3.1 No centerbody. - Cross-section $\mathrm{N}-\mathrm{l}$ ines are to be constructed, each of which starts at the cross-section point and ends at an intersection point on an inlet $\mathrm{N}-\mathrm{l}$ ine. Clearly one cross-section $\mathrm{N}-\mathrm{T}$ ine is constructed for each inlet $\mathrm{N}-$ line. For each cross-section $\mathrm{N}-\mathrm{l}$ ine the first point is the cross-section point, the last is the intersection point on the inlet $\mathrm{N}-\mathrm{line}$, and the interior points are obtained by interpolation (Figure 9).

(k) Let $\left.(k) x_{c s}, y\right)^{y}, z_{c s}$ be the coordinates of the input cross-section point and $x_{i}^{(k)}, y_{i}^{(k)}, z_{i}$ be the coordinates of the intersection point on the $k$-th inlet $N-l$ ine, $k=1,2, \ldots, T$, where $T$ is the total number of inlet $N-l$ ines. The points on the $\mathrm{k}$-th cross-section $\mathrm{N}-\mathrm{l}$ ine have the coordinates

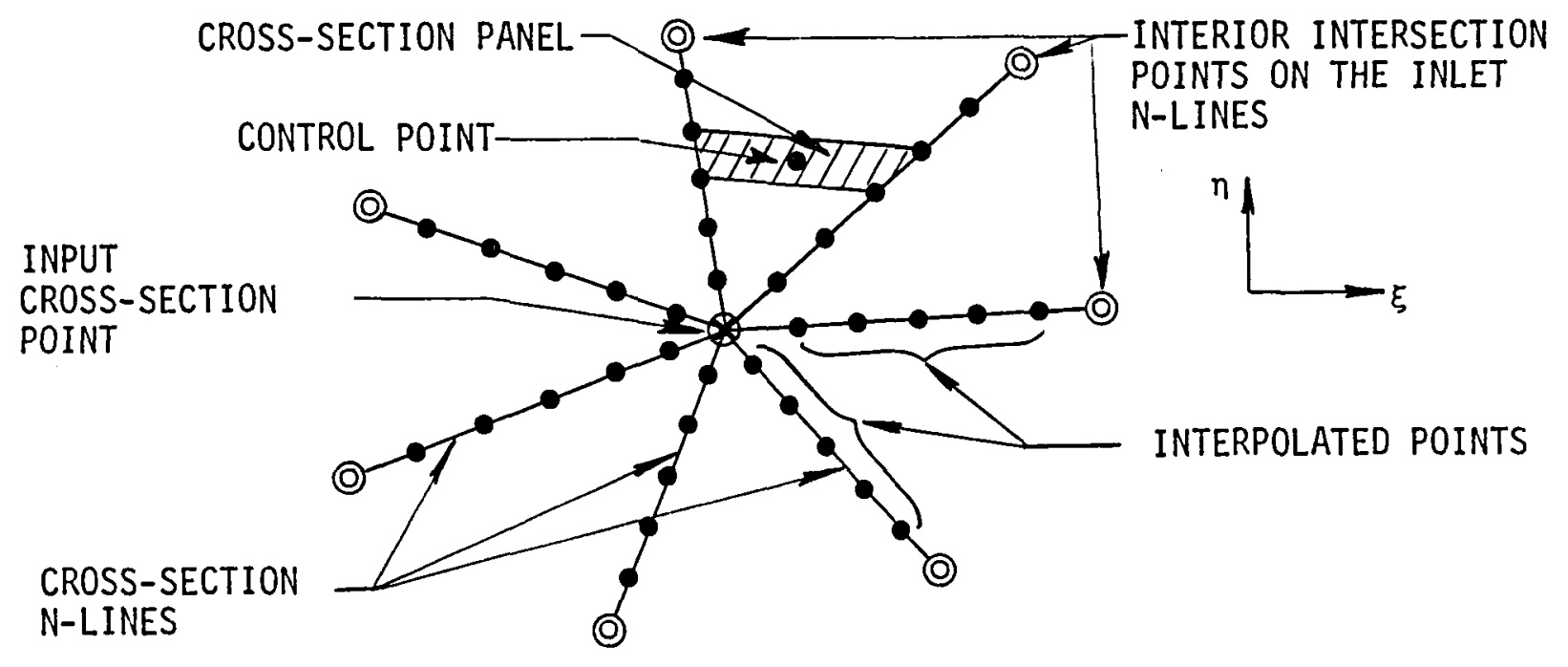

Figure 9. Generation of cross-section points and panels in the absence of a centerbody. 


$$
\begin{array}{ll}
x_{m}^{(k)}=x_{c s}+\left[x_{i}^{(k)}-x_{c s}\right] \frac{m}{r} & \\
y_{m}^{(k)}=y_{c s}+\left[y_{i}^{(k)}-y_{c s}\right] \frac{m}{r}, & m=0,1, \ldots, r \\
z_{m}^{(k)}=z_{c s}+\left[z_{i}^{(k)}-z_{c s}\right] \frac{m}{r}, & k=1,2, \ldots, T
\end{array}
$$

where $r$ is the input integer mentioned in Section 9.1. Each cross-section $\mathrm{N}-\mathrm{l}$ ine has $(r+1)$ points.

9.3.2 With centerbody. - Cross-section N-lines are to be constructed, each of which starts at an intersection point on a centerbody $\mathrm{N}-\mathrm{line}$ and ends at an intersection point on an inlet $\mathrm{N}-\mathrm{l}$ ine. For each cross-section $\mathrm{N}-\mathrm{l}$ ine the first point is the centerbody intersection point, the last is the inlet intersection point, and the interior points are obtained by interpolation (Figure 10).

It is assumed that there are the same number of inlet and centerbody $\mathrm{N}-\mathrm{T}$ ines, say $T$ of each; clearly there are $T$ cross-section $N$-lines.

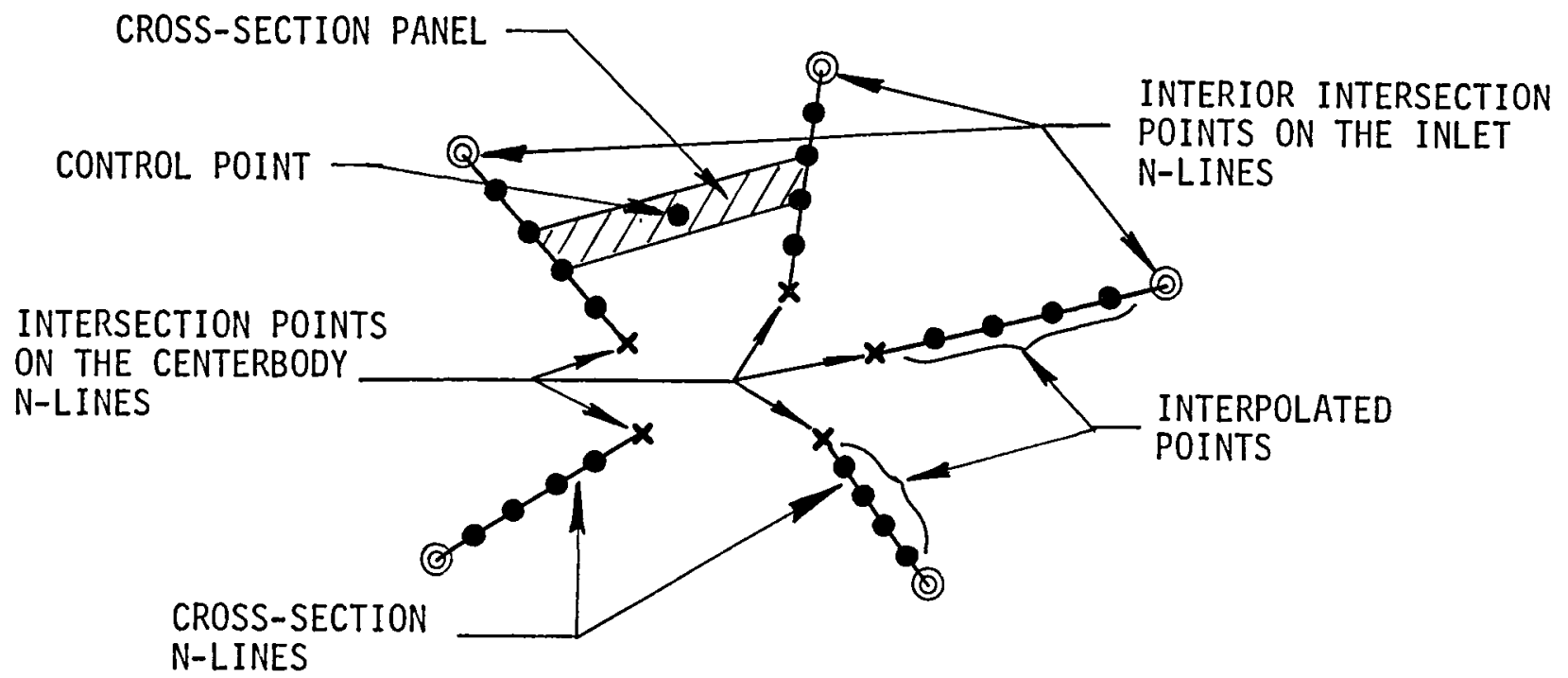

Figure 10. Generation of cross-section points and panels in the presence of a centerbody. 
Let $x_{c}^{(k)}, y_{c}^{(k)}, z_{c}^{(k)}$ be the coordinates of the intersection on the $k$-th centerbody $N-l$ ine and, as before, let $x_{i}^{(k)}, y_{i}^{(k)}, z_{j}^{(k)}$ be the coordinates of the interior intersection point on the $k$-th inlet $N$-line where $k=1,2, \ldots, T$. The points of the $k$-th cross-section $\mathrm{N}-\mathrm{l}$ ine have the coordinates

$$
\begin{aligned}
& x_{m}^{(k)}=x_{c}^{(k)}+\left[x_{i}^{(k)}-x_{c}^{(k)}\right] \frac{m}{r}, \\
& y_{m}^{(k)}=y_{c}^{(k)}+\left[y_{i}^{(k)}-y_{c}^{(k)}\right] \frac{m}{r}, \quad m=0,1, \ldots, r \\
& z_{m}^{(k)}=z_{c}^{(k)}+\left[z_{i}^{(k)}-z_{c}^{(k)}\right] \frac{m}{r}, \quad k=1,2, \ldots, T
\end{aligned}
$$

As before, each $\mathrm{N}-\mathrm{l}$ ine has $r+1$ points.

\subsection{Cross-Section Panels and Control Points}

Cross-section panels are formed from the points of the cross-section $\mathrm{N}-\mathrm{lines}$ in a manner logicaliy similar to (but using different formulas than) that used to form surface panels from the on-body $\mathrm{N}-\mathrm{lines}$. In particular, a panel is formed from four points, which consist of two consecutive points on an $\mathrm{N}-\mathrm{l}$ ine and the corresponding two points on the adjacent $\mathrm{N}-\mathrm{line}$. Symbolically, the $\mathrm{m}$-th panel of the $k$-th cross-section strip is formed from the points:

$$
\begin{aligned}
& {\left[x_{m-1}^{(k)}, \quad y_{m-1}^{(k)}, \quad z_{m-1}^{(k)}\right]} \\
& {\left[x_{m}^{(k)}, \quad y_{m}^{(k)}, \quad z_{m}^{(k)}\right]} \\
& {\left[x_{m-1}^{(k+1)}, \quad y_{m-1}^{(k+1)}, \quad z_{m-1}^{(k+1)}\right]} \\
& {\left[x_{m}^{(k+1)}, \quad y_{m}^{(k+1)}, \quad z_{m}^{(k+1)}\right]}
\end{aligned}
$$

In parallel to the on-body procedure, first the diagonal vectors

$$
\begin{aligned}
& \vec{R}_{1}=\left[x_{m}^{(k+1)}-x_{m-1}^{(k)}\right] \vec{i}+\left[y_{m}^{(k+1)}-y_{m-1}^{(k)}\right] \vec{j}+\left[z_{m}^{(k+1)}-z_{m-1}^{(k)}\right] \vec{k} \\
& \vec{R}_{2}=\left[x_{m-1}^{(k+1)}-x_{m}^{(k)}\right] \vec{i}+\left[y_{m-1}^{(k+1)}-y_{m}^{(k)}\right] \vec{j}+\left[z_{m-1}^{(k+1)}-z_{m}^{(k)}\right] \vec{k}
\end{aligned}
$$

are formed. These are in the cross-section plane. 
The unit normal vector is the same for all panels on all strips. It is the input cross-section normal vector divided by its own length, say

$$
\vec{n}=n_{x} \vec{i}+n_{y} \vec{j}+n_{z} \vec{k}
$$

where

$$
n_{x}=\frac{N_{x}}{N}, \quad n_{y}=\frac{N_{y}}{N}, \quad n_{z}=\frac{N_{z}}{N}, \quad N=\sqrt{N_{x}^{2}+N_{y}^{2}+N_{z}^{2}}
$$

and where $N_{x}, N_{y}, N_{z}$ are the input components. The unit tangent vectors are the same for all panels on all strips. Define

$$
\begin{aligned}
& \vec{t}_{2}=\vec{n} \times \vec{j}=-n_{z} \vec{j}+0 \vec{j}+n_{x} \vec{k}, \\
& \vec{T}_{1}=\vec{T}_{2} \times \vec{n}=-n_{x} n_{y} \vec{j}+\left(n_{x}^{2}+n_{z}^{2}\right) \vec{j}-n_{y} n_{z} \vec{k}
\end{aligned}
$$

These vectors are divided by their own lengths to obtain unit vectors

$$
t_{1 x}=\frac{T_{1 x}}{T_{1}}, \quad t_{1 y}=\frac{T_{1 y}}{T_{1}}, \quad T_{1 z}=\frac{T_{1 z}}{T_{1}}, \quad T_{1}=\sqrt{T_{1 x}^{2}+T_{1 y}^{2}+T_{1 z}^{2}}
$$

and the same for $t_{2 x}, t_{2 y}, t_{2 z}$. These are used as a transformation matrix (just one matrix for all panels)

$$
\begin{array}{lll}
a_{11}=t_{1 x}, & a_{12}=t_{1 y}, & a_{13}=t_{12} \\
a_{21}=t_{2 x}, & a_{22}=t_{2 y}, & a_{23}=t_{2 z} \\
a_{31}=n_{x}, & a_{32}=n_{y}, & a_{33}=n_{z}
\end{array}
$$

The area of a panel is given by

$$
A=\frac{1}{2} \vec{R}_{1} \times \vec{R}_{2} \cdot \vec{n}=\frac{1}{2}\left|\begin{array}{lll}
R_{1 x} & R_{1 y} & R_{1 z} \\
R_{2 x} & R_{2 y} & R_{2 z} \\
n_{x} & n_{y} & n_{z}
\end{array}\right| \quad \text { (a determinant) }
$$

The control-point of the panel, which is treated as an off-body point in the flow calculation, has coordinates 


$$
\begin{aligned}
& x_{0}=\frac{1}{4}\left[x_{m-1}^{(k)}+x_{m}^{(k)}+x_{m-1}^{(k+1)}+x_{m}^{(k+1)}\right] \\
& y_{0}=\frac{1}{4}\left[y_{m-1}^{(k)}+y_{m}^{(k)}+y_{m-1}^{(k+1)}+y_{m}^{(k+1)}\right] \\
& z_{0}=\frac{1}{4}\left[z_{m-1}^{(k)}+z_{m}^{(k)}+z_{m-1}^{(k+1)}+z_{m}^{(k+1)}\right]
\end{aligned}
$$

Also desired are the cross-section coordinates, $\xi, \eta$, of the control point. These are obtained by a transformation using the above transformation matrix and the cross-section point as origin. From formulas (18) - (20) it can be verified that if the cross section is normal to the $x$-axis, then the $\xi$ axis is parallel to the $y$-axis and the n-axis to the $z$-axis. In all cases the n-axis is paralle? to the $y=0$ plane.

The quantities needed for each panel are

$$
x_{0}, y_{0}, z_{0}, \xi, n, A
$$

These are computed and stored for all panels on the cross-section - a total of $(T-1) r$ panels.

Quantities needed for the cross section as a whole are

$$
\begin{array}{lllll}
x_{C S}, y_{C S}, z_{C S} & a_{11} & a_{12} & a_{13} & A_{F P} \\
& a_{21} & a_{22} & a_{23} \\
& a_{31} & a_{32} & a_{33} &
\end{array}
$$

Also needed for each cross section are the reference and cross-section coordinates of the boundary points. These are just the intersection points on the inlet $\mathrm{N}-\mathrm{lines}$. That is,

$$
x_{i}^{(k)}, y_{i}^{(k)}, z_{i}^{(k)}, \quad k=1,2, \ldots, T
$$

together with the coordinates $\xi_{j}^{(k)}, \eta_{i}^{(k)}$ obtained by transforming these into cross-section coordinates. The same is done for the centerbody intersection points (if any); 


$$
x_{c}^{(k)}, y_{c}^{(k)}, z_{c}^{(k)}
$$

and their transformed cross-section coordinates $\xi_{c}^{(k)}, n_{c}^{(k)}$.

\subsection{Flow Calculation}

The data generated above are used with: the basic potential-flow program, the geometric quantities data set, and the source densities from the fundamental solution data set. Each cross-section control point is treated as an off-body point, and the flow there is computed.

For each cross-section control point a row of $\vec{v}_{i j}$ matrix is computed by the usual formulas. Also calculated are the vorticity velocities at the off-body points due to each of the individual vorticity flows (one for each lifting strip). These last are combined with the B's in the same manner as for the on-body points to yield the static onset flow velocity in the form of equation (2).

Fundamental flow velocities are computed in a manner analogous to equation (3) for the cross-section control points, i.e.,

$$
\begin{aligned}
\vec{v}_{i}^{(100)} & =\sum_{j=1}^{N} \vec{v}_{i j} \sigma_{j}^{(100)+\vec{i}} \\
\vec{v}_{i}^{(010)} & =\sum_{j=1}^{N} \vec{v}_{i j}(010)+\vec{j} \\
\vec{v}_{i}^{(001)} & =\sum_{j=1}^{N} \vec{v}_{i j}(001)+\vec{k} \\
\vec{v}_{i}(\text { static }) & =\sum_{j=1}^{N} \vec{v}_{i j} \sigma_{j}^{(s)}+\vec{v}_{i}^{(s)}
\end{aligned}
$$

It is understood that in symmetry cases a different matrix $\vec{v}_{i j}$ is used for the 010 flow. 
The above velocities are computed for each cross-section control point to form the cross-section data set. Also in this data set are the vector $\vec{F}$ and scalar $F$ volume fluxes - one set for each fundamental solution. These are given by

$$
\vec{F}=\sum_{\substack{\text { cross } \\ \text { section }}} \vec{v}_{\mathfrak{i}} A_{\mathbf{i}}
$$

and

$$
F=\vec{F} \cdot \vec{n}
$$

where $\vec{v}_{i}$ is identified with each of the four velocities above. $A_{i}$ is the $i$ th panel area. The scalar flux at the control station is needed in the combination program. In symmetry cases the $F^{\prime} s$ calculated from the dove equation are doubled and then the $F$ corresponding to the 010 onset flow is set equal to zero. 


\subsection{COMBINATION PROGRAM INPUT AND PRELIMINARY CALCULATIONS}

\subsection{Incompressible Option}

If the flow is incompressible, this option is selected and only the following quantities are input:

$V_{\infty} \quad$ freestream velocity

$V_{c}$ average velocity at the control station

$V_{\text {ref }}$ reference velocity used in computing pressure coefficient

a angle of attack

$\beta \quad$ angle of yaw

$k \quad$ integer denoting that the $k$-th input cross section is to be used as control station

The volume flux $Q$ at the control station is obtained from

$$
Q=V_{c} \cdot A_{F P}(k)
$$

where $A_{F P}(k)$ is the area of the control station. This is used in equation (5) to evaluate the combination constant $B$. Then velocity is calculated from equation (4).

\subsection{Freestream Conditions}

For compressible flow the freestream conditions are defined by inputting angle of attack $\alpha$, angle of yaw $\beta$, and three additional quantities:

either velocity $V_{\infty}$ or Mach number $M_{\infty}$

either total pressure $P_{t}$ or static pressure $P_{s}$

either total temperature $T_{t}$ or static temperature $T_{s}$

Then the preliminary calculations are as follows. 
10.2.1 $\underline{M}_{\infty}$ input. -

(a) If $P_{t}$ is input, $P_{s}$ is given by

$$
P_{s}=P_{t}\left(1+\frac{1}{5} M_{\infty}^{2}\right)^{-3.5}
$$

If $P_{s}$ is input, $P_{t}$ is given by

$$
P_{t}=P_{s}\left(1+\frac{1}{5} M_{\infty}^{2}\right)^{3.5}
$$

If neither is input, the default is

$$
P_{t}=2116.23
$$

and $P_{S}$ is as above.

(b) If $T_{t}$ is input, $T_{s}$ is given by

$$
T_{s}=T_{t}\left(1+\frac{1}{5} M_{\infty}^{2}\right)^{-1}
$$

If $T_{s}$ is input, $T_{t}$ is given by

$$
T_{t}=T_{s}\left(1+\frac{1}{5} M_{\infty}^{2}\right)
$$

If neither is input, the default is

$$
T_{t}=518.67
$$

and $T_{S}$ is as above.

In either case stagnation and freestream sound speeds $a_{t}$ and $a_{s}$ are calculated from

$$
a_{t}=49 \sqrt{T_{t}}, \quad a_{s}=49 \sqrt{T_{s}}
$$

and $V_{\infty}$ from

$$
v_{\infty}=a_{t} M_{\infty}\left(1+\frac{1}{5} M_{\infty}^{2}\right)^{-1 / 2}
$$

45 
10.2.2 $\underline{V}_{\infty}$ Input. -

(a) If $T_{t}$ is input, $a_{t}$ is given by

$$
a_{t}=49 \sqrt{T_{t}}
$$

$M_{\infty}$ is then calculated from

$$
M_{\infty}=\frac{v_{\infty}}{a_{t}}\left[1-\frac{1}{5}\left(\frac{v_{\infty}}{a_{t}}\right)^{2}\right]^{-1 / 2}
$$

The remainder of the calculation proceeds as in 10.2.1 above.

(b) If $T_{s}$ is input, $a_{s}$ is given by

$$
a_{s}=49 \sqrt{T_{S}}
$$

and $M_{\infty}$ by

$$
M_{\infty}=V_{\infty} / a_{S}
$$

The remainder of the calculation proceeds as in 10.2.1 above.

10.2.3 Additional Freestream Quantities. - Built into the program are constants

$$
\begin{aligned}
& g=32.174 \\
& R=1715.63
\end{aligned}
$$

The following quantities are calculated:

$$
\begin{array}{ll}
\text { Total density: } & \rho_{t}=\frac{P_{t}}{R T_{t}} \\
\text { Static density: } & \rho_{s}=\frac{P_{s}}{R T_{s}} \\
\text { Dynamic pressure: } & q_{\infty}=0.7 P_{t}\left(\frac{P_{s}}{P_{t}}\right) M_{\infty}^{2}
\end{array}
$$

Pressure ratio: $\quad \mathrm{P}_{\mathrm{s}} / \mathrm{P}_{\mathrm{t}}$ 
Density ratio: $\quad \rho_{s} / \rho_{t}$

Temperature/sea-level ratio: $\theta=\frac{T_{t}}{518.67}$

Pressure/sea-level ratio: $\quad \delta=\frac{P_{t}}{2176.23}$

Critical speed: $\quad a_{\star}=a_{t} / \sqrt{1.2}$

Maximum velocity: $v_{\max }=\sqrt{5} a_{t}$

Equivalent Incompressible Freestream velocity: $V_{\infty}^{\prime}=V_{\infty}\left(\frac{\rho_{s}}{\rho_{t}}\right)$

Equivalent Incompressible Critical velocity: $a_{\star}^{\prime}=0.6339 a_{\star}$

10.2.4 Summary. - Three freestream conditions are input: $V_{\infty}$ or $M_{\infty}$, $P_{t}$ or $P_{s}, T_{t}$ or $T_{s}$ (or default values). Calculated and saved are

$$
\begin{aligned}
& v_{\infty}, M_{\infty}, P_{t}, P_{s}, T_{t}, T_{s}, a_{t}, a_{s} \\
& \rho_{t}, \rho_{s}, q_{\infty}, P_{s} / P_{t}, \rho_{s} / \rho_{t}, \theta, \delta \\
& a_{\star}, v_{\max }, V_{\infty}^{\prime}, a_{\star}^{\prime}
\end{aligned}
$$

Nineteen quantities altogether.

\subsection{Control Station Conditions}

Input consists of one of the following three quantities:

$$
\begin{aligned}
& \dot{w} \text { inlet mass flow rate } \\
& V_{c} \text { average velocity } \\
& M_{C} \text { average Mach number }
\end{aligned}
$$

The remaining two must be calculated plus some additional quantities. 
10.3.1 $\mathrm{V}_{\mathrm{c}}$ Input. $-\rho_{\mathrm{c}}$ is given by

$$
\rho_{c}=\rho_{t}\left[1-\frac{1}{5}\left(\frac{V_{c}}{a_{t}}\right)^{2}\right]^{2.5}
$$

$\dot{w}$ by

$$
\dot{w}=g_{\rho_{c}} V_{c} \frac{A_{F P}(k)}{144}
$$

and $M_{C}$ by

$$
M_{c}=\frac{V_{c}}{a_{t}}\left[1-\frac{1}{5}\left(\frac{V_{c}}{a_{t}}\right)^{2}\right]^{-1 / 2}
$$

10.3.2 $M_{c}$ Input. $-V_{c}$ is given by

$$
v_{c}=a_{t} M_{c}\left(1+\frac{1}{5} M_{c}^{2}\right)^{-1 / 2}
$$

Then $\rho_{c}$ and $\dot{w}$ are obtained as in 10.3.1 above.

10.3.3 $\dot{w}$ Input. - Here $V_{c}$ must be calculated iteratively by solving the equation

$$
v_{c}=\frac{\dot{w}}{g\left(A_{F P}(k) / 144\right) \rho_{t}\left[1-1 / 5\left(V_{c} / a_{t}\right)^{2}\right]^{2.5}}
$$

starting with $V_{c}=0$

Once $V_{c}$ is known, $M_{c}$ and $\rho_{c}$ are obtained as in 10.3.1 above.

10.3.4 Additional Control-Station Quantities. - These are calculated as follows:

Pressure ratio: $\quad\left(P_{c} / P_{t}\right)=\left[1-\frac{1}{5}\left(\frac{V_{c}}{a_{t}}\right)^{2}\right]^{3.5}$

Density ratio: $\quad \rho_{c} / \rho_{t}$ 
Dynamic pressure: $q_{c}=0.7 P_{t}\left(\frac{P_{c}}{P_{t}}\right) M_{c}^{2}$

Velocity ratio: $\quad V_{\infty} / V_{c}$

Corrected mass flow: $\dot{w}_{\text {cor }}=\dot{w} \frac{\sqrt{\theta}}{\delta}$

Equivalent Incompressible Average velocity: $V_{c}^{\prime}=V_{c}\left(\frac{\rho_{c}}{\rho_{t}}\right)$

10.3.5 Summary. - One quantity, $\dot{w}, V_{c}$, or $M_{c}$ is input. Quantities saved are

$$
\dot{w}, V_{c}, M_{c}, \rho_{c},\left(P_{c} / P_{t}\right),\left(\rho_{c} / \rho_{t}\right), q_{c},\left(V_{\infty} / V_{c}\right), \dot{w}_{c o r}, v_{c}^{\prime}
$$

A total of ten quantities.

\subsection{Combination Calculation}

The basic combined incompressible velocity at each on-body, off-body and cross-section point is obtained from equations (5) and (4), where

$$
Q=V_{c}^{\prime} A_{F P}(k)
$$

and $V_{\infty}^{\prime}$ is used instead of $V_{\infty}$ in these equations. Once the vector $\vec{V}_{j}$ is calculated from (4), the scalar magnitude $V_{i}$ is calculated by the usual square root of sum of squares.

For the present discussion the $i$ in $v_{i}$ denotes incompressible rather than the usual meaning of velocity at $i$-th control point. However, it is obvious that all calculations must be done for every control point individually, as well as for every off-body point and cross-section point.

\subsection{Compressibility Correction}

There is a flow passage area $A_{F P}$ associated with every on-body control point, off-body point, and cross-section point (section 8.0). This is now used in the compressibility correction. 
First the average incompressible velocity is calculated from

$$
\bar{v}_{i}=\frac{\dot{w}}{g \rho_{t}\left(A_{F P} / 144\right)}
$$

If $\bar{v}_{i}>a_{\star}^{\prime}, \bar{v}_{i}$ is set equal to $a_{*}^{\prime}$ and the average density ratio $\varepsilon$ is

$$
\varepsilon=\frac{\bar{\rho}}{\rho_{t}}=0.6339
$$

If this occurs the point is labelled "choked" on the output.

If $\bar{v}_{i}<a_{*}^{1}$, it is used as it stands to compute $\left(\bar{\rho} / p_{t}\right)$ by an iterative procedure. The iterative equation is

$$
\varepsilon=\left[1-\frac{1}{5}\left(\frac{\bar{V}_{i}}{a_{t}}\right)_{\varepsilon}^{2} \frac{1}{2}\right]^{2.5}
$$

with initial value $\varepsilon=1$.

Finaliy, the compressible velocity magnitude $V$ is calculated from

$$
v=v_{i}\left(\frac{l}{\varepsilon}\right)^{m} \quad m=\frac{v_{i}}{\bar{v}_{i}}
$$

This is used to calculate all output quantities (Section 11.0). First $V$ is tested. If $V \geq V_{\max }$, set $V=V_{\max }$ and use $M=\infty$ and $P_{s} / P_{t}=0$ instead of values calculated below, and denote this point as "vacuum." If $V<V_{\max }$ use it as it stands in subsequent calculations. 


\subsection{FINAL COMPUTATION}

\subsection{Incompressible Option}

Once the velocity has been computed as described in Section 10.1, the only remaining calculation is the pressure coefficient

$$
c_{p}=1-\left(\frac{v}{v_{\text {ref }}}\right)^{2}
$$

Quantities output are described in Section 14.6 .

\subsection{Basic Compressible Calculation}

Once the calculations of Section 10.5 have been completed the following quantities are known at each on-body point, off-body point and control station point:

Compressible Velocity Magnitude:

V

Incompressible Velocity Vector:

$\overrightarrow{\mathrm{v}}_{\mathbf{i}}$

with components:

$v_{i x}, v_{i y}, v_{i z}$

and magnitude:

Flow Passage Area:

$v_{i}$

Average Incompressible Velocity:

A FP

Average Density Ratio:

$\bar{v}_{\mathbf{i}}$

$\varepsilon=\left(\bar{\rho} / \rho_{t}\right)$

These can now be used to compute other quantities

Compressible Velocity Components:

$$
v_{x}=v_{i x}\left(V / v_{i}\right), \quad v_{y}=v_{i y}\left(V / v_{j}\right), \quad v_{z}=v_{i z}\left(V / v_{j}\right)
$$

Mach Number

$$
M=\frac{v}{a_{t}}\left[1-\frac{1}{5}\left(\frac{v}{a_{t}}\right)^{2}\right]^{-1 / 2}
$$


Pressure Ratio

$$
\frac{P}{P_{t}}=\left(1+\frac{1}{5} M^{2}\right)^{-3.5}
$$

The quantities output at all on-body, off-body, and control station points are described in Section 14.7.

11.3 Additional Output Quantities Pertaining to a Cross Section as a Whole

Additional overall quantities calculated are:

Mass Flow Rate:

$$
\dot{w}_{\text {int }}=\frac{g \rho_{t}}{144} \sum \frac{\rho}{\rho_{t}}(\vec{v} \cdot \vec{n}) A
$$

where $\vec{V}$ is compressible velocity with components computed in Section 11.2 above, and the density ratio to be used in equation (6a) is

$$
\frac{\rho}{\rho_{t}}=\left[1-\frac{1}{5}\left(\frac{\mathrm{v}}{a_{t}}\right)^{2}\right]^{2.5}
$$

Corrected Mass Flow Rate:

$$
\dot{w}_{\text {cor }}=\frac{\dot{w}_{\text {int }} \sqrt{\theta}}{\delta}
$$

Specific Corrected Mass Flow Rate:

$$
\dot{w}_{s p}=\frac{\dot{w}_{c o r}}{A_{F P}}
$$

Average Mach number $\bar{M}$ is obtained by iteration using

$$
\bar{M}=\frac{\dot{w}_{\text {sp }}\left[1+(1 / 5) \bar{M}^{2}\right]^{3}}{85.38}
$$

with initial value $\bar{M}=0$. 
To date only one realistic three-dimensional case has been calculated and the results compared with experimental data. The inlet is the scoop inlet shown in the sketch of Figure 11. Calculated and experimental surface pressures are compared along three curves at different "circumferential" locations around the inlet. Since the freestream is at zero angle of attack and yaw, if the inlet were axisymmetric, all three pressure distributions would be identical. Thus the variation between the three pressure distributions is a measure of the three-dimensionality of the flow. This variation is predicted rather well by the calculations, which also agree quite well with the data. Obviously, a good many more cases must be run to establish the accuracy of the present method, but the results shown in Figure 11 are certainly encouraging. 


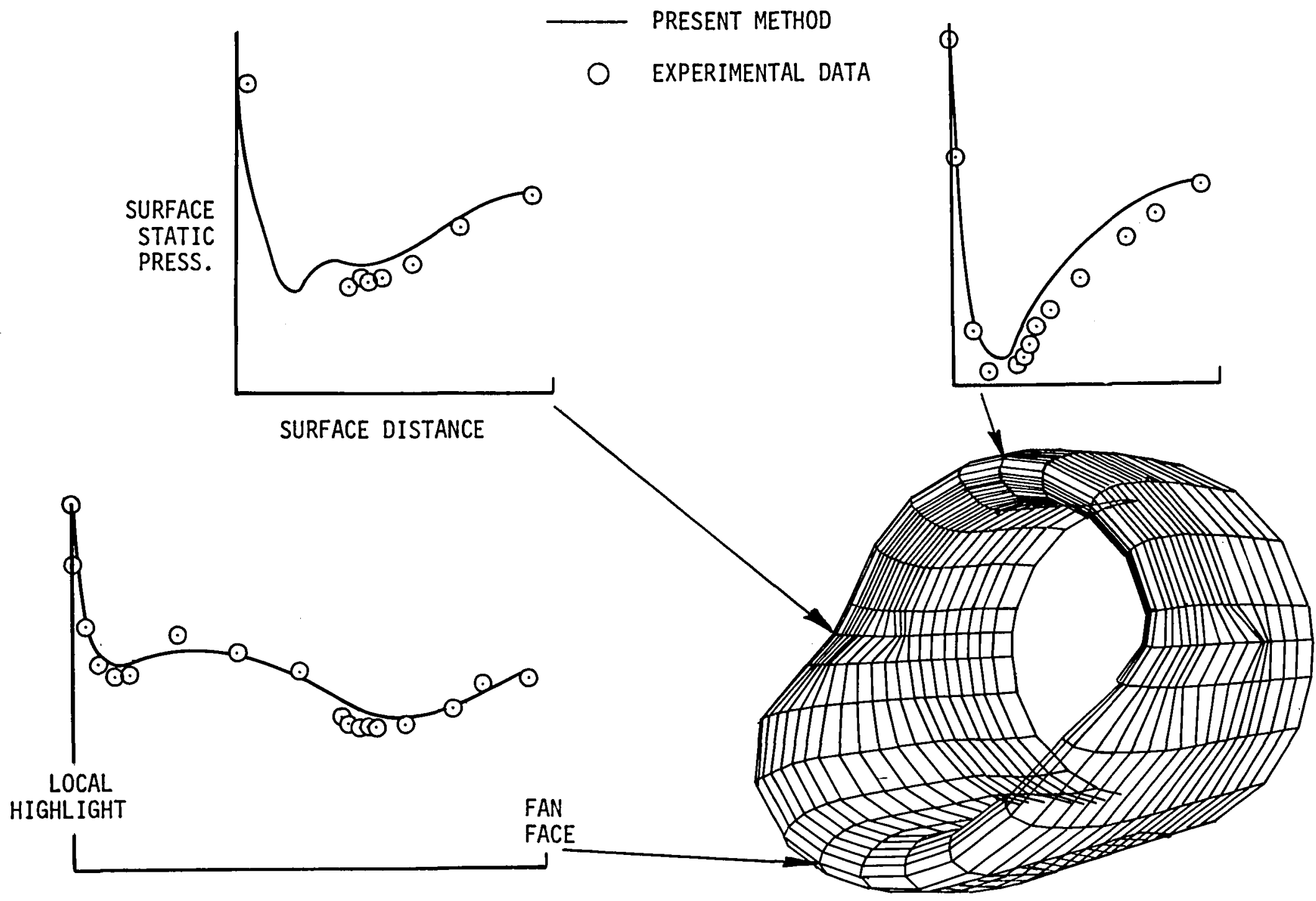

Figure 11. Comparison of calculated and experimental pressure distributions inside a scoop inlet. 


\subsection{INPUT TO THE PROGRAM}

\subsection{Types of Execution}

There are three modes of operation of the program:

1. Complete Run (Mode 0)

In this mode the program calculates the fundamental solutions, and continues to produce combined flow for prescribed values of the physical parameters. Input consists of geometric specification of the inlet including cross sections and a control station, and the inlet operating conditions. The fundamental solutions may be stored for future use as in Mode 1 below. It is anticipated that usually interrupted runs will be desired and that this mode will be run infrequentiy.

2. Fundamental Solution Run (Mode 1)

In this mode only the fundamental solutions are calculated and stored for future use on external units 4, 22, 23, 29, 32, 33 (see Appendix B). Cross sections, a control station, and operating conditions are not required This is the time-consuming portion of the calculation and is performed only once for each geometry (see Figure 5, Section 5.0).

3. Combination Program Run (Mode 2)

This is the most common type of run. Obvious7y either Mode 0 or Mode 1 must have been run previously to produce the Fundamental Solution Data Set. This run starts with this data set and produces combined flow solutions. Input consists of cross sections, a control station, and the inlet operating conditions (see Figure 6, Section 5.0).

\subsection{The Various Input Cards}

The following are the input cards required by the program:

Card \#1: $\quad$ Option card

Card \#2: Title card 


\section{Card \#3: $\quad$ Control data card}

Card \#4: Inlet strips control

Card \#5: Vorticity coefficient card (optional)

Card \#6: $\quad$ On-body coordinates card

Card \#7: $\quad$ off-body point card (optional)

Card \#8: Viewing angle card

Card \#9: Viewing angle input data

Card \#10: Total cross-section point input

Card \#11: Cross-section point data card

Card \#12: Incompressible combination card

Card \#13: Compressible combination Input card \#1

Card \#14: Compressible combination Input card \#2

Card \#15: Contour plot card (optional)

Card \#16: $\quad$ Streamline tracing input card (optional)

Obviously either Card 12 or Cards 13 and 14 are used. Cards from 10 on are unnecessary for Mode 1 , and Cards 2 through 9 are unnecessary for Mode 2. However, Cards 10 and 11 and either 12 or 13 and 14 are necessary for every Mode 2 run.

\subsection{Specific Input Card Formats}

Card \#1 - Option Card (Generaliy a nonzero integer calls for the option) Format (13I5)

Card

Columns Variables

\begin{tabular}{|c|c|c|c|}
\hline $1-5$ & IFUND & $\begin{array}{l}=0 \\
\neq 0\end{array}$ & $\begin{array}{l}\text { means do not calculate fundamental solutions. } \\
\text { means do calculate fundamental solutions. The first } \\
\text { is used only for Mode } 2 \text { execution }\end{array}$ \\
\hline $6-10$ & ICR $\emptyset \mathrm{S}$ & $\begin{array}{l}=0 \\
\neq 0\end{array}$ & $\begin{array}{l}\text { means no cross sections are input. } \\
\text { means cross sections are input }\end{array}$ \\
\hline $11-15$ & ICMPRS & $=\mathrm{N}$ & $\begin{array}{l}\text { where } \mathrm{N} \text { is the number of compressible combinations } \\
\text { to be run }\end{array}$ \\
\hline $16-20$ & ICØМB & $=M$ & $\begin{array}{l}\text { where } M \text { is the number of incompressible } \\
\text { combinations to be run. }\end{array}$ \\
\hline & & Note & $\begin{array}{l}\text { e: Either ICMPRS }=0 \text { or ICQMB }=0 \\
\text { For Mode } 1 \text {, both are } 0 .\end{array}$ \\
\hline
\end{tabular}


Card

Columns Variables

\begin{tabular}{|c|c|c|}
\hline $27-25$ & NCS & $\begin{array}{l}=\text { the number of the cross section to be used as the } \\
\text { control station }\end{array}$ \\
\hline $26-30$ & IPRINT & $\begin{array}{l}=0 \text { will print the combination program output } \\
=1 \text { will suppress combination and cross-section output } \\
=4 \text { will print cross-section geometry as well as } \\
\text { combination output }\end{array}$ \\
\hline $31-35$ & ISYMPR & $\begin{array}{l}\text { means print solution only on input half of the inlet } \\
\text { means print solution also on the reflected half of } \\
\text { the inlet (used with cases having yaw) }\end{array}$ \\
\hline $36-40$ & INUNIT & $\begin{array}{l}\text { Unit that will read the input data }(=5 \text {, if input is from } \\
\text { cards) }\end{array}$ \\
\hline $41-45$ & INSAVE & $\begin{array}{l}=0 \text { means fundamental solutions are not saved } \\
\neq 0 \text { means save fundamental solutions and all other data } \\
\text { necessary to restart with Mode } 2\end{array}$ \\
\hline $46-50$ & NSL & $\begin{array}{l}=\text { number of streamlines to be used in the streamline } \\
\text { tracing option }\end{array}$ \\
\hline $51-55$ & IPERS & $\begin{array}{l}=0 \text { means use orthographic projection to plot streamlines } \\
\neq 0 \text { means use perspective projection }\end{array}$ \\
\hline $56-60$ & ISØPLT & $\begin{array}{l}\text { means no cross-section plots } \\
\text { means plot contours of constant pressure, etc. at } \\
\text { each cross section }\end{array}$ \\
\hline $67-65$ & IGEQM & $\begin{array}{l}=0 \text { means use input points unaltered } \\
\neq 0 \text { means use geometry package to repanel }\end{array}$ \\
\hline
\end{tabular}

Card \#2 - TITLE card (Required if IFUND $\neq 0$ on card \#1)

Format (18A4)

Card

Column Variables

\begin{tabular}{|c|c|c|}
\hline $1-68$ & $\begin{array}{l}\text { TITLE(1) } \\
\text { to } \\
\text { TITLE(17) }\end{array}$ & $\begin{array}{l}\text { An alphanumeric array which describes the case data to } \\
\text { be run. The array should contain no more than } 68 \\
\text { characters. }\end{array}$ \\
\hline-72 & $\operatorname{TITLE}(18)$ & $\begin{array}{l}=\text { 'WTWQ' means two points per card format is used fo } \\
\text { inputting body coordinates } \\
=\text { blanks means one point per card format is used }\end{array}$ \\
\hline
\end{tabular}


Card \#3 - Control Data Card (Required if IFUND $\neq 0$ on card \#1)

Format (A4, 3X, 2I3, 12X, 5I3, 6X, 4L1, 2F70.0)

Card

Columns Variables

1-4 CASE Case ID number

8-10 NøFF $\quad=0$ means no off-body point is input

$\neq 0$ means there is off-body point input

11-13 LIST $\quad=0$ program continues after body panels are formed

$\neq 0$ program terminates after body panels are formed (i.e. program ends at the completion of INPUT subroutine)

26-28 NSYM

$=0$ symmetry is not used, entire body is input

$=1$ one plane of symmetry is used. Oniy half the body, for which $y \geq 0$, is input.

29-31 IB Input vorticity coefficient option

$=0$ no $B$-values input. Program sets a11 B's to 1.0

$=1$ uses input $B^{\prime} s$.

32-34 NøRM

$=1$ lengths will be normalized by an input reference length

$=2$ velocities will be normalized by input reference velocity

$=3$ both lengths and velocities will be normalized

35-37 METIN $\quad=1$ means the input is in metric units

$=0$ means the input is in English units

38-40 METØUT $=1$ means metric output is desired

$=0$ means the output is in English units

47 TYPEA $=T$ if there is no centerbody

$=F$ if there is a centerbody

48 TYPEB $=T$ if the front of the centerbody is aligned with the inlet highlight

$=\mathrm{F}$ otherwise

$49 \quad$ TYPEC

$=T$ if the centerbody is completely $i_{i}$. ide the inlet downstream of the highlight

$=F$ otherwise

$50 \quad$ TYPED

$=T$ if the centerbody protrudes outside the inlet upstream of the highlight

$=F$ otherwise

(Note: Exactly one of the previous four flags must be set to $T$, the other three to F.) 
Card

Columns Variables

$\begin{array}{lll}51-60 & \text { SF } & \text { scale factor } \\ 61-70 & \text { RFLENG } & \begin{array}{l}\text { reference length for normalizing the length data. } \\ \text { Input only if } N \emptyset R M=1 \text { or } N \emptyset R M=3\end{array}\end{array}$

Card \#4 - Inlet Strips Control Card (Required if IFUND $\neq 0$ on card \#1)

Format (3I4)

Card

Columns Variables

1-4 NSøRCE number of on-body source panels in each strip of the inlet (lifting body) section

5-8 NWAKE number of wake panels in each strip of the inlet. Usually one

9-12 NSTRIP number of strips of panels on the inlet

Card \#5 - Vorticity Coefficient Input Card (This card is input only if IB=1 is input on card \#3 and IFUND $\neq 0$ on card \#1.)

Format (6F12.6)

Card

Columns Variables

$1-12$
$13-24$
$25-36$
$37-48$
$49-60$
$61-72$

values of vorticity coefficient -6 values per card. Repeat the same format on next card if more than $6 \mathrm{~B}^{\prime} \mathrm{s}$ are input.

(Note: The total number of B's input must equal the total number of strips that define the inlet.)

Card \#6 - On-Body Coordinates Input Card (Required if IFUND $\neq 0$ on card \#1.)

Format $(3 E 10.0,211)$ - For one point per card

Format $(2(3 \mathrm{E} 10.0,2 \mathrm{II}))$ - For two points per card

The maximum number of on-body panels on inlet and centerbody together is 1000. The maximum number of input points may slightly exceed this.

Card

Columns Variables

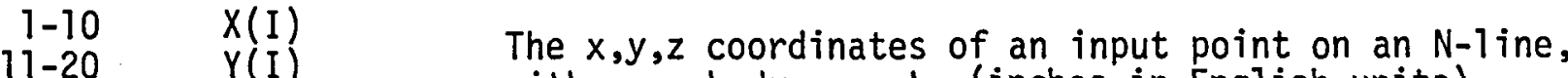
21-30 Z(I) either on-body or wake (inches in English units) 
Card

Columns Variables

31

ISTAT

Status flag

$=2$ new section (lst point of inlet and of centerbody)

$=1$ new $N-1$ ine

$=0$ same $\mathrm{N}-1$ ine

$=3$ end of all input data

(Note: The status flags are somewhat different if the geometry package is used to repanel the body, Section 13.0.)

$32 \quad$ LABEL $\quad 1$ lifting body - used for the inlet

$=0$ nonl ifting body - used for the centerbody

(Note: For two points per card repeat the above sequence from Card Columns 33 - Card Columns 64.)

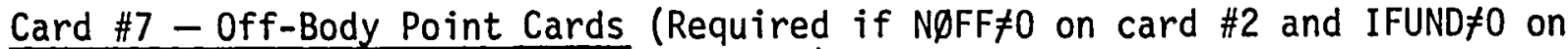
card \#1)

Format $(2(3 E 10.0$, II $))$

Card

Columns Variables

$1-10 \quad X \emptyset F F(I)$

$11-20 \quad Y g F F(I)$

$21-30$

$\operatorname{Z\emptyset FF}(I)$

$x, y, z$ coordinates of an input off-body point

31

ISTAT

Status flag

$=3$ indicates end of all off-body point input

(Note: Repeat the above sequence from Card Columns 32 - Card Columns 63.)

Card \#8 - Total Number of Viewing Angles Input Card (Required if IFUND $\neq 0$ )

Format (I5)

Card

Columns Variables

1-5 NVIEW number of viewing angles input

Card \#9 - Viewing Angle Input Data Card (Required if IFUND $\neq 0$ )

Format (3F6.0, I2, 15A4) One viewing angle is input per card (required even if graphics is not called for) 
Card

Columns Variables

1-6 PSI

7-12 THETA

13-18 PHI

angles the viewing direction makes with the $x, y, z$ directions, respectively (degrees) (see Section 15.1)

$19-20 \quad$ LAST

set equal to 1 if this is the last viewing angle card, otherwise, set it to 0

27-80 PLABEL 60-character array that describes the viewing angle

Card \#10 - Total Number of Cross-Sections Input Card (Required if ICRøS $\neq 0$ )

Format (I5)

Card

Columns Variables

1-5 NPLANE number of cross-section points input

Card \#11-Cross-Section Input Data Card (Required if ICRøS $\neq 0$ )

Format $(6 \mathrm{E} 10.0, \mathrm{I5})$

Card

Columns Variables

$1-10 \quad X C S P$

$11-20 \quad Y C S P$

21-30 ZCSP

$x, y, z$ coordinates of the input cross-section point (inches in English units)

$31-40 \quad$ UI

$41-50$ UJ

51-60 UK

61-65 ICSR number of pane1s in each of the strips in the crosssection plane (a maximum of ten)

Repeat this format for another cross-section point until the total number of cards \#11 equals NPLANE input in card \#10.

Card \#12 - Combination (Incompressible) Program Input Card (This card is required if IC $\emptyset \mathrm{MB} \neq 0$ on card \#?.)

Format $(5 \mathrm{~F} 10.6,215)$

Card

Columns Variables

1-10 ALFANG angle of attack $\alpha$ in degrees

11-20 YAWANG yaw angle $\beta$ in degrees 
Card

Columns Variables

\begin{tabular}{|c|c|c|c|}
\hline $27-30$ & VINF & \multicolumn{2}{|c|}{ freestream velocity $V_{\infty}$ ) } \\
\hline $37-40$ & VREF & ref & $\begin{array}{l}\text { (feet per second } \\
\text { in English units) }\end{array}$ \\
\hline $41-50$ & VAVG & ave & age velocity \\
\hline $57-55$ & ISKIPC & $\begin{array}{l}=0 \\
=1\end{array}$ & $\begin{array}{l}\text { combination program will be called } \\
\text { bypass the combination program even though IC } \ \mathrm{MB} \neq 0 \text {, } \\
\text { and go directly into the streamline tracing program }\end{array}$ \\
\hline $56-60$ & IDEL & & $\begin{array}{l}\text { use the program default delta values for cross- } \\
\text { section plot } \\
\text { input delta values to be used for cross-section plot }\end{array}$ \\
\hline
\end{tabular}

Card \#13 - Flow Passage Program Input Cards (Required only if ICMPRS $\neq 0$ on card \#1.)

(a) Format (I5)

Card

Columns Variables

1-5 NCPT number of centerline points input

(b) Format (6E10.0)

Card

Columns Variables

$\begin{array}{rll}1-10 & \text { XCPT } & x, y, z \text { coordinates of the centerline point } \\ 11-20 & \text { YCPT } & \text { (inches in Fnnlish units) } \\ 21-30 & \text { ZCPT } & \\ 37-40 & \text { UI } & \text { components of the unit normal vector of the } \\ 41-50 & \text { UJ } & \text { centerline point } \\ 51-60 & \text { UK } & \end{array}$

Repeat card (b) as many times as specified by NCPT in card (a).

The following set of cards is also needed if the inlet is TYPE D, i.e. the centerbody is upstream of the inlet lip.
(c) Format (I5)

Card

Columns Variables

1-5 NEGCPT number of centerline points upstream (outside) of the inlet lip 
(d) Format (6E10.0)

Card

Columns Variables

$1-10 \quad X N E G$

$17-20 \quad$ YNEG

21-30 ZNEG

$x, y, z$ coordinates of an upstream centerline point

$\begin{array}{lll}37-40 & V I & \text { components of the unit vector of an upstream centeri ine } \\ 47-50 & \text { VJ } & \text { point } \\ 57-60 & \text { VK } & \end{array}$

Repeat card (d) as many times as specified by NEGCPT in card (c).

Card \#14a - Combination (Compressible) Program Input Card (This card is required if ICMPRS $\neq 0$ on card \#1. The format and input variables are the same as in card \#12.)

Format $(5 \mathrm{~F} 10.0,2 \mathrm{I} 5)$

Card

Columns Variables

$\begin{array}{lll}1-10 & \text { ALFANG } & \text { angle of attack } \alpha \text { in degrees } \\ 11-20 & \text { YAWANG } & \text { yaw angle } \beta \text { in degrees } \\ 21-30 & \text { VINF } & \text { freestream velocity } V_{\infty} \\ 31-40 & \text { VREF } & \text { reference velocity } V_{\text {ref }} \\ 41-50 & \text { VAVG } & \text { average velocity } V_{C} \\ 51-55 & \text { ISKIPC } & \text { same meaning as in card } \# 12 \\ 56-60 & \text { IDEL } & \end{array}$

(feet per second

in English units)

Card \#14b - Second Input Card for the Compressible Combination Program

Format (7F10.0)

Card

Columns Variables

$\left.\begin{array}{rll}1-10 & \text { RMINF } & \text { Mach number } M_{\infty} \\ 11-20 & \text { RMAVG } & \text { average Mach number } \bar{M} \\ 21-30 & \text { PTøTAL } & \text { total pressure } P_{t} \\ 31-40 & \text { PSTATC } & \text { freestream static pressure } P_{s}\end{array}\right\}$ see Section 10.0


Card

Columns Variables

$\left.\begin{array}{llll}41-50 & \text { TEMPT } & \text { total temperature } T_{t} \\ 51-60 & \text { TEMPS } & \text { freestream static temperature } T_{s} & \begin{array}{l}\text { (degrees Rankine } \\ \text { in English } \\ \text { units) }\end{array} \\ 61-70 & \text { FRATE } & \text { inlet mass flow rate } \dot{w} & 1 \mathrm{~b} \text { mass } / \mathrm{sec}\end{array}\right\} \begin{aligned} & \text { See } \\ & \text { Section } \\ & 10.0\end{aligned}$

Card \#15 - Increment Values for Contour Plots (1 card for each input cross-section point.) (Required if and only if IDEL=1)

Format (4F10.0)

Card

Columns Variables

\begin{tabular}{|c|c|c|}
\hline $1-10$ & DELCP & isobar increment (default value $=0.1$ ) \\
\hline $11-20$ & DELTHX & $\begin{array}{l}\text { flow angle in the } \xi \text {-direction contour plot increment } \\
\text { (default value }=1^{\delta} \text { ) }\end{array}$ \\
\hline $27-30$ & DELTHY & $\begin{array}{l}\text { flow angle in the } 0^{n-d i r e c t i o n ~ c o n t o u r ~ p l o t ~ i n c r e m e n ~} \\
\text { (default value }=1^{0} \text { ) }\end{array}$ \\
\hline $31-40$ & DELMCH & $\begin{array}{l}\text { Mach number increment (omit this for incompressible } \\
\text { combination) (default value }=0.1 \text { ) }\end{array}$ \\
\hline
\end{tabular}

Card \#16 - Streaml ine Tracing Input Data Card(s) (One card per streamline)

Format $(4 I 5, F 10.0,2 I 5,3 I 1,2 X, 3 I 1)$

Card

Columns Variables

\begin{tabular}{|c|c|c|}
\hline $1-5$ & ICFLAG & centerbody or inlet flag: $1 \rightarrow$ centerbody; $2 \rightarrow$ inlet* \\
\hline $6-10$ & IPIESL & strip number on the centerbody (or inlet) \\
\hline $17-15$ & IELNø & the panel number of this strip** \\
\hline $16-20$ & IDIREC & $\begin{array}{l}\text { the direction of the streami ine march: }+7 \rightarrow \text { in local } \\
\text { flow direction; }-1 \rightarrow \text { opposite to local flow direction }\end{array}$ \\
\hline $21-30$ & XCUTפF & $\begin{array}{l}\text { maximum } x \text {-value for streamline calculation (cutoff } \\
\text { condition) }\end{array}$ \\
\hline $31-35$ & NPMAX & $\begin{array}{l}\text { maximum number of streamline points to be allowed for } \\
\text { this streamline (cutoff condition) }\end{array}$ \\
\hline $\begin{array}{r}* \text { cen } \\
\text { cal } \\
* * \operatorname{ct}\end{array}$ & 1.8 & it be input before the inlet if streamlines are to be \\
\hline
\end{tabular}


Card

Columns Variables

36-40 IPRINT print flag for streamline tracing calculations:

$0=$ minimum print. (This is the normal option for a production case)

$2=$ maximum print (for batch or TSO debug)

$3=$ medium print (mostiy for TSO debug)

41

42

43

$44-45$

46

47

48
IAVSX

IMVSS

IPVSS

IAVSS

(blank)

IMVSX

IPVSX
Flag to generate a plot of Mach No. vs normalized distance along this streamline.

Flag to generate a plot of $P_{s} / P_{t}$ vs normalized distance along the streamline.

Flag to generate a plot of flow inclination angles (rel. to $x$-axis) vs normalized distance along this streamline.

Flag to generate a plot of Mach No. vs $x$ for this streamline.

Flag to generate a plot of $P_{s} / P_{t}$ vs $x$ for this streamline

Flag to generate a plot of flow inclination angles (rel. to $x$-axis) vs $x$ for this streamline.

Card no. 16 should be repeated NSL times. 


\subsection{INPUT TO THE GEOMETRY PACKAGE}

Note: If it is desired to use the geometry package (references 6 and 7) to repanel the body, then IGEQM $\neq 0$ is specified on card \#1. The following instructions pertain to the input cards for the geometry package. The geometry package has been greatly simplified for use in the inlet program, but it is still more general than is needed. For example, many of the spacing options are superfluous. The inlet and centerbody are referred to as body 1 and body 2. Either may be input first*. They should be inserted behind card \#5 and card group \#6 is not needed if this option is chosen.

\begin{tabular}{|c|c|c|c|c|c|}
\hline $\begin{array}{l}\text { Card } \\
\text { Type }\end{array}$ & $\begin{array}{c}\text { Required } \\
\text { or } \\
\text { Optional }\end{array}$ & $\begin{array}{l}\text { Card } \\
\text { Columns }\end{array}$ & Format & Variable & Description \\
\hline 1 & Required & $1-4$ & I4 & NSEC & Total number of sections \\
\hline \multirow[t]{5}{*}{2} & \multirow[t]{5}{*}{ Required } & $1-4$ & I4 & $\mathrm{NB}(\mathrm{I})$ & $\begin{array}{l}\text { Specified number of on-body } \\
\text { points per } N-1 \text { ine on body I }\end{array}$ \\
\hline & & $5-8$ & I4 & NW(I) & $\begin{array}{l}\text { Specified number of wake points } \\
\text { per } N \text {-line on body I }\end{array}$ \\
\hline & & $9-12$ & I4 & NS (I) & $\begin{array}{l}\text { Specified number of } \mathrm{N}-\mathrm{l} \text { ines on } \\
\text { body I }\end{array}$ \\
\hline & & $13-16$ & I4 & $\operatorname{NALGB}(\mathrm{I})$ & 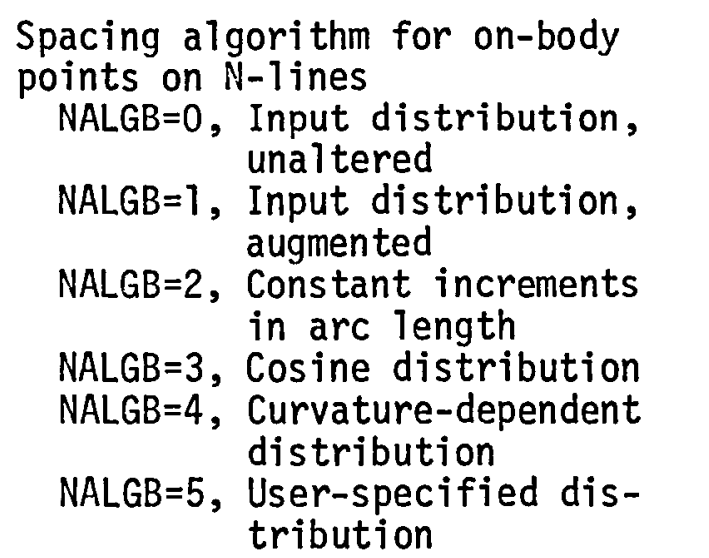 \\
\hline & & $17-20$ & 14 & NALGW(I) & $\begin{array}{l}\text { Spacing algorithm for wake points } \\
\text { on } N-1 \text { ines. (Values have same } \\
\text { significance as values of NALGB, } \\
\text { except that NALGW } 3 \text { and NALGW }=4 \\
\text { should not be used.) Normally } \\
\text { only one wake point is used. }\end{array}$ \\
\hline
\end{tabular}

*However, if streamlines are to be calculated, the nonlifting body must be input first. 


\begin{tabular}{|c|c|c|c|c|c|}
\hline $\begin{array}{l}\text { Card } \\
\text { Type }\end{array}$ & $\begin{array}{l}\text { Required } \\
\text { or } \\
\text { Optional }\end{array}$ & $\begin{array}{l}\text { Card } \\
\text { Columns }\end{array}$ & Format & Variable & Description \\
\hline \multirow[t]{5}{*}{$\begin{array}{c}2 \\
(\operatorname{con} t)\end{array}$} & \multirow[t]{5}{*}{ Required } & $21-24$ & 14 & NALGS(I) & $\begin{array}{l}\text { Spacing algorithm for } N \text {-lines } \\
\text { NALGS }=0, \text { Input distribution, } \\
\text { unaltered } \\
\text { NALGS }=1, \text { Input distribution, } \\
\text { NALGS }=2 \text { augmented } \\
\text { NALGS }=3 \text {, Usertant increments } \\
\text { tribution }\end{array}$ \\
\hline & & $29-32$ & I4 & NSEG (I) & $\begin{array}{l}\text { Number of segments into which } \\
\text { M-lines are broken (Default } t=1 \text { ) } \\
\text { This is to allow for corners }\end{array}$ \\
\hline & & $33-36$ & I4 & NTR(I) & $\begin{array}{l}\text { Component transformation flag. } \\
\text { (The value indicates the number } \\
\text { of transformations to be per- } \\
\text { formed.) }\end{array}$ \\
\hline & & $37-40$ & I4 & IPI (I) & $\begin{array}{l}\text { Punch flag for transformed input } \\
\text { coordinates } \\
\text { IP } 1=0 \text {, No punch } \\
\text { IPI } \neq 0 \text {, Punch }\end{array}$ \\
\hline & & $41-44$ & I4 & IP2 (I) & $\begin{array}{l}\text { Punch flag for coordinates after } \\
\text { repaneling bodies } \\
\text { IP2 }=0 \text {, No punch } \\
\text { IP2 } \neq 0 \text {, Punch }\end{array}$ \\
\hline 4 & Optional & $\begin{array}{r}1-10 \\
11-20 \\
21-30 \\
31-40 \\
41-50 \\
51-60 \\
61-70 \\
71-80\end{array}$ & $8 \mathrm{~F} 10.0$ & $\begin{array}{l}\operatorname{SSB}(I, 1) \\
\operatorname{SSB}(I, 2) \\
: \\
:\end{array}$ & $\begin{array}{l}\text { Specified arc lengths of on-body } \\
\text { points on } N \text {-lines on body I } \\
0.0 \leq \mathrm{SSB} \leq 1.0 \\
8 \text { points per card, } N B(\mathrm{I}) \text { total }\end{array}$ \\
\hline
\end{tabular}




\begin{tabular}{|c|c|c|c|c|c|}
\hline $\begin{array}{l}\text { Card } \\
\text { Type }\end{array}$ & $\begin{array}{c}\text { Required } \\
\text { or } \\
\text { Optional }\end{array}$ & $\begin{array}{l}\text { Card } \\
\text { Columns }\end{array}$ & Format & Variable & Description \\
\hline 5 & Optional & $\begin{array}{l}1-10 \\
11-20 \\
21-30 \\
31-40 \\
41-50 \\
51-60 \\
61-70 \\
71-80\end{array}$ & $8 \mathrm{~F} 10.0$ & $\begin{array}{l}\operatorname{SSW}(I, 1) \\
\operatorname{SSW}(I, 2) \\
\quad \cdot \\
\quad \cdot\end{array}$ & $\begin{array}{l}\text { Specified arc lengths of wake } \\
\text { points on } N-1 \text { ines on body I } \\
0.0 \leq S S W \leq 1.0 \\
8 \text { points per card, NW(I) total } \\
\text { This card is required if } \\
\text { NALGW(I) }=5\end{array}$ \\
\hline 6 & Optional & $\begin{array}{l}1-10 \\
11-20 \\
21-30 \\
31-40 \\
41-50 \\
51-60 \\
61-70 \\
71-80\end{array}$ & $8 F 10.0$ & $\begin{array}{l}\operatorname{SSS}(I, 1) \\
\operatorname{SSS}(I, 2) \\
\quad \cdot \\
\dot{.}\end{array}$ & $\begin{array}{l}\text { Specified distribution of } \mathrm{N} \text {-lines } \\
\text { on body I } \\
0.0 \leq \text { SSS } \leq 1.0 \\
8 \text { points per card, NS(I) total }\end{array}$ \\
\hline
\end{tabular}

\begin{tabular}{|c|c|c|c|c|c|}
\hline 7 & Optional & $\begin{array}{l}1-4 \\
5-8 \\
9-12 \\
13-16 \\
17-20\end{array}$ & 514 & $\begin{array}{l}\operatorname{IEND}(I, 1) \\
\operatorname{IEND}(I, 2) \\
\quad \cdot \\
\quad \cdot\end{array}$ & $\begin{array}{l}\text { Point numbers of the ends of the } \\
\text { segments on M- } 1 \text { ines on body I } \\
\text { NSEG(I) total (max. }=5 \\
\text { This card is required if } \\
\text { NSEG }(I)>1\end{array}$ \\
\hline \multirow[t]{2}{*}{8} & Optional & $1-4$ & I 4 & $\operatorname{ITR} 2(\mathrm{I}, \mathrm{J})$ & $\begin{array}{l}\text { Type of Jth transformation to be } \\
\text { applied to body I } \\
\text { ITR2 }=1 \text {, Scaling } \\
\text { ITR2 }=2 \text {, Translation } \\
\text { ITR3 }=3 \text {, Rotation }\end{array}$ \\
\hline & & $11-20$ & F10.0 & $\operatorname{TR}(I, J, I)$ & $\begin{array}{l}\text { First transformation parameter: } \\
x \text { multiplication factor if ITR2 }=1 \\
x \text { translation } \\
\text { angle of rotation If ITR2 }=2 \\
\text { (positive clockwise, looking down } \\
\text { axis cf rotation away from origin) }\end{array}$ \\
\hline
\end{tabular}




\begin{tabular}{|c|c|c|c|c|c|}
\hline $\begin{array}{l}\text { Card } \\
\text { Type }\end{array}$ & $\begin{array}{l}\text { Required } \\
\text { or } \\
\text { Optional }\end{array}$ & $\begin{array}{l}\text { Card } \\
\text { Columns }\end{array}$ & Format & Variable & Description \\
\hline \multirow[t]{4}{*}{$\begin{array}{c}8 \\
\text { (cont) }\end{array}$} & \multirow[t]{4}{*}{ Optional } & \multirow[t]{2}{*}{$21-30$} & F10.0 & $\operatorname{TR}(I, J, 2)$ & 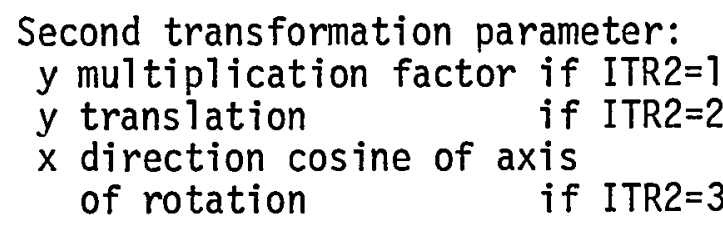 \\
\hline & & & F10.0 & $\operatorname{TR}(I, J, 3)$ & $\begin{array}{l}\text { Third transformation parameter: } \\
z \text { multiplication factor if ITR } 2=1 \\
z \text { translation } \\
\begin{array}{ll}y \text { direction cosine of axis } \\
\text { of rotation } & \text { if ITR } 2=3\end{array}\end{array}$ \\
\hline & & \multirow[t]{2}{*}{$41-50$} & \multirow[t]{2}{*}{ F10.0 } & \multirow[t]{2}{*}{$\operatorname{TR}(I, J, 4)$} & $\begin{array}{l}\text { Fourth transformation parameter: } \\
\text { Dummy if ITR } 2=1 \text { or ITR } 2=2 \\
\begin{array}{l}z \text { direction cosine of axis of } \\
\text { rotation }\end{array}\end{array}$ \\
\hline & & & & & $\begin{array}{l}\text { Note: The axis of rotation is } \\
\text { assumed to pass through the } \\
\text { origin. Up to } 10 \text { transformations } \\
\text { may be performed, in any order. } \\
\text { Input this card type NTR(I) times. }\end{array}$ \\
\hline \multirow[t]{3}{*}{9} & \multirow[t]{3}{*}{ Required } & $\begin{array}{l}1-10 \\
11-20 \\
21-30\end{array}$ & $\begin{array}{l}\text { F10.0 } \\
\text { F10.0 } \\
\text { F10.0 }\end{array}$ & $\begin{array}{l}X \\
Y \\
Z\end{array}$ & $\begin{array}{l}x, y, z \text { coordinates of a point (all } \\
\text { points input } N \text {-line by } N \text {-line, } \\
\text { body by body). }\end{array}$ \\
\hline & & 31 & II & STATUS & $\begin{aligned} & \text { STATUS }=0 \text { same } N-l \text { ine } \\
& \text { STATUS }=1 \text { new } N-7 \text { ine } \\
& \text { STATUS }=2 \text { new body } \\
& \text { STATUS }=3 \text { last point input (excep- } \\
& \text { tion is } \# 5 \text { below) } \\
& \text { STATUS }=4 \text { first point on wake } \\
& \text { STATUS }=5 \text { first point on wake and } \\
& \\
& \text { also last point input }\end{aligned}$ \\
\hline & & 32 & $I 1$ & LABEL & $\begin{array}{l}\text { LABEL }=0 \text { nonlifting body } \\
\text { (center body) } \\
\text { LABEL-1 lifting body (inlet) }\end{array}$ \\
\hline
\end{tabular}




\begin{tabular}{|c|c|c|c|}
\hline $\begin{array}{l}33-42 \\
43-52 \\
53-62\end{array}$ & $\begin{array}{l}\text { F10.0 } \\
\text { F10.0 } \\
\text { F10.0 }\end{array}$ & $\begin{array}{l}x \\
y \\
z\end{array}$ & $\begin{array}{l}x, y, z \text { coordinates of the next } \\
\text { point input }\end{array}$ \\
\hline \multirow[t]{2}{*}{$\begin{array}{l}63 \\
64\end{array}$} & $\begin{array}{l}\text { I1 } \\
\text { I1 }\end{array}$ & $\begin{array}{l}\text { STATUS } \\
\text { LABEL }\end{array}$ & Same meaning as above \\
\hline & & & $\begin{array}{l}\text { Repeat cards to input more } \\
\text { points. If TITLE(18)= } 6 \text { TW } \emptyset \text { on } \\
\text { card no. } 1 \text {, input } 2 \text { points per } \\
\text { card. If TITLE(18) is not equal } \\
\text { to "bTW ", it implies } 1 \text { point } \\
\text { per card. }\end{array}$ \\
\hline
\end{tabular}




\subsection{TABULAR OUTPUT}

14.1 Basic Body Geometry

N

M

$X, Y, Z$ Coordinates of the four input points used to form the pane1 $N X, N Y, N Z x, y, z$ components of the panel normal vector

XO, YO, ZO Coordinates of the control point

D

A

I

STATVX

STATVY

STATVZ

UVXI

UVY?

UVZ1

UVX2

UVY2

UVZ2

UVX3

UVY3

UVZ3

Strip number

Panel number

For lifting (inlet) panels, it is an average panel length

For nonlifting (centerbody) panels, it is the projection

distance required to make the input points coplaner

Maximum diagonal of the panel

Area of the panel

14.2 Fundamental Solution Output

Panel number. Here all panels are listed in a single array containing all strips

$x, y, z$ components of the velocity at a control point for the static solution

$x, y, z$ components of the velocity at a control point for the $(1,0,0)$ flow, in which the uniform freestream is parallel to the $x$-axis

$x, y, z$ components of the velocity at a control point for the $(0,0,1)$ flow, in which the uniform freestream is parallel to the $z$-axis

$x, y, z$ components of the velocity at a control point for the $(0,1,0)$ flow, in which the uniform freestream is parallel to the $y$-axis 


\subsection{Cross-Section Control Data}

C.S.Nの. Cross-section number

XCSP

YCSP

ZCSP

Input coordinates of the cross-section point

UI

UJ

UK

Input components of the cross-section normal vector

RADIAL

PANELS

Number of panels to be formed on each radial strip in the cross-section plane

\subsection{Cross-Section Panel Geometry}

J

Strip number

I

Panel number

$X, Y, Z$ Coordinates of the corner points of a panel

$X C$

$Y C$

ZC

$X I$

ETA

$x, y, z$ coordinates of the panel control point where flow quantities are to be calculated

AREA

Coordinates of the control point in the cross-section coordinate system

Panel area 


\subsection{Cross-Section Flux}

FLoW Indicates what type of flow

$\mathrm{FL} \emptyset \mathrm{W}=1 \quad$ static solution

$F L Q W=2 \quad(1,0,0)$ flow, uniform freestream parallel to the $x$-axis

$\mathrm{FL} \varphi \mathrm{W}=3 \quad(0,0,1)$ flow, uniform freestream parallel to the z-axis

$F L \emptyset W=4 \quad(0,1,0)$ flow, uniform freestream parallel to the $y$-axis

FLUXX Components of the vector volume flux at the cross-section,

FLUXY equations (28) and (29) plus subsequent discussion

FLUXZ

TøTAL FLUX Normal volume flux through the cross-section plane, equation (29)

14.6 Incompressible Combination Output

N

M

$X C$

$Y C$

ZC

NX

NY

NZ

COMBVX

COMBVY

COMBVZ

VN

V

$\mathrm{CP}$

DCX

DCY

DCZ
Strip number

Panel number

Coordinates of control point

Components of normal vector

Components of velocity

Normal velocity

Total velocity magnitude

Pressure coefficient

Components of directional cosines of velocity

The above explanations applied to all elements (i.e. on-body, off-body \& cross-sections). 


\subsection{Compressible Combination Output - On Body}

N Strip number*

M Panel number

$X C, Y C, Z C$ Control point coordinates

$V X, V Y, V Z$ Velocity components

VMAG

Velocity magnitude $=\sqrt{v_{x}^{2}+v_{y}^{2}+v_{z}^{2}}$

MACH Local Mach number

P/PT Static-to-total pressure ratio

VBAR Average incompressible velocity

EPSLøN $\varepsilon$, Average density ratio, equations(53) and (54)

AREA (FP) Flow passage area

*If letter $R$ is suffixed to the strip number, it denotes that the strip is on the reflected half of the body.

\subsection{Error Messages}

(1) Message: **END OF INPUT DATA. NORMAL PROGRAM TERMINATION.

Source: MAIN program

Cause: End of all data.

Action: None

(2) Message: THE MATRIX OF XXXXXX ELEMENTS EXCEED XXXXXXX.

Source: MAIN program

Cause: The input matrix is too large for the program's allowable computer storage.

Action: Change the working area size in MAIN program.

(3) Message: TOTAL NUMBER OF CENTER-BODY INTERSECTION POINTS DOES NOT EQUAL TO THE NUMBER OF NONLIFTING NLINES INPUT.

Source: Subroutine CSGEQM

Cause: $\quad$ Each cross-section plane (defined by the input cross-section point and its normal vector) should give one intersection point with each line that defines the centerbody. If the total number of intersection points does not equal the number of input nonlifting $\mathrm{N}-\mathrm{lines}$, the above message will be printed and the program continues. 
Action: Check the input cross-section point and its normal vector to see if the cross-section plane does cut through each nonlifting $\mathrm{N}$-line.

(4) Message: (a) TOTAL NUMBER OF INTERIOR POINTS DOES NOT EQUAL TO THE LIFTING NLINES INPUT.

(b) TOTAL NUMBER OF EXTERIOR POINTS DOES NOT EQUAL TO THE LIFTING NLINES INPUT.

Source: Subroutine CSGEØM

Cause: Intersection of the cross-section plane and the lifting $\mathrm{N}-\mathrm{line}$ should generate two intersecting points as illustrated below:

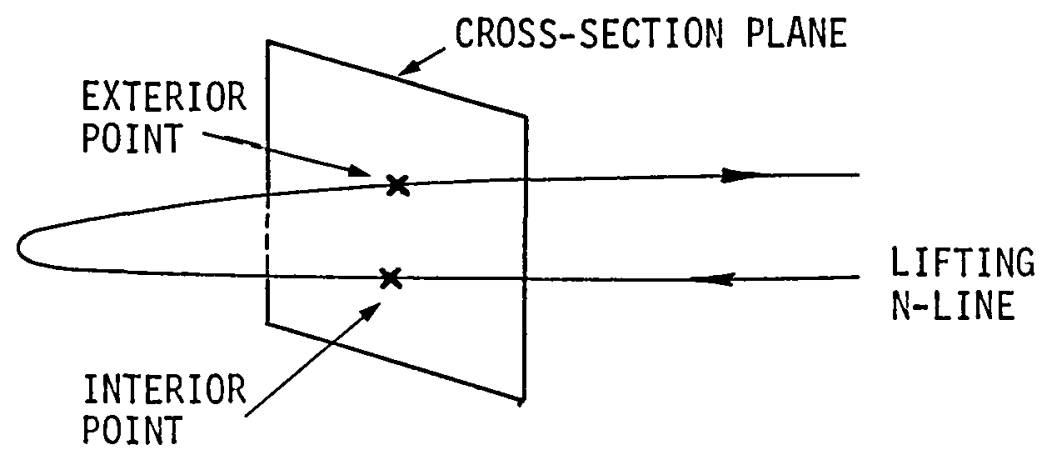

If the number of the interior point or the exterior point does not equal the number of lifting $\mathrm{N}$-lines, the above message will be printed but program continues to execute.

Action: Check the input cross-section point and normal vector to see if the cross-section plane does cut through the lifting $\mathrm{N}$-line.

(5) Message: CURRENTLY EXECUTING SECTION TYPE $=, X X X$

SECTION TYPE FROM UNIT NO. $4=, X X X$

PROGRAM STOPS

Source: Subroutine FLPASG

Cause: External unit No. 4 stores the geometrical quantities of the input panels for both the inlet and centerbody. If the body type retrieved from unit 4 does not match the body type that the program is currently using, the above message will be printed and execution stops.

Action: Check the contents of the external unit No.4 and see if it matches the case that is used. 
(6) Message: NON-LIFTING INTERSECTION POINTS NOT EQUAL TO THE NUMBER OF NLINES INPUT

Source: Subroutine FLPASG

$\left.\begin{array}{l}\text { Cause: } \\ \text { Action: }\end{array}\right\}$ See Message No. (3)

(7) Message: INTERIOR POINTS NOT EQUAL TO THE NUMBER OF NLINES INPUT.

Source: Subroutine FLPASG

Cause: $\}$ See Message No. (4)

(8) Message: EXTERIOR POINTS NOT EQUAL TO THE NUMBER OF NLINES INPUT.

Source: Subroutine FLPASG

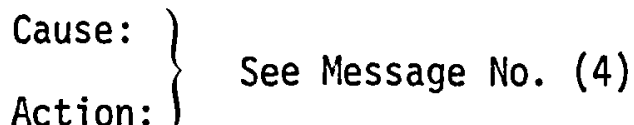

(9) Message: ALLOWABLE NUMBER OF POINTS EXCEEDED IN SUBROUTINE PANELS, EXECUTION TERMINATING.

Source: Subroutine GEINPT

Cause: Input total number of panels (for both inlet and centerbody) exceeds 1100 .

Action: Change the input geometry and rerun.

(10) Message: MISMATCH OF ELEMENTS IN A LIFTING STRIP IS DETECTED. ELEMENTS FORMED $=X X X$, ELEMENTS INPUT $=X X X$. COMPUTATION TERMINATED.

Source: Subroutine INPUT

Cause: Input number of strip and elements for the inlet is not consistent with the input lifting information card.

Action: Check the body coordinates input cards and see if the flags for new line or new section are punched correctly.

(11) Message: NPMAX $=X X X$ HAS BEEN REACHED. COMPUTATIONS TERMINATING FOR THIS STREAMLINE.

Source: Subroutine TRACE 
Cause: Generated streamline tracing exceeds the allowable dimension. Program goes to the next streamline.

Action: None

(12) Message: INPUT XX PLANE OF SYMMETRY OPTION IS NOT IN THE PROGRAM. IT IS REPLACED BY 1 PL. SYM.

Source: Subroutine VFMLFT and VFMNLF

Cause: Input number of symmetry plane is more than 1.

Action: User's action none. Program changes the input symmetry to one.

(13) Message: ERROR IN VFORM. THE ELEMENTS FORMED DO NOT CORRESPOND TO THE NO. OF BODY ELEMENTS.

Source: Subroutine VFMLFT and VFMNLF

Cause: On-body pane1 counter error

Action: Check and see if the variables appeared in the labelled commons "INFORM" and "INLIFT" have been changed.

(14) Message: LABEL ERROR IN LIFTING VFORM

Source: Subroutine VFMLFT

Cause: Data on the external unit No. 4 did not correspond to the type of body at the time of execution.

Action: Check the data on unit No. 4.

(15) Message: LABEL ERROR IN NONLIFTING VFORM.

Source: Subroutine VFMNLF

Cause: Same as in (14)

Action: Same as in (14)

(16) Message: TOTAL NUMBER OF CONTROL POINTS SHOULD BE XXXXX.

THE NUMBER OF POINTS STORED ON UNIT NSETV IS XXXXX.

EXECUTION STOPS.

Source: Subroutine CØMPR $\emptyset$, CØMPRS

Cause: The total number of control points (on-body plus off-body) in the variable NØN is not equal to the variable NPØINT stored in the external unit NSETV. (NSETV stores all of the fundamental solutions.) 
Action: Check and see if the unit NSETV did store the correct data.

(17) Message: INPUT CONTROL STATION NO. $=X X X X X$.

READ FROM UNIT NFLUX STATION NO. = XXXXX.

PROGRAM STOPS FOR CHECKING.

Source: $\quad$ Subroutine COMPRO, COMPRES

Cause: Input control station number NCS is not the same as the control station number stored in unit NFLUX.

Action: Check contents of unit NFLUX.

(18) Message: ON-BODY ELEMENT MISSED. JOB STOPS.

Source: $\quad$ Subroutine COMPRO, COMPRS

Cause: $\quad$ Total number of on-body control panels is stored in variable KONTRL. The counter KK is used for counting total number of on-body panels. When these two variables are not equal, the message will be printed.

Action: Check labelled common CONFLG to see if the variable KONTRL has been changed.

(19) Message: CROSS-SECTION PLANE NUMBER CURRENTLY USING XXXXX PLANE NO. FROM UNIT NV IS XXXX.

PLANE NO. FROM UNIT NOFSAV IS $X X X X$.

STOP 77.

Source: $\quad$ Subroutine COMPRO, COMPRS

Cause: $\quad$ The three numbers explained in the message should be the same, if they are not, it indicates either the units have different contents or the counter for the cross-section plane number IP is incorrect. Stop code 77, 78 applied to COMPRO and COMPRS, respectively.

Action: Check external units NV and NOFSAV.

(20) Message: STRIP NO. NOW USING IS XXXX.

STRIP NO. FROM UNIT NOFSAV IS XXXX.

PROGRAM HALTS.

Source: $\quad$ Subroutine COMPRO, COMPRS

Cause: Unit NOFSAV is used in retrieving the cross-section geometry data. Strip counter JI is read from NOFSAV and do-loop (2800 in COMPRO, 3800 in COMPRS) counter $J$ is the current strip counter. If these two variables ( $J 1$ and $\mathrm{J}$ ) are not equal, it indicates data read in from NOFSAV is incorrect. 
Action: Check contents of the unit NOFSAV.

(27) Message: POINT NUMBER ERROR. ON UNIT NV $N=X X X X X$.

BUT $N$ IS INCREMENTED $=X X X X X$.

STOP 59.

Source: Subroutine COMPRO, COMPRS

Cause: In do-10op (2700 in COMPRO, 3700 in COMPRS) counter JS is incremented for each control panel. Unit NV also has a counter $\mathrm{N}$ which should be the same as JS. If these two do not agree, message is printed.

Action: Check contents of unit NV.

(22) Message:

Source: Subroutine COMPRS

Cause: Iteration for the computation of $\varepsilon$ equal to 100. The 100th iterated $\varepsilon$ value is used.

Action: None

(23) Message:

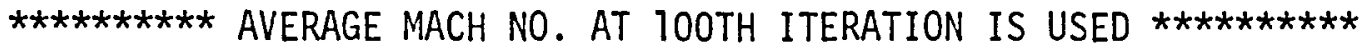

Source: Subroutine COMPRS

Cause: Iteration for the computation of the average Mach number $\bar{M}$ equal to 100 . The rooth iterated $\bar{M}$ is used.

Action: None

(24) Message: AFTER 100 ITERATIONS, COMPUTED VC IS $\pm X X X X X X X . X X X X X X X X X X X$ DELTA $V C$ IS $\pm X X X X X X . X X X X X X X X X$. PROGRAM STOPS.

Source: Subroutine COMPRS

Cause: Computed $\delta V_{c}>10^{-4}$, program stops.

Action: Reconsider the input data to the combination program (compressible) and make proper change.

(25) Message: NUMBER OF (PRESSURE MACH NO. FLOW ANGLE) ISOLINES EXCEEDS DIMENSION ALLOWED. PROGRAM STOPS.

Source: Subroutine ISOPLN.

Cause: Computed total number of isolines exceeds the dimension allowed in the program.

Action: Change the input delta values for the isoline plot and reinput. 


\subsection{EXAMPLES OF GRAPHICAL OUTPUT}

\subsection{Surface Streamlines}

The user identifies a particular body panel by inputting the number of the strip on which it lies and the number of the panel on that strip. The panel may be on either the inlet or the centerbody. The program then calculates the surface streamline that goes through the control point of that panel in either the upstream or downstream direction. (If both are desired, two inputs are required, since the program regards them as two separate streamlines.) A number of panels may be specified and streamlines calculated through each of their centroids.

To facilitate interpretation of the results, two types of graphical output have been provided. One is rather straightforward. Local values of pressure, Mach number, and flow angle are displayed as functions of arc length (and/or Cartesian $x$ ) along the streamline on conventional two-variable Cartesian plots.

The second type of graphical output is more complicated. The program plots the actual streamlines themselves against the panel representation of the inlet configuration. The angles from which the resulting configuration is viewed may be specified by the user. Their choice is quite important. Viewed from an inappropriate direction, the streamline pattern can be quite deceptive. A set of default viewing angles have been built into the program. In complicated cases more than one run may be required to determine the best angles. One complication is the fact that only the panels facing the observer are plotted, while the streamline is plotted regardless. Thus a view of an interior streaml ine viewed from the exterior is quite misleading.

The plotted view of the inlet with its streamlines may be obtained either by orthographic (paralle1) projection or by perspective projection for which a viewing distance has been built into the program. Examples of the output are presented in Figure 12, which shows streamlines on the interior surface of an inlet at angle of attack for both types of projection. The viewing angle is 10 degrees with respect to the inlet centerline, which often has been found to be an effective angle from which to view. While the viewing angle is the same 


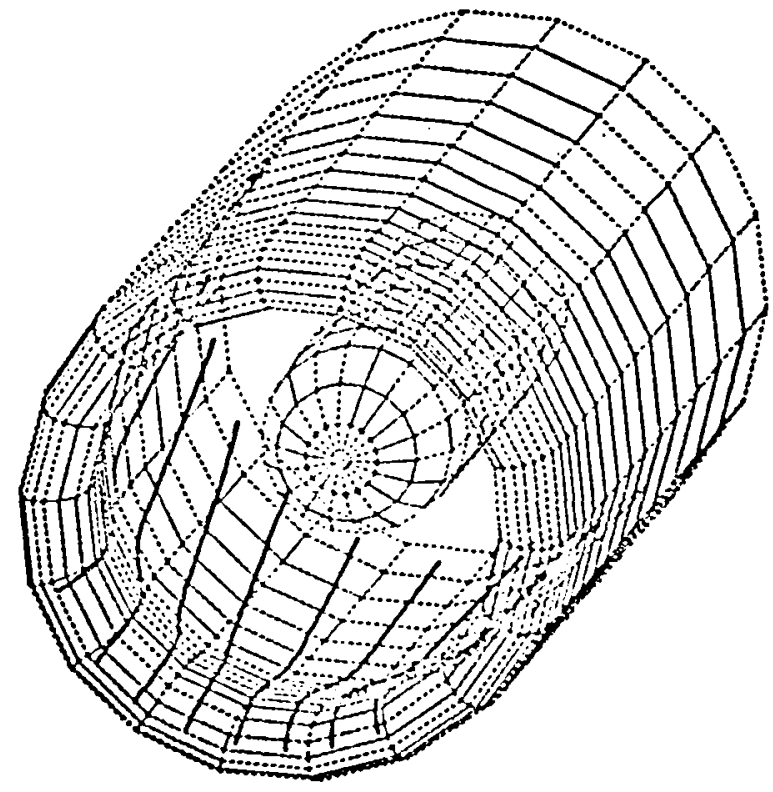

(a) Orthographic projection.

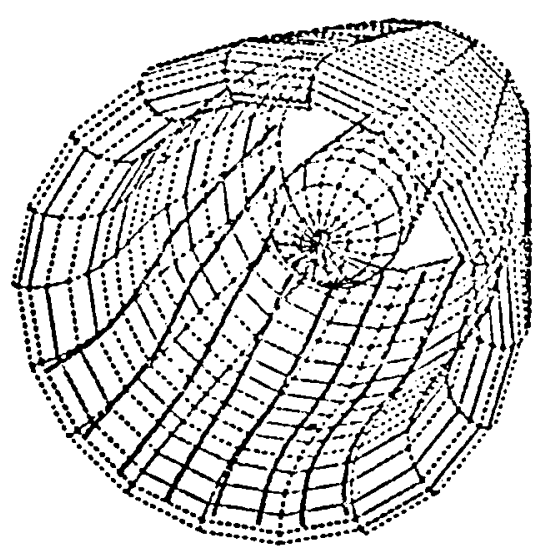

(b) Perspective projection.

Figure 12. Calculated streamlines on the interior surface of an inlet.

for both projections, it appears to be quite different. In this case the perspective view appears more informative, but examples can be found for which orthographic is to be preferred.

The viewing angles input by the user are: a yaw angle PSI, a pitch angle THETA, and a roll angle PHI. They are used both for examining the geometry before performing the flow calculation and for viewing final results as discussed in this section. Since the rotation axes pertinent to the viewing angles remain fixed in the body, it is simpler to imagine that the body and the coordinate system remain fixed while the observer is rotated by the prescribed yaw, pitch, and roll angles about the coordinate axes. In each case rotation about a particular coordinate axes implies that the value of that particular coordinate of the observer remains constant, as does his distance from the axes, and the positive sense of rotation is clockwise. Initially, the observer is assumed to be situated on the positive $x$-axis and to be looking towards the origin, which he continues to do at all times. He is first rotated about the $z$-axis by the yaw angle and thus remains in the $x y$-plane. The observer is then rotated about the $y$-axis by the pitch angle and finally about the $x$-axis by the roll angle. This last rotation is rarely used, because the observer can be brought to any desired inclination using only the yaw and pitch angles. 


\subsection{Equi-Value Contours in a Cross Section}

As described in Sections 9.0 and 14.0, plane cross sections are defined at various locations inside the inlet by means of a point and a normal vector. Control points are automatically distributed "spiderweb style" over the cross section from the input point to the inner surface of the inlet if there is no centerbody at that location or from the surface of the centerbody to the inner surface of the inlet if there is a centerbody. Coordinates are defined in the cross-section plane having the input point as origin. Tabular output of various flow quantities at the control points is provided.

The graphical output option for a cross section first plots the geometric shape of the cross section using its own coordinate system, i.e., the intersection of the cross-section plane with the centerbody (if any) and the interior surface of the inlet. It then constructs four separate plots against this geometry consisting of curves of equal value of: nondimensional pressure (pressure coefficient incompressibly and static-to-total pressure ratio compressibly), Mach number, and flow angles with respect to the cross-section normal vector in the planes defined by this vector and the cross-section coordinate axes. Increments of value to be used for these curves may be input by the user, but the same values must be used for all cross sections. Default values for the plotting increments are 0.1 for nondimensional pressure and Mach number and one degree for the two angles. As an aid to interpretation, the equi-value curve having the smallest value of the quantity in question and the curve having a value halfway between the largest and smallest values of the quantity are plotted as heavy and dotted curves, respectively. The values of the quantity corresponding to these two curves and the value increment are printed on the plot.

To illustrate this capability, the example shown in Figure 13 was selected. It is a round inlet but was panelled as a three-dimensional body. The locations of the two cross sections where flow quantities are computed are shown. The forward cross section was designated the control station where the average velocity was specified as three times freestream. The angle of attack was $40^{\circ}$. Figure 14 shows isobar plots at the two cross sections. Figure 15 shows plots of equal values of flow angle. Here the cross-section normal vector is parallel to the $x$-axis. Thus the flow angle in the $x z$-plane has the meaning of a pitch 
angle and has been so designated in Figure 15. In general no such neat designation would be available.

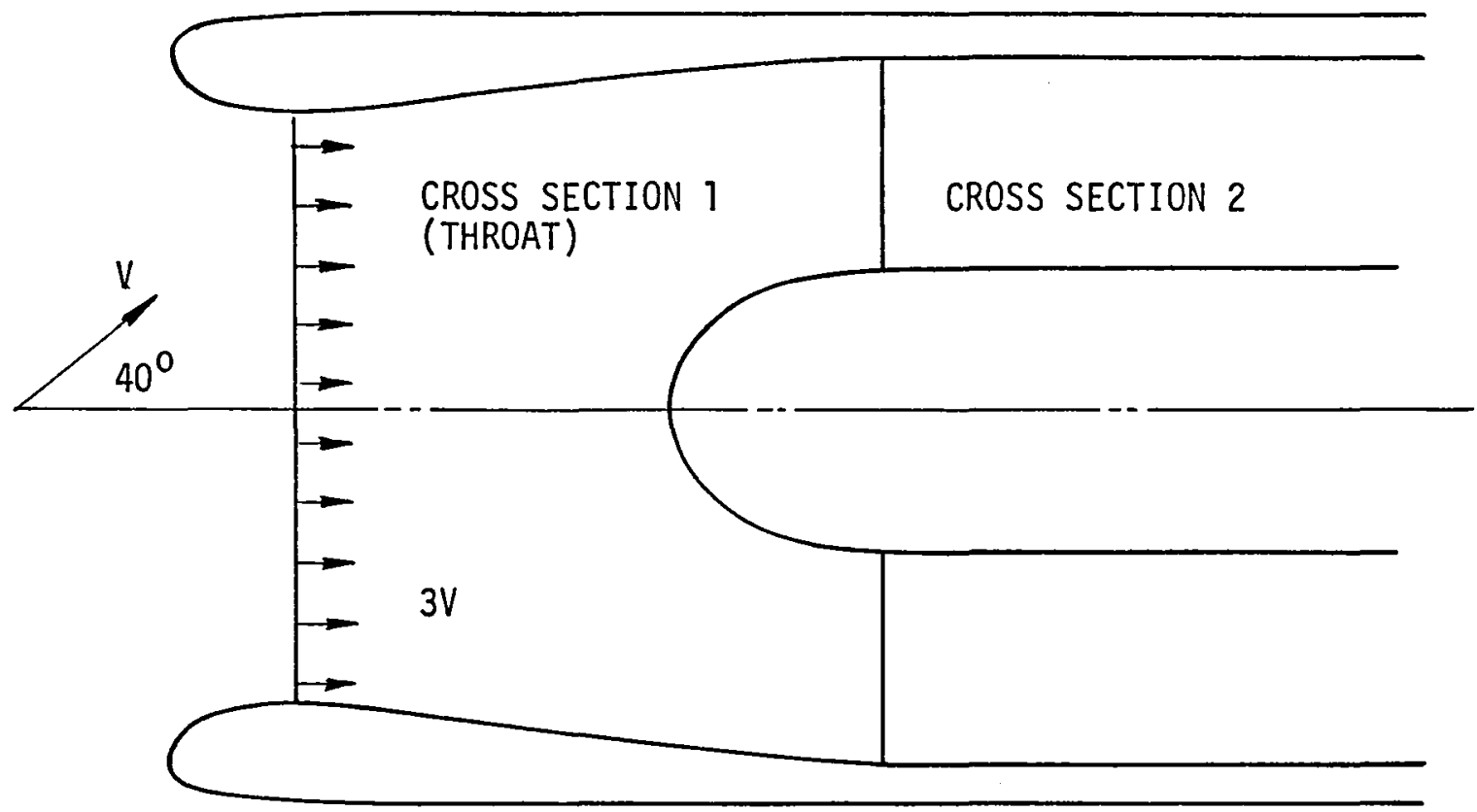

Figure 13. Cross sections selected for output and inlet operating conditions.

369 ELEMENT BFOC2I INLET CP DATA

CROSS SECTION NUMBER 1

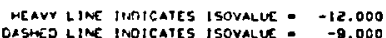

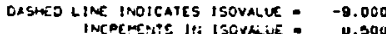

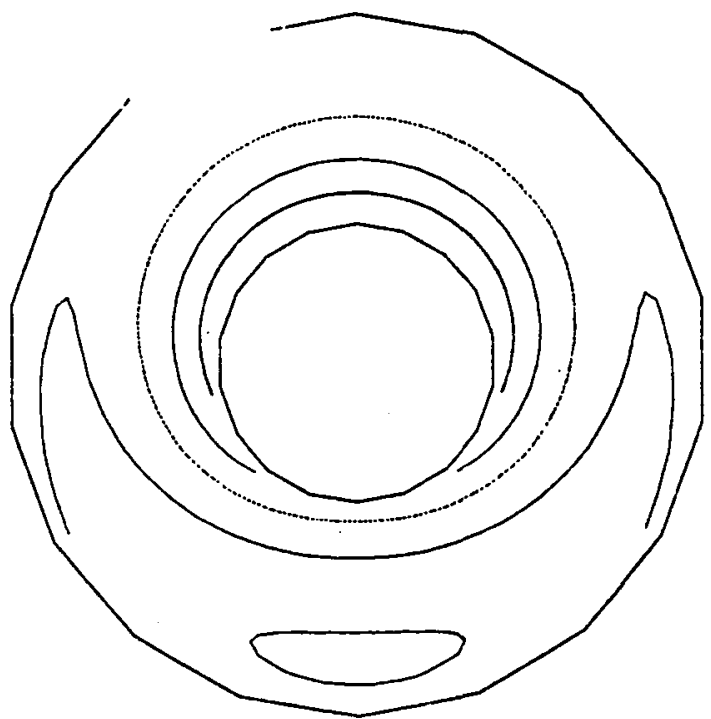

369 ELEMENT BFOC2I INLET

CP DATA

CROSS SECTION NUMBER 2

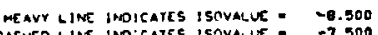
incerients in isovelue: $\quad \begin{array}{r}-7.500 \\ 0.900\end{array}$

Figure 14. Calculated curves of constant pressure coefficient. (a) Cross section 1. (b) Cross section 2 . 

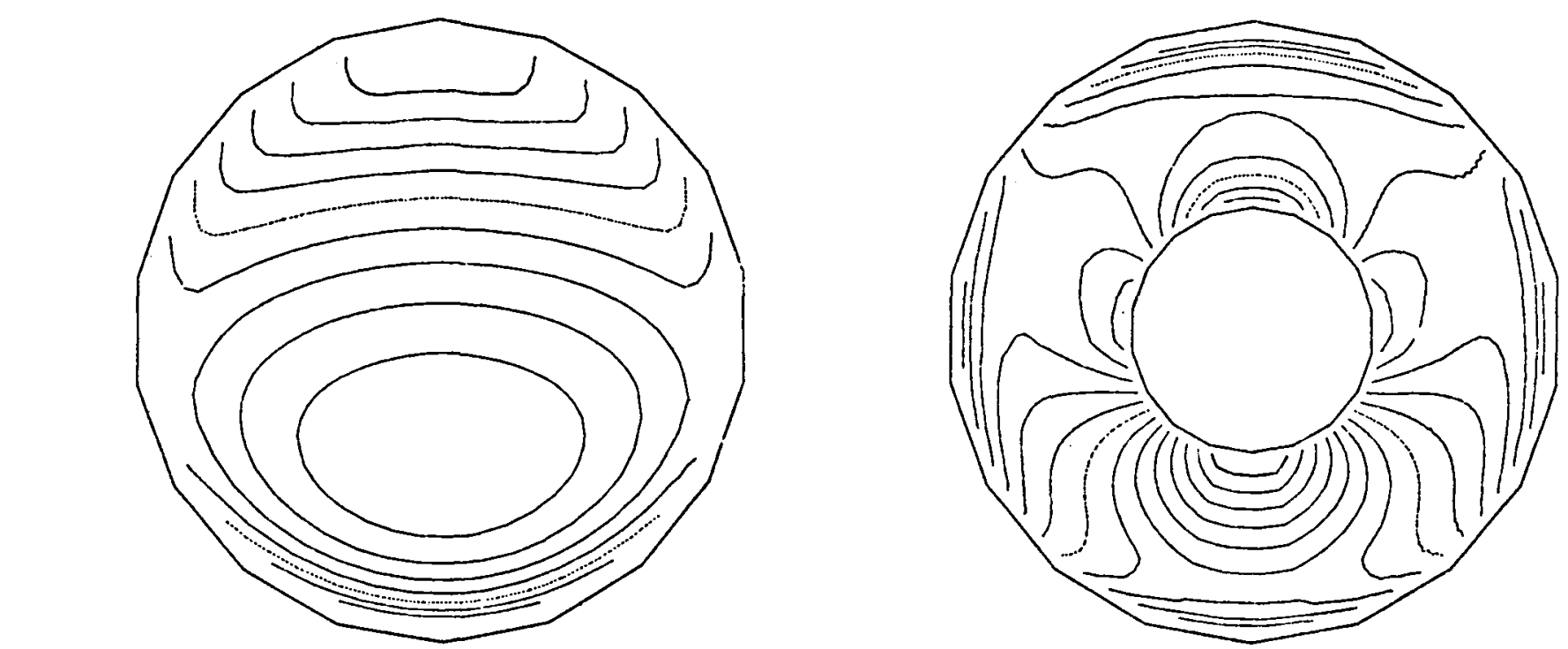

369 ELEMENT BFOC21 INLET

FLOW ANGLE ZOATA

CRCSS SECTION NUMBER I

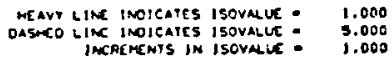

369 ELEMENT BFOC2I INLET

FLOW ANGLE ZDATA

CROSS SECTION NUMBER 2

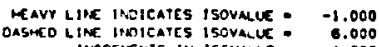

Figure 15. Calculated curves of constant flow pitch angle. (a) Cross section 1. (b) Cross section 2. 


\subsection{ACKNOWLEDGMENT}

While virtually all major computer programs are the result of group efforts, the present work has been especially dependent on the creative contributions of a number of colleagues. Very significant portions of the final program were contributed by Mr. Douglas Halsey and Mr. Douglas Friedman. The running of cases for program checkout and evaluation, together with all manual graphics, was performed by Mrs. Sue Schimke. 
A

$A_{C}$

$A_{0}$

$A_{F P}$

$A_{F P}^{*}$

$A_{i j}$

a

B

${ }_{B}(k)$

c

$\vec{F}$

j

L

M

N

$n_{x}, n_{y}, n_{z}$

$P$

Q

$r$

9

S

area of a panel

area of the intersection of a plane with the centerbody

area of the intersection of the initial centerline plane with the interior of the inlet

flow passage area

geometric area associated with exterior points of the inlet's surface

normal velocity at $i$ th control point due to unit source density on $j$ th pane1

speed of sound, $a_{*}$ is critical speed, equation (43)

combination constant for static solution, equation (5)

strength of bound vorticity on the kth strip of the inlet

subscript used with $V, \mu, \rho, q$, and $P$ to denote average conditions over a cross section

vector volume flux through a cross section

subscript denoting quantities associated with the $j$ th panel

number of lifting strips

Mach number

total number of panels on both inlet and centerbody

components of unit normal vector

pressure

control station mass flow used in combination program, equations (5), (30), and (51)

number of control points in radial direction across a cross section

dynamic pressure

as a subscript denotes freestream static conditions; as a superscript denotes quantities associated with solution to flow about inlet in static operation 
number of $\mathrm{N}$-lines on the inlet; also denotes temperature

a subscript denoting reservoir conditions

fluid velocity

$\vec{v}_{\infty}$

$\vec{v}_{i}$

freestream velocity

velocity vector at $i$ th control point. Subscript 0 denotes onset flow velocity. Subscript $k$ denotes velocities due to vorticity solution on $k$ th strip. Superscript $f$ denotes velocity of fth fundamental flow solution. Specifically $f$ can be either: s denoting static solution, (100) denoting solution at zero angle of attack and yaw, (010) denoting pure yaw, or (001) denoting $90^{\circ}$ angle of attack with no yaw.

$x, y, z$

$x_{c s}, y{ }_{c s}, z_{c s}$

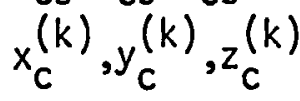

$x_{i}^{(k)}, y_{i}^{(k)}, z_{i}^{(k)}$

$\alpha$

$\beta$

$\varepsilon$

$\xi, n$

$\rho$

$\sigma$

Cartesian coordinates

coordinates of input cross-section point

coordinates of intersection of $k$ th centerbody $\mathrm{N}-\mathrm{Tine}$ with crosssection plane

coordinates of intersection of $k$ th inlet $\mathrm{N}-\mathrm{Tine}$ with crosssection plane

angle of attack

angle of yaw

density ratio, equation

Cartesian coordinates in the plane of a cross section. The $n$-axis is parallel to the $y=0$ plane, which is the symmetry plane in symmetric cases.

fluid density

source density 


\subsection{REFERENCES}

1. Stockman, N.O.: Potential and Viscous Flows in VTOL, STOL or CTOL Propulsion System Inlets. AIAA Paper 75-1186, 0ct. 1975.

2. Hess, J.L.: Calculation of Potential Flow about Arbitrary Three-Dimensional Lifting Bodies. Final Tech. Report. McDonnell Douglas Rept. No. MDC J5679-01, oct. 1972. (A somewhat condensed version is contained in Comp. Meth. in App 1. Mech. and Engg., Vol. 4, No. 3, Nov. 1974.)

3. Lieblein, S.; and Stockman, N.0.: Compressibility Correction for Internal Flow Solutions. J. of Aircraft, Vol. 9, No. 4, Apr. 1972.

4. Albers, J.A.: Theoretical and Experimental Internal Flow Characteristics of a 13.97-Centimeter-Diameter Inlet at STOL Takeoff and Approach Conditions. NASA TN D-7185, Mar. 1973.

5. Mack, D.P.: Calculation of Potential Flow about Arbitrary Three-Dimensional Lifting Bodies. Users Manual. McDonnell Douglas Report No. MDC J5679-02, Oct. 1972 .

6. Halsey, N.D.; and Hess, J.L.: A Geometry Package for Generation of Input Data for a Three-Dimensional Potential-Flow Program. NASA CR 2962

(McDonnel1 Douglas Rept. No. MDC J7710), Mar. 1978.

7. Halsey, N.D.: A Three-Dimensional Potential-Flow Program with a Geometry Package for Input Data Generation. NASA CR 145311 (McDonnel1 Douglas Rept. No. MDC J7733), Mar. 1978. 


\section{APPENDIX A. OVERLAY STRUCTURE}

(IBM 370)

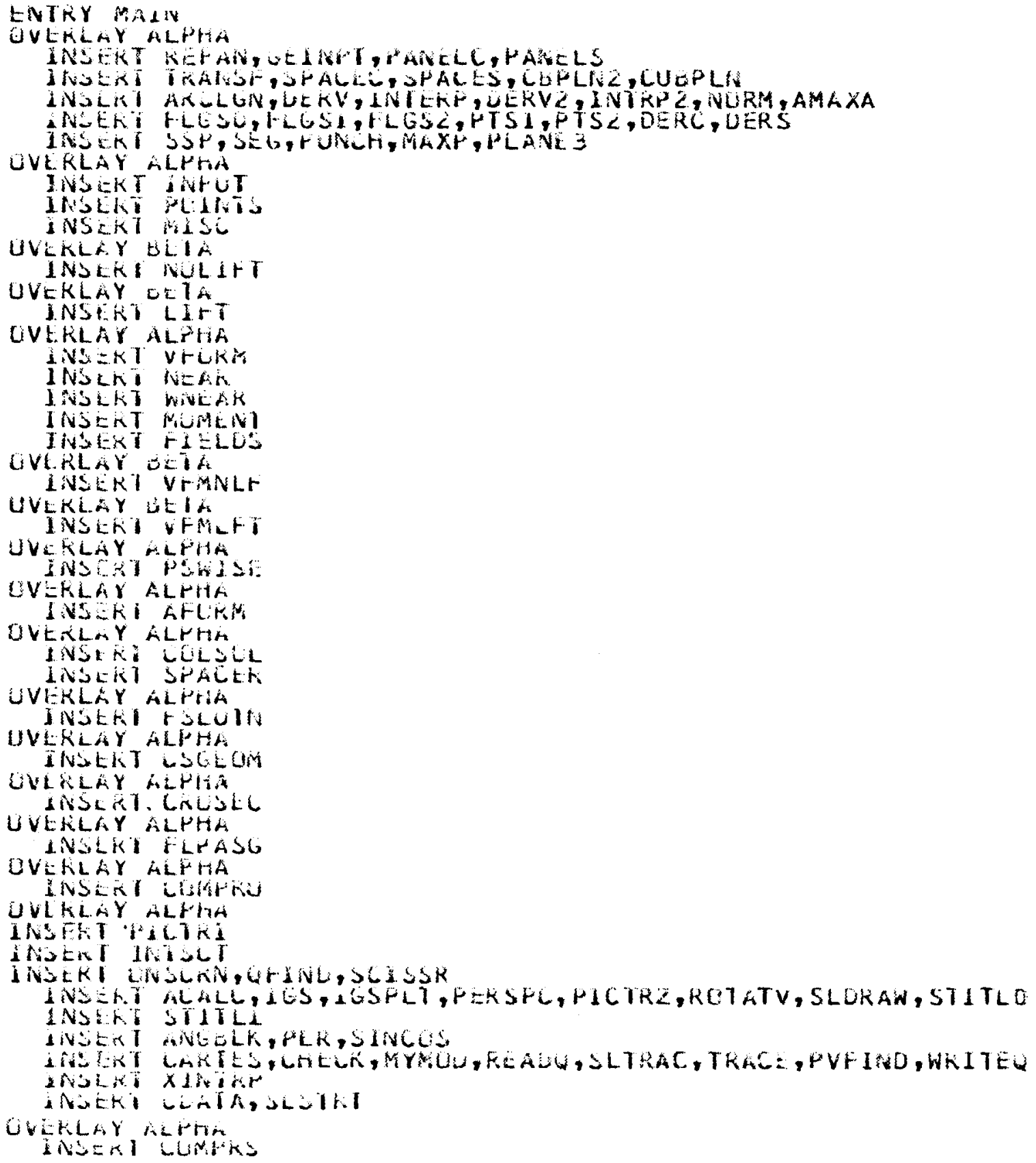


A total of 30 temporary storage external units are used. The unit numbers are: $1,2,3,4,8,9,10,11,12,13,14,15,16,17,18,19,20,21,22,23$, $24,25,26,27,28,29,30,31,32,33$. In addition to these units, a SD-4060 unit is also required if graphical plot option is selected.

There are 3 modes of operation in this program:

Mode 0: To obtain the fundamental solution, cross-section and combined solution (incompressible or compressible).

Mode 1: To obtain the fundamental solution. Basic geometry data is input only and unit numbers $4,22,23,24,29,30,32,33$ should be saved so that data may be used for the combination solution.

Mode 2: To obtain the combination solution only. Cross-section data and the combination data should be input but not the basic data that defined the inlet.

Example of the external units set up is illustrated below. 


\section{B.1 External Unit Set-Up}

(IBM 370)

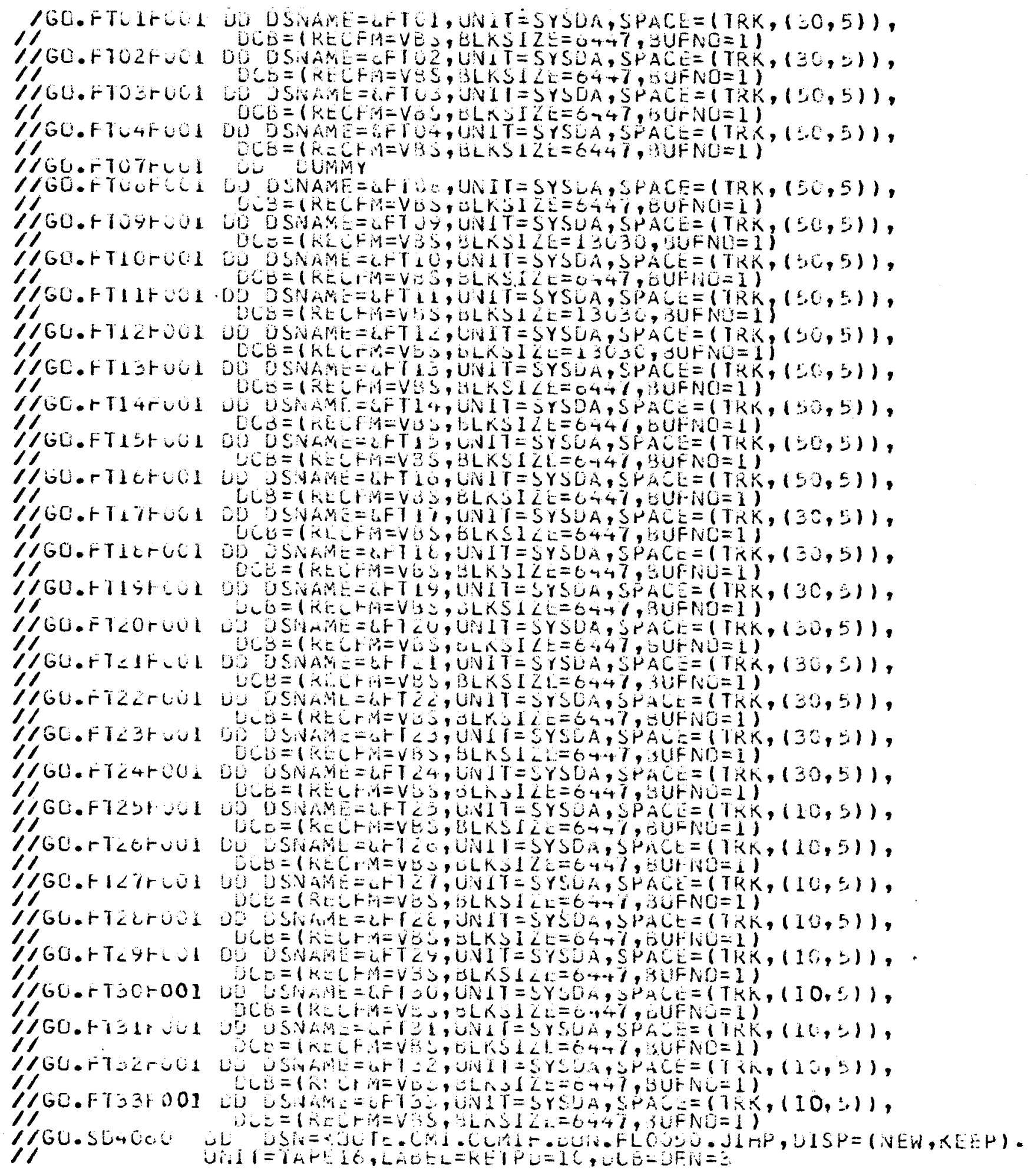


B.2 Data Assignments to External Storage

Unit Unit

Variable Number

Unit \#1

Unit \#2

NøUT Unit \#3

IGEQM Unit \#4

NKUTTA Unit \#8

NAIJ Unit \#9

NRSIDE Unit \#10

NT

Unit \#11

Unit \#12

ND

Unit \#13

Unit \#14

Unit \#15

Unit \#16

NSIG Unit \#17

NM Unit \#18

Unit \#19

NAMIJ Unit \#20

NRM

Unit \#21

NSETS Unit \#22

NSETV Unit \#23

Unit \#24

NøFSAV Unit \#25

SCSAVE Unit \#26

NFLUX Unit \#27

NV

Unit \#28

KUNIT Unit \#29

IUA

IUB

Unit \#30

Unit \#31

IUNITI Unit \#32

IUNIT Unit \#33
Unit Function

scratch units

individual vorticity onset flows

geometric quantities for each input panel (on-body + wake)

intermediate (left and right) vorticity flows

"plus" $A_{i j}$ matrix

right-hand sides for "plus" matrix

"plus" on body + off-body $\vec{v}_{i j}$

scratch units to be used in CØLSøL (matrix solutions)

source density solutions for each onset flow

"minus" on-body + off-body $\vec{v}_{i j}$

"minus" $A_{i j}$ matrix

right-hand side for "minus" matrix

static (summed) source densities

static velocity distributions

scratch unit

generated cross-section data from the input cross-section points

volume flux data

combined velcoities at cross-section control points

important data are saved on this unit for restart capability

data for streamline tracing program

data for streamline plots

viewing angles for the input geometry plots

coordinates of input on-body points 
APPENDIX C. SAMPLE INPUT AND OUTPUT FOR A SMALL PANEL NUMBER TEST CASE

\section{C.1 Input for the Test Case}

(Card Column)

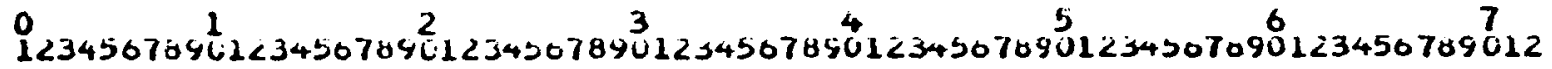

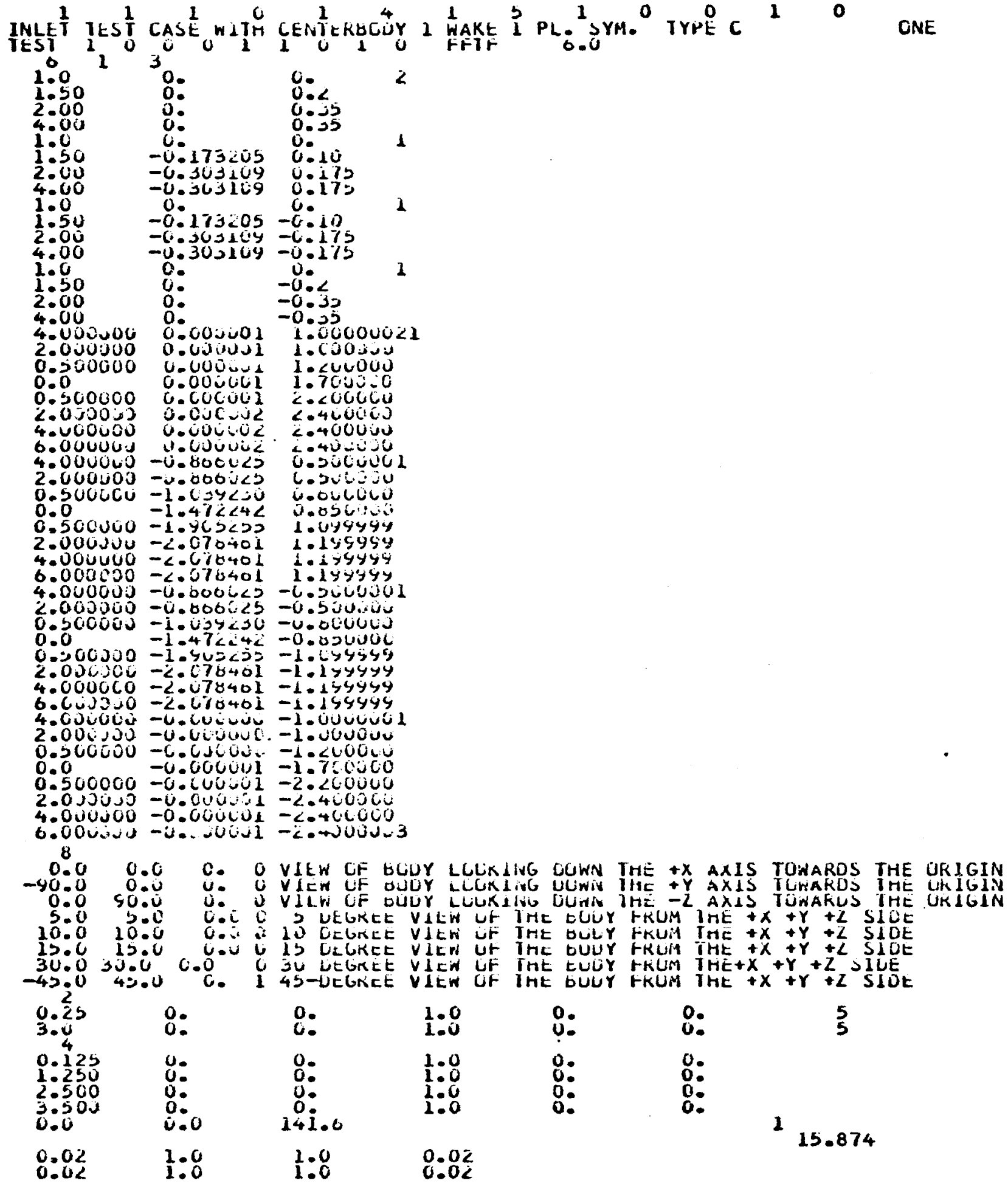




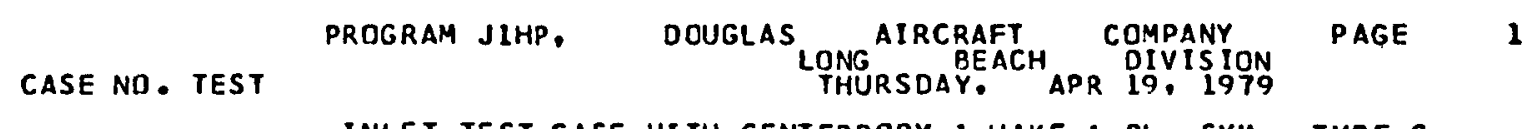

INLET TEST CASE HITH CENTERBODY 1 WAKE 1 PL. SYM. TYPE C

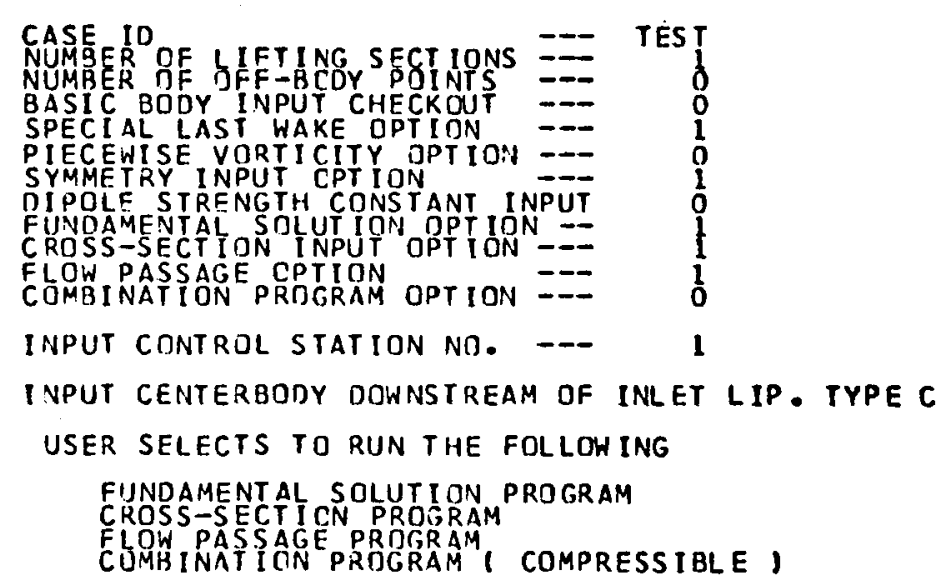

COMPONENTS OF THE UNIFRRM ONSET FLOWS
1111.000000 .
$0.0,0.0$
$\begin{array}{llllll}12 & 0.0 & 0.0 & 0.000000\end{array}$
$1310.0,1.000000,0.0$
INPUT SCALE FACTOR VALUE 6.000000 
CASE NO. TEST

PROGRAM JIHP.

DOUgLAS

AIRCRAFT COMPANY DIVIS ION

PAGE

INLET TEST CASE WITH CENTERBODY \& WAKE 1 PL. SYM. TYPE C

ONE

N M

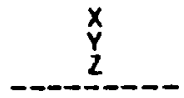

1

0.0

29.000000

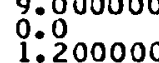

312.000000 2.099999

216.000000 0.0

2

9.000000

$-8.039229$

$3 \quad 12.000000$ -1.818053
1.049999

316.000000 0.0
0.0

$2 \quad-9.000000$ $-0.600000$

3 $\begin{array}{ll}12.018653 & -1.818653 \\ -1.049999 & -1.049999\end{array}$

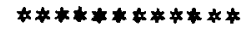

1124.000000 0.000006
6.000000

212.000000 6.000000
12.000000 6. 000006

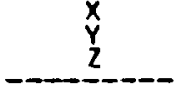

S. 000000 1: 200000

12. 000000

24.000000

2.099949

9.000000

-1.039229
0.600000

12.000000
-1.813653
1.049999

24.000000
-1.818653
1.049909

9.000000

-1.039229
-0.600000

12. 000000

$-1.049999$

4. 000000

3.003000

7.199999
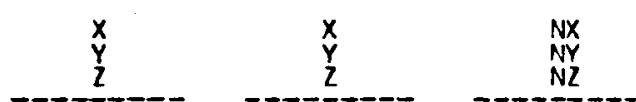

.

$\times 0$
Yo
20

6.000000

$0: 0$

$-0.327327$

$-0.472456$

$-0.251459$

12.000000

9.000000

-1.039229
0.600000

$-0.483934$

24.000000

$-1: 818653$

9.0000100

-1.03922
-0.600000

12.000000

$=1: 818653$

24. 000000

9.000000

$-1.200000$

12.000000

$-2.099999$

24:000000

$-2.099999$

12.000000

1.049999

6.000000

0.0

9.000000

- 1.039229

12.000000
-1.818653
-1.049990

6.000000

0.0

9. 000000

$-1.200000$

12.000000

$-2.099999$

0.0
-0.500000

0.866025

-0.327326
-0.944911

0.0

-0.251460
-0.967868

0.0

$-\frac{0}{0}: 000000$

-0.327327
-0.3472456

-0.472456
-0.818317

-0.251459
-0.483934

$-0.838198$

0.0
-0.500000
-0.866025

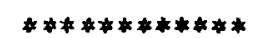

12.000000

-5. 196150

24.000000

-5.196150
3.000000

0.0

3.000090

$-3.599999$

12: $: 000008$

0.500000
-0.866026

$-0.114708$

$-0.860309$

7.999998
-0.346410
0.600000

10.636363

10.732183
1.268181

18.000000

1.574998

7.999998

$-0.692819$

10.636362

$=d: 464368$

18.000900
-1.818653

7.999998

-0.346410
-0.600000

10.63636 .3

$-1.268180$

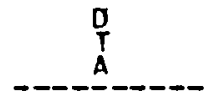

TYPF DF

$2.3842 E-07$

$1: 2311 E+00$

NLIF

$2.0489 F-07$
$3.5114 E+00$

$5.3644 \mathrm{C}-07$

$1.2182 E+01$
$2.5200 \mathrm{E}+01$

$1.1921 E-07$ NLIF

$1.2311 E+00$

$3.576 .3 F-07$

$5: 11431+00$

$0: 0028+01$

$2.3842 E-07$

$3.2311 F+00$
$1.9049 E+00$

$0.0114 E+00$

$5.11435+00$

$18: 000000 \quad 2: 9802 E-07$

$-1: 574998 \quad 2.5200 E+01$

************4

18.000000

$-2.598071$

$2.4000 E+01$

$1.3416 E+01$
$7.2000 E+01$

LIFT 


\begin{tabular}{|c|c|c|c|c|c|}
\hline$N$ & M & $\begin{array}{l}X \\
Y \\
z\end{array}$ & $\begin{array}{l}x \\
y \\
z\end{array}$ & $\begin{array}{l}X \\
Y \\
Z\end{array}$ & $\underset{x}{x}$ \\
\hline \multirow[t]{5}{*}{1} & 3 & $\begin{array}{l}3.000000 \\
0: 0000006 \\
7: 199999\end{array}$ & $\begin{array}{r}8: 800006 \\
10: 199999\end{array}$ & $\begin{array}{r}0.0 \\
-8033454 \\
5.099999\end{array}$ & $\begin{array}{r}3.000000 \\
-6: 235382 \\
3.599999\end{array}$ \\
\hline & 4 & $\begin{array}{r}8: 900006 \\
10: 199999\end{array}$ & $\begin{array}{r}3: 800090 \\
0: 080006 \\
13.199999\end{array}$ & $\begin{array}{r}3: 000000 \\
-11: 431532 \\
6.599997\end{array}$ & $\begin{array}{r}8.0 \\
-8: 833454 \\
5: 099999\end{array}$ \\
\hline & 5 & $\begin{array}{r}3.060000 \\
0: 000000 \\
13: 199999\end{array}$ & $\begin{array}{l}12.000000 \\
0: 0000012 \\
14: 399998\end{array}$ & $\begin{array}{r}12: 000000 \\
-122: 470764 \\
7: 199993\end{array}$ & $\begin{array}{r}3.000000 \\
-11: 431532 \\
6.599997\end{array}$ \\
\hline & 6 & $\begin{array}{l}12.000000 \\
0.000012 \\
14.399998\end{array}$ & $\begin{array}{l}24.000000 \\
0: 000012 \\
14.399998\end{array}$ & $\begin{array}{r}24.000000 \\
-12: 470764 \\
7.199993\end{array}$ & $\begin{array}{r}12.000000 \\
-12.470764 \\
7.199993\end{array}$ \\
\hline & 7 & $\begin{array}{l}24.000000 \\
0.000012 \\
14.39999 d\end{array}$ & $\begin{array}{l}36.000000 \\
0.000012 \\
14.399998\end{array}$ & $\begin{array}{r}36.000000 \\
-12: 470764 \\
7.199993\end{array}$ & $\begin{array}{r}24.000000 \\
-12: 470764 \\
7.199993\end{array}$ \\
\hline \multirow[t]{7}{*}{2} & 1 & $\begin{array}{r}24.000000 \\
-5: 196150 \\
3: 000500\end{array}$ & $\begin{array}{r}12.000000 \\
-5: 196150 \\
3: 000000\end{array}$ & $\begin{array}{r}12.000000 \\
-5: 196150 \\
-3: 000000\end{array}$ & $\begin{array}{l}24.000000 \\
-5: 196150 \\
-3: 000000\end{array}$ \\
\hline & 2 & $\begin{array}{r}12.000000 \\
-5.156150 \\
3.005000\end{array}$ & $\begin{array}{r}3.000000 \\
-6: 235382 \\
3.599999\end{array}$ & $\begin{array}{r}3.000000 \\
-6: 235382 \\
-3.599999\end{array}$ & $\begin{array}{l}12.000000 \\
-5: 196150 \\
-3.000000\end{array}$ \\
\hline & 3 & $\begin{array}{r}3.000000 \\
-6: 235382 \\
3.599999\end{array}$ & $\begin{array}{r}0.0 \\
-8: 833454 \\
5.099999\end{array}$ & $\begin{array}{r}0.0 \\
-8: 833454 \\
-5.099999\end{array}$ & $\begin{array}{r}3.000000 \\
-6: 235382 \\
-3.599999\end{array}$ \\
\hline & 4 & $\begin{array}{r}0.0 \\
-8.833454 \\
5.099999\end{array}$ & $\begin{array}{r}3.000000 \\
-11: 431532 \\
6.599997\end{array}$ & $\begin{array}{r}3.0030000 \\
-11: 431532 \\
-6.599997\end{array}$ & $\begin{aligned} 0.0 \\
-8: 033454 \\
-5: 099999\end{aligned}$ \\
\hline & 5 & $\begin{array}{r}3.000000 \\
-11.431533 \\
0.599997\end{array}$ & $\begin{array}{r}12.000000 \\
-12: 470764 \\
7.199993\end{array}$ & $\begin{array}{r}12: 000000 \\
-12: 470764 \\
-7.199993\end{array}$ & $\begin{array}{r}3.000000 \\
-11: 431532 \\
-6.599997\end{array}$ \\
\hline & 6 & $\begin{array}{r}12.000300 \\
-12: 475764 \\
7.199993\end{array}$ & $\begin{array}{r}24.009000 \\
-12: 470764 \\
7199993\end{array}$ & $\begin{array}{r}24.009000 \\
-12: 470764 \\
-7.199993\end{array}$ & $\begin{array}{r}12.000000 \\
-12: 470764 \\
-7.109993\end{array}$ \\
\hline & 7 & $\begin{array}{r}24.003900 \\
-12: 470764 \\
7.199993\end{array}$ & $\begin{array}{r}36.000000 \\
-12: 470764 \\
7.199993\end{array}$ & $\begin{array}{r}36.000000 \\
-12: 470254 \\
-7: 199993\end{array}$ & $\begin{array}{r}24.000000 \\
-12: 470764 \\
-7: 199993\end{array}$ \\
\hline
\end{tabular}

\begin{tabular}{|c|}
\hline $\begin{array}{r}-0.654653 \\
0: 379964 \\
-0.654654\end{array}$ \\
\hline $\begin{array}{r}-0.654654 \\
-0: 377965 \\
0.654654\end{array}$ \\
\hline $\begin{array}{r}-0.114707 \\
-0.496700 \\
0.860309\end{array}$ \\
\hline $\begin{array}{r}0.0 \\
-0.500000 \\
0.866026\end{array}$ \\
\hline $\begin{array}{r}0.0 \\
-0.500000 \\
0.866026\end{array}$ \\
\hline $\begin{array}{l}0.0 \\
1: 100000 \\
0: 0\end{array}$ \\
\hline $\begin{array}{r}-0.114708 \\
0: 993399 \\
0.0\end{array}$ \\
\hline $\begin{array}{l}-0.854653 \\
0: 755929 \\
0.0\end{array}$ \\
\hline $\begin{array}{c}-0.654654 \\
-0.755929 \\
0.0\end{array}$ \\
\hline $\begin{array}{l}-0.114708 \\
-0.0993999 \\
0.0\end{array}$ \\
\hline $\begin{aligned} 0.0 \\
-1: 800000 \\
0.0\end{aligned}$ \\
\hline $\begin{aligned} & 0: 0 \\
&-1: 000000 \\
& 0.0\end{aligned}$ \\
\hline
\end{tabular}<smiles>C1CCC1</smiles>

\begin{tabular}{l} 
xo \\
Yo \\
20 \\
\hline
\end{tabular} $-\frac{1}{3}: 500000$ $-6.524998$

$-5.500000$ $-5.066241$

7.500000 10.9755666

18.000000 -6.235375
10.799988

30.000000

30.0235375

18.000000 $-5: 196150$

500000 $\begin{array}{rl}7.5 & 500000 \\ -515766 & 0\end{array}$ $-7.5500000$ $-0.0$

1.500000 $-10: 132492$ 7.500000
$-11: 951141$
0.0 18.000000
$-12: 470764$ $-12: 470764$ 30.000000
-12.470764
0.0
TYPE OF
ELEMENT

LIFT

$7.9373 E+00$

$7: 0373 E+00$ $4.9639 E+01$

$1.8120 c+01$
$1: 6519 \%+01$
$1.2530 E+02$

$2.4000 \mathrm{~F}+01$ $1.8745 E+01$
$1.7280 E+02$

$2.4000 E+01$ $1: 8745 E+01$

$2.4000 E+01$ $1: 3416 E+? 1$ $1.8120 E+01$
$1: 1225 E+01$
$5: 90265+01$

$7.9372 E+00$ 3.691 $61 \mathrm{LE}+01$

$7.9373 E+00$ $1.2445 E+01$
$4.9639 E+01$ $1.9120 F+01$
$1.6519 E+01$

200 +01 $2: 8745 E+01$
$1: 7280 F+02$

$2.4000 E+01$ $1: 8745 E+01$
$: 7280 E+02$ 
N

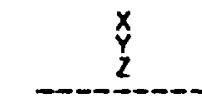

3

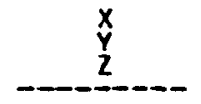

12.000000 -5.196150
-3.000000 -5.196150
-3.000000

12.000000 -5.196150
-3.000300

\subsection{0}

-6.235382
-3.599999

$3 \quad 3.000000$ -6.235332
-3.599999

0.0

0.0
-8.833454
-5.099999

0.0
-8.833454
-5.099999

3.000000
-11.431532

-11.431532
-6.599997

$5-13.000000 \quad 12.000000$ $\begin{array}{r}-11.431532 \\ -6.599997\end{array}-12.470764$ $\begin{array}{rr}12.000000 & 24.000000 \\ -12.470764 & -12.470764 \\ -1.199993 & -7.190993\end{array}$

$\begin{array}{rr}24.070000 & 36.000090 \\ -12.470764 & -12.477764 \\ -1.199993 & -7.199993\end{array}$

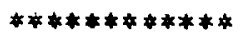

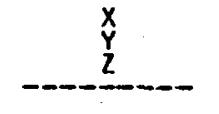

$-6.000000$

3.000000

$-7: 199999$

$$
0.0
$$

$-10: 000006$

3.000000

$-13.199999$

12.000000

$-14: 003006$
-14.39998

24.000000

-0.000006
-14.399998

36.000000

$\begin{array}{rl}-14 & 0 \\ -14 & 00000969\end{array}$

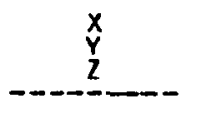

24. 000000

$-6.000000$

12.000000

$-6.000000$

3.000000

$\begin{array}{rl}0 & 0 \\ -7 & 0 \\ 1 & 0\end{array} 99999$

$-0: 000006$

$-10.199999$

3.000000

-0.000006
-13.199999

12.000000

-0.000006
-14.399998

24.000000

-0.900006
-14.399998
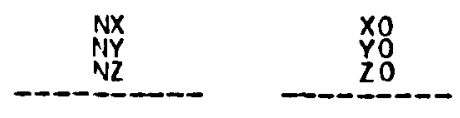

0.500000

18.000000 -2.598075
-4.500000

$-0.114708$

0.496700
0.860309

7.500000
-2.85738

$-0.654654$

0.377964
0.654654

$-0.655654$

$-0.654654$

$-0.114708$

$=0.496700$

$-0.0000001$

-0.866026

- 0.00000001

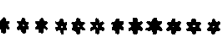

18.000000

$-10.79998$
TYPEE OOF

LIF T

$1.3416 E+01$
$7.2000 F+01$

$1.9120 E+01$

$1.1225 \mathrm{E}+01$
$5.9926 \mathrm{E}+01$

$7.9373 E+00$ $9.6793 \mathrm{E}+00$
$3.6911 \mathrm{E}+0 \mathrm{~L}$

$7.9373 \mathrm{~F}+00$

$1.2445 E+01$
$4.9639 E+01$ $\begin{array}{rl}7.500000 & 1.8120 E+01 \\ -5.975574 & 1.65195+01 \\ -10.349991 & 1.25305+02\end{array}$

$2.4000 E+01$
$1.87455+01$

$\begin{array}{rr}30.000000 & 2.4090 F+01 \\ -16.235385 & 1.8745 E+01\end{array}$

WAKE 


\section{TABLE OF INPUT INFORMATION}

\begin{tabular}{|c|c|c|c|c|c|c|}
\hline SECINPUT & $\begin{array}{l}\text { SEC TION } \\
\text { TYPE }\end{array}$ & $\begin{array}{l}\text { TOTAL NOP OF EELEMENTS } \\
\text { IN EACH SECTION }\end{array}$ & $\begin{array}{l}\text { EXTRA } \\
\text { SIRIPS } \\
\end{array}$ & $\begin{array}{l}\text { STRIP } \\
\text { NOE. }\end{array}$ & $\begin{array}{l}\text { SOURCE ELEMENTS } \\
\text { IN THE SIRIP }\end{array}$ & WAKE ELEMENTS IN \\
\hline 1 & 0 & 9 & & $\frac{1}{2}$ & $\begin{array}{l}3 \\
3\end{array}$ & $\begin{array}{l}0 \\
0 \\
0\end{array}$ \\
\hline 2 & 1 & 21 & & $\begin{array}{l}3 \\
5 \\
6 \\
6\end{array}$ & $\begin{array}{l}6 \\
6 \\
6 \\
6\end{array}$ & $\begin{array}{l}1 \\
1\end{array}$ \\
\hline
\end{tabular}

CASE NO. TEST

PROGRAM JIHP, DOUglas AIRCRAFT COMPANY PAGE 8 LONG THURSDAY, BCH APR PIVISION

INLET TEST CASE WITH CENTERBODY 1 WAKE 1 PL. SYM. TYPE C ONE

BODY SECTION NO. =

TYPE $=1$

TOTAL
NO. OF STRIPS $=3$

NO. DF HAKE ELEMENTS 1 TOTAL ND. OF ELEMENTS PER STRIP 7

TOTAL NO. OF CONTROL POINTS I INCL. OFF BODY POINTS $)=27$ TOTAL NO. OF ELEMENTS IN THE LIFTING SECTION $=21$

NO. OF FAR ELEMENTS $=36$ NO. OF INTERMECIATE ELEMENTS $=168$ NO. OF NEAR ELEMENTS $=1416$

THE $27 \times 27$ MATRIX WITH 5 RIGHT SIDES HAS SOLVED DIRECTLY IN 0.01 IMINUTES.

THE $27 \times 27$ MATRIX HITH 1 RIGHT SIDES WAS SOLVED DIRECTLY IN 0.01 MINUTES. 


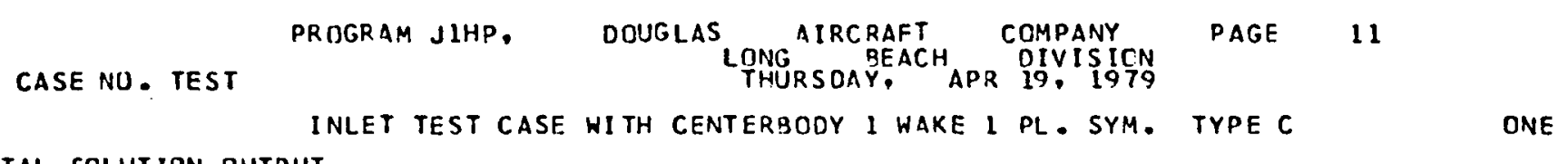

FUNDAMENTAL SOLUIION OUTPUT

\begin{tabular}{|c|c|c|c|c|c|c|c|c|c|c|c|c|}
\hline I & STATVX & ATVY & STA TVZ & $J \vee \times 1$ & UVY1 & UVZ1 & UVX2 & UVY 2 & UVZ2 & $u v \times 3$ & UVY3 & UV23 \\
\hline $\begin{array}{l}1 \\
2 \\
3 \\
4 \\
5 \\
6 \\
7 \\
8 \\
99 \\
10 \\
11 \\
12 \\
13 \\
14 \\
15 \\
16 \\
17 \\
18 \\
19 \\
20 \\
21 \\
22 \\
23 \\
24 \\
25 \\
26 \\
27\end{array}$ & 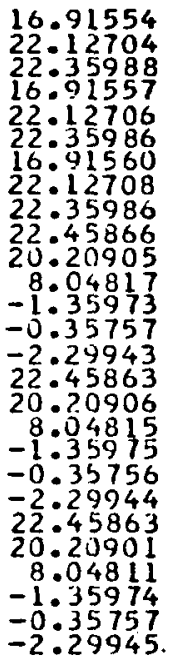 & 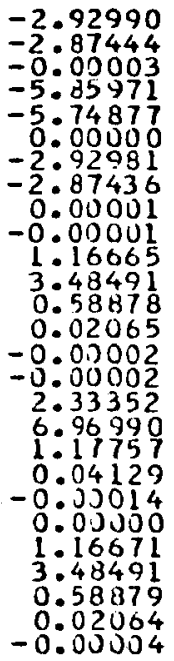 & 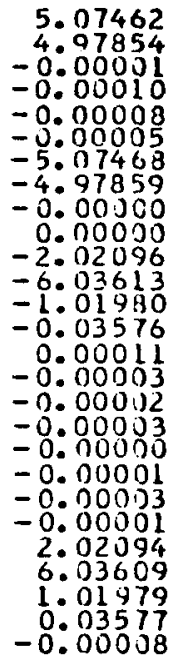 & $\begin{array}{l}0.95474 \\
1: 22937 \\
1: 23063 \\
0: 95474 \\
1: 22937 \\
1: 23063 \\
0: 95474 \\
1: 22937 \\
1: 23063 \\
1: 19751 \\
1: 13273 \\
0: 33951 \\
0: 92633 \\
1: 19592 \\
1: 07329 \\
1: 19751 \\
1: 13274 \\
0: 33951 \\
0: 92633 \\
1: 19592 \\
1: 07329 \\
1: 19751 \\
1: 13273 \\
0: 33950 \\
0: 92633 \\
1: 19592 \\
1.07330\end{array}$ & 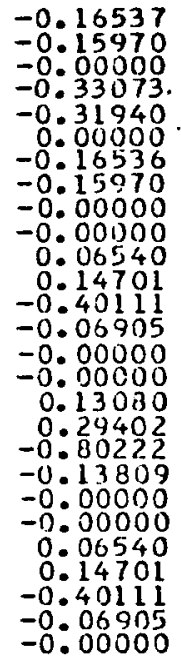 & $\begin{array}{r}0.28642 \\
0: 07661 \\
-0: 00000 \\
-0: 00000 \\
0: 00000 \\
0: 00000 \\
-0: 08642 \\
-0: 27661 \\
0: 00000 \\
0: 00000 \\
-0: 011327 \\
-0: 25463 \\
0: 69475 \\
0.11959 \\
0: 00000 \\
0.00000 \\
0.00000 \\
0.00000 \\
0: 00000 \\
0.00000 \\
0: 00000 \\
-0.00000 \\
0.11327 \\
0.25463 \\
-0.69475 \\
-0.11959 \\
-0.00000\end{array}$ & 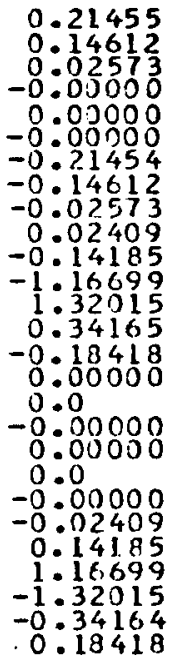 & 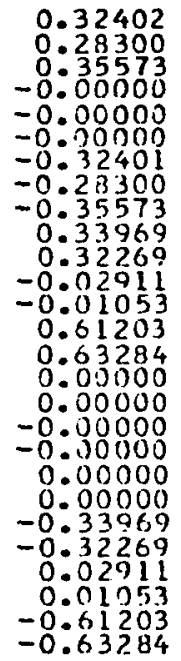 & 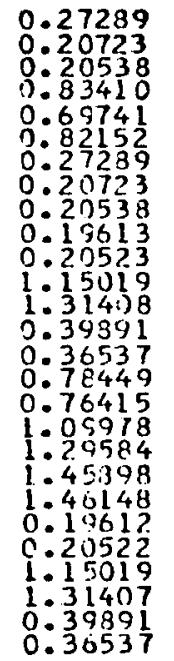 & 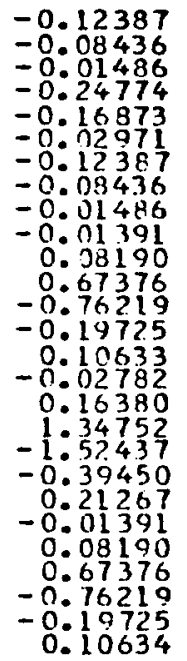 & 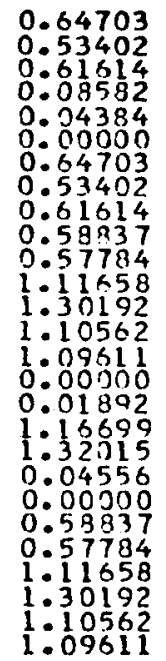 & $\begin{array}{r}0: 32 \\
0: 08 \\
0: 35 \\
-0: 00 \\
0: 00 \\
-0: 00 \\
-0: 32 \\
-0: 28 \\
-0: 35 \\
0: 33 \\
0: 032 \\
-0: 02 \\
-0001 \\
0: 61 \\
-0.63 \\
-0: 00 \\
-0: 00 \\
-0: 00 \\
-0: 00 \\
0: 00 \\
-0: 00 \\
-0: 33 \\
-0.32 \\
0: 02 \\
0: 01 \\
-0.61 \\
-0.63\end{array}$ \\
\hline
\end{tabular}




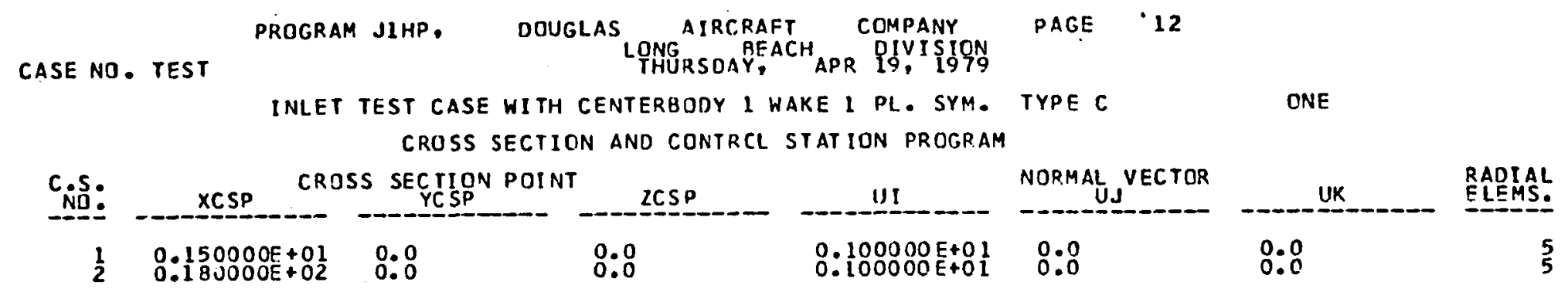

FORMATION OF CRCSS SECTION ELEMENTS

CROSS SECTION NO. 1

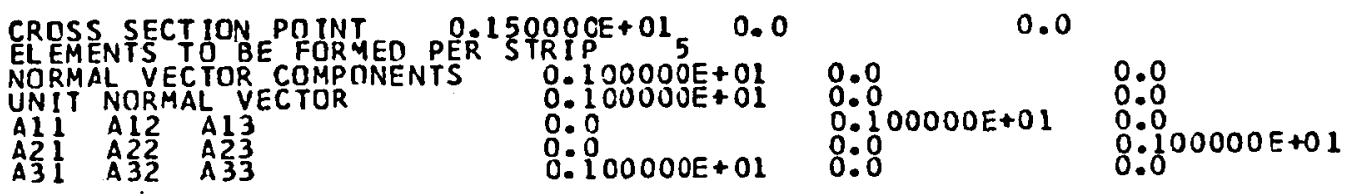


INLET TEST CASE WITH CENTERBODY \& HAKE I PL. SYM. TYPE C

ONE CROSS SECTION AND CONTRCL STATION PROGRAM

\begin{tabular}{|c|c|c|c|c|c|c|c|c|c|c|}
\hline J & I & $\begin{array}{l}x \\
Y \\
Z\end{array}$ & $\begin{array}{l}x \\
y \\
z\end{array}$ & $\begin{array}{l}x \\
y \\
z \\
-x\end{array}$ & $\begin{array}{l}X \\
Y \\
Z \\
\end{array}$ & $\begin{array}{l}R 1 X \\
R 1 Y \\
R 12 \\
\end{array}$ & $\begin{array}{r}R 2 X \\
R 2 Y \\
R 2 Z \\
\end{array}$ & $\begin{array}{l}x C \\
Y C \\
2 C\end{array}$ & $\begin{array}{l}X I \\
\text { EITA } \\
\text { AREA }\end{array}$ & TYPE \\
\hline 1 & 1 & $\begin{array}{l}1.50000 \\
0: 0^{0} \\
0.0\end{array}$ & $\begin{array}{l}1.50000 \\
0.00000 \\
1.74000\end{array}$ & $\begin{array}{r}1.50000 \\
-1.50688 \\
0.37000\end{array}$ & $\begin{array}{l}1.50000 \\
0: 0 \\
0.0 .\end{array}$ & $\begin{array}{rl}0 & .0 \\
-1 & 50688 \\
0 & .87000\end{array}$ & $\begin{array}{r}0.00 \\
-0.00000 \\
-1.74000\end{array}$ & $\begin{array}{r}1.50000 \\
-0.37672 \\
0.65250\end{array}$ & $\begin{array}{r}-0.37672 \\
0.65250 \\
1.3109\end{array}$ & CROS \\
\hline & 2 & $\begin{array}{l}1.50000 \\
0.00000 \\
1.74000\end{array}$ & $\begin{array}{l}1.50000 \\
0.00000 \\
3.48500\end{array}$ & $\begin{array}{r}1.50000 \\
-3.91377 \\
1.74000\end{array}$ & $\begin{array}{r}1.50000 \\
-1.50688 \\
0.87000\end{array}$ & $\begin{aligned} 0.0 \\
-3: 01377 \\
0.0\end{aligned}$ & $\begin{array}{r}0.0 \\
-1.50688 \\
-2.61000\end{array}$ & $\begin{array}{r}1.50000 \\
-1.13016 \\
-1.95750\end{array}$ & $\begin{array}{r}-1.13016 \\
\frac{1}{3}: 95750 \\
93296\end{array}$ & CROS \\
\hline & 3 & $\begin{array}{l}1.50000 \\
0.00000 \\
3.49000\end{array}$ & $\begin{array}{l}1.50000 \\
0.00000 \\
5.22000\end{array}$ & $\begin{array}{r}1.50000 \\
-4.52065 \\
2.51000\end{array}$ & $\begin{array}{r}1.50000 \\
-3.01377 \\
1.74000\end{array}$ & $\begin{aligned} & 0.0 \\
&-4.52065 \\
&-0.87000\end{aligned}$ & $\begin{array}{l}0.9 \\
-3.01377 \\
-3.48000\end{array}$ & $\begin{array}{r}1.50000 \\
-1.88360 \\
3.26250\end{array}$ & $\begin{array}{r}-1.89360 \\
3.26250 \\
6.55494\end{array}$ & CROS \\
\hline & 4 & $\begin{array}{l}1.50000 \\
0.00000 \\
5.22000\end{array}$ & $\begin{array}{l}6: 50000 \\
6.00050 \\
6.96000\end{array}$ & $\begin{array}{r}1.59099 \\
-6.02753 \\
3.48000\end{array}$ & $\begin{array}{r}1.50009 \\
-4.52065 \\
2.61000\end{array}$ & $\begin{array}{l}0.0 \\
-6.02754 \\
-1.74000\end{array}$ & $\begin{array}{r}0.0 \\
-4.52065 \\
-4.35000\end{array}$ & $\begin{array}{r}1.50700 \\
-2.63704 \\
4.56750\end{array}$ & $\begin{array}{r}-2.63704 \\
4.56750 \\
9.17691\end{array}$ & CROS \\
\hline & 5 & $\begin{array}{l}1.50000 \\
0.00000 \\
6.96000\end{array}$ & $\begin{array}{l}1.50000 \\
0.00001 \\
8.70000\end{array}$ & $\begin{array}{r}1.50000 \\
-7.53442 \\
4.35000\end{array}$ & $\begin{array}{r}1.50000 \\
-6.02753 \\
3.48000\end{array}$ & $\begin{array}{l}0.0 \\
-7: 53442 \\
-2.61000\end{array}$ & $\begin{array}{r}0.0 \\
-6: 02754 \\
-5.22000\end{array}$ & $\begin{array}{r}1.50000 \\
-3.39048 \\
5.87250\end{array}$ & $\begin{array}{r}-3.39048 \\
5.87250 \\
11.79890\end{array}$ & CROS \\
\hline 2 & 1 & $\begin{array}{l}1.50000 \\
0: 0 \\
0.0\end{array}$ & $\begin{array}{r}1.50000 \\
-1.50688 \\
0.87000\end{array}$ & $\begin{array}{r}1.50000 \\
-1.50698 \\
-0.87000\end{array}$ & $\begin{array}{l}1.50000 \\
0: 0^{\circ} \\
0.0\end{array}$ & $\begin{array}{r}0.0 \\
-1: 50688 \\
-0.87000\end{array}$ & $\begin{array}{r}0.0 \\
1.50688 \\
-0.87000\end{array}$ & $\begin{array}{r}1.50000 \\
-0: 75344 \\
0.0\end{array}$ & $\begin{array}{r}-0.75344 \\
0.001099 \\
1.3109\end{array}$ & CROS \\
\hline & 2 & $\begin{array}{r}1.50000 \\
-1.50688 \\
0.87000\end{array}$ & $\begin{array}{r}1.50000 \\
-3.01377 \\
1.74000\end{array}$ & $\begin{array}{r}1.50000 \\
-3.01377 \\
-1.74000\end{array}$ & $\begin{array}{r}1.50000 \\
-1.50688 \\
-1.57000\end{array}$ & $\begin{array}{r}0.0 \\
-1.53688 \\
-2.61000\end{array}$ & $\begin{array}{r}0.80688 \\
-2.50600\end{array}$ & $\begin{array}{r}1.50000 \\
-2.26032 \\
-0.00000\end{array}$ & $\begin{array}{r}-2.26037 \\
-0 . j 0000 \\
3.93296\end{array}$ & ĊROS \\
\hline & 3 & $\begin{array}{r}1.50000 \\
-3.01377 \\
1.74000\end{array}$ & $\begin{array}{r}1.510000 \\
-4.52065 \\
2.61000\end{array}$ & $\begin{array}{r}1.50000 \\
-4.52065 \\
-2.61000\end{array}$ & $\begin{array}{r}1.50010 \\
-3.01377 \\
-1.74050\end{array}$ & $\begin{array}{r}0.0 \\
-1.50688 \\
-4.35000\end{array}$ & $\begin{array}{r}0.0 \\
1.50688 \\
-4.35000\end{array}$ & $\begin{array}{l}\frac{1}{3} .50900 \\
-0.76721 \\
0.0\end{array}$ & $\begin{array}{r}-3.76721 \\
0.075494 \\
6.55494\end{array}$ & CROS \\
\hline & 4 & $\begin{array}{r}1.50000 \\
-4.52065 \\
2.610 .30\end{array}$ & $\begin{array}{r}1.50000 \\
-6.07753 \\
3.48000\end{array}$ & $\begin{array}{r}1.50000 \\
-6.02753 \\
-3.48000\end{array}$ & $\begin{array}{r}1.50000 \\
-4.52065 \\
-2.61000\end{array}$ & $\begin{array}{l}0.0 \\
-1.50688 \\
-6.09000\end{array}$ & $\begin{array}{l}0.0 \\
1.50688 \\
-6.09000\end{array}$ & $\begin{array}{r}1.50000 \\
-5.27409 \\
0.0\end{array}$ & $\begin{array}{r}-5.2 .7409 \\
9.07691 \\
9.1769\end{array}$ & CROS \\
\hline & 5 & $\begin{array}{r}1.50000 \\
-6.02753 \\
3.48000\end{array}$ & $\begin{array}{r}1.50000 \\
-7.53442 \\
4.35000\end{array}$ & $\begin{array}{r}1.50000 \\
-7.53442 \\
-4.35000\end{array}$ & $\begin{array}{r}1.50000 \\
-6.02753 \\
-3.48000\end{array}$ & $\begin{array}{r}0.0 \\
-1.50689 \\
-7.83000\end{array}$ & $\begin{array}{r}0.0 \\
1.50688 \\
-7.83500\end{array}$ & $\begin{array}{l}1.50000 \\
-6: 78597 \\
0.0\end{array}$ & $\begin{array}{r}-6.78097 \\
0: 0 \\
11.79890\end{array}$ & CROS \\
\hline 3 & & $\begin{array}{l}1.53000 \\
0.00 \\
0.0\end{array}$ & $\begin{array}{r}1.50000 \\
-1.50688 \\
-0.87000\end{array}$ & $\begin{array}{r}1.50000 \\
-0.00000 \\
-1.74000\end{array}$ & $\begin{array}{l}5.0^{0000} \\
0.0^{2}\end{array}$ & $\begin{array}{r}0.0 \\
-0.00000 \\
-1: 74000\end{array}$ & $\begin{array}{l}0.0 \\
1: 50688 \\
0.87000\end{array}$ & $\begin{aligned} & 1.5000 \\
&-0.37672 \\
&-0.65250\end{aligned}$ & $\begin{array}{r}-0.37672 \\
-0.85250 \\
1.31099\end{array}$ & ROS \\
\hline
\end{tabular}


$\vec{D}$

CASE ND. TEST

PROGRAM JIHP,

DOUGLAS

AIRCRAFT COMPANY
LONG
THURSDAYACH DPR DIVISION
19, 1979

INLET TEST CASE HITH CENTERBODY 1 WAKE 1 PL. SYM. TYPE $C$ CROSS SECTION AND CONTRCL STATION PROGRAM
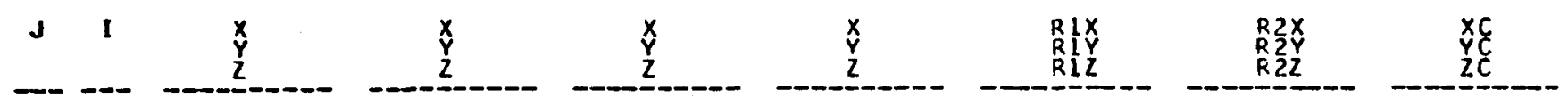

$-$

KIAA

TYPE

3

$\begin{array}{rrr}2 & 1.50000 & -1.50000 \\ & -1.50088 & -3.01377 \\ 3 & -0.87000 & -1.74000 \\ & 1.50000 & 1.50000 \\ & -\frac{3}{3} .01377 & -4.52065 \\ & -1.74000 & -2.61000 \\ 4 & -1.50000 & -1.50000 \\ & -4.52065 & -6.02753 \\ & -2.61000 & -3.48000 \\ 5 & 1.50000 & -1.50000 \\ & -6.502753 & -7.53442 \\ & -3.48000 & -4.35000\end{array}$

1.50000
-0.00000

1.50000
-0.00000

0.0
-1
$-2: 50688$
0

0.007

1.50000

$---$

1.50000
-0.50000

-0.500000
-5.22000

1.50000

-0.00000
-3.48000

0.0

0.0

$-1.95750$

$=1.13016$

CROS

$-3.50000$

$-0.50000$

3.01376
-3.48000

0.0

4.52065
-0.87000

$-1.50000$

-1.88360 CROS

$-6.96000$

4:0 02065

0.0

-3.26250
6.55494

1.50000
$-0: 00000$
-8.70000

1.50000
-0.00000

$-4.35000$

$-1.74000$

$-\frac{1}{2}: 6370$

$=2.63705$ CROS

$-6.96000$

0.002753

0.0

7.53442
-2.61000

1.50000
-3.309049

- -

FINISHFD COMPUTATION FOR CROSS SECT ION

TOTAL NUMBER OF OFF-BOOY POINTS T,ENERATED =

FIRMATION OF CRCSS SECTION ELEMENTS

CROSS SECTION NO. 2

0.0

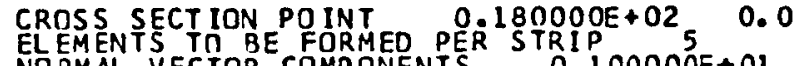
$\begin{array}{ll}\text { NORMAL VECTOR COMPONENTS } & 0.100000 E+01 \\ \text { UNIT NORMAL VECTOR } & 0: 100000 E+01\end{array}$

$\begin{array}{lll}A 12 & A 12 & A 13 \\ A 31 & A 22 & A 23 \\ A 3 & A 33\end{array}$

0: $100000 E+01$

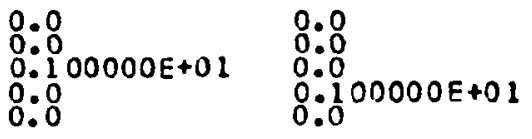


PROGRAM JIHP, DOUGLAS AIRCRAFT COMPANY PAGE 17 LONG
THURSDAY, BEACH APR DIVISITN

INLET TEST CASE WITH CENTERBODY I WAKE 1 PL. SYM. TYPF C

DNE CROSS SECTION AND CONTRCL STATION PROGRAM

\begin{tabular}{|c|c|c|c|c|c|c|c|c|c|c|}
\hline J & I & $\begin{array}{l}x \\
\mathbf{Y} \\
z \\
-\end{array}$ & $\begin{array}{l}X \\
Y \\
Z \\
-2\end{array}$ & $\begin{array}{l}X \\
Y \\
Z \\
-\end{array}$ & $\begin{array}{l}x \\
y \\
z \\
-\end{array}$ & $\begin{array}{l}\text { R1X } \\
\text { RIY } \\
\text { RIZ } \\
\end{array}$ & $\begin{array}{l}R 2 X \\
R 2 Y \\
R 2 Z \\
\end{array}$ & $\begin{array}{l}X C \\
Y C \\
Z C \\
\end{array}$ & $\begin{array}{l}\text { XI } \\
\text { EIA } \\
\text { AREA }\end{array}$ & TYPE \\
\hline 1 & 1 & $\begin{array}{r}18.00000 \\
0.0 \\
2.10000\end{array}$ & $\begin{array}{r}18.00000 \\
0.00000 \\
2.88000\end{array}$ & $\begin{array}{r}18.00000 \\
-2.49415 \\
1.44000\end{array}$ & $\begin{array}{r}18.00000 \\
-1.81865 \\
1.05000\end{array}$ & $\begin{array}{l}0.0 \\
-2.49415 \\
-0.66000\end{array}$ & $\begin{array}{l}0.0 \\
-1.81865 \\
-1.83000\end{array}$ & $\begin{array}{r}18.00000 \\
-1.07820 \\
1.86750\end{array}$ & $\begin{array}{r}-1.07820 \\
1.86750 \\
1.68199\end{array}$ & CROS \\
\hline & 2 & $\begin{array}{r}18.00000 \\
0.00000 \\
2.88000\end{array}$ & $\begin{array}{r}18.00000 \\
0.00000 \\
3.66000\end{array}$ & $\begin{array}{r}18.00000 \\
-3.16465 \\
1.83000\end{array}$ & $\begin{array}{r}18.00000 \\
-2.49415 \\
1.44000\end{array}$ & $\begin{array}{l}0.0 \\
-3.16965 \\
-1.05000\end{array}$ & $\begin{array}{l}0.0 \\
-2.49415 \\
-2.22000\end{array}$ & $\begin{array}{r}18.00000 \\
-1.41595 \\
2.45250\end{array}$ & $\begin{array}{r}-1.41595 \\
2.45250 \\
2.20898\end{array}$ & CROS \\
\hline & 3 & $\begin{array}{r}18.00000 \\
0.00000 \\
3.66000\end{array}$ & $\begin{array}{r}18.00000 \\
0.00000 \\
4.44000\end{array}$ & $\begin{array}{r}18.00900 \\
-3.84515 \\
2.22000\end{array}$ & $\begin{array}{r}18.00090 \\
-3.16965 \\
1.83000\end{array}$ & $\begin{array}{r}0.8 \\
-3.84515 \\
-1.44000\end{array}$ & $\begin{array}{l}0.0 \\
-3: 16965 \\
-2.61000\end{array}$ & $\begin{array}{r}18.00000 \\
-1.75370 \\
3.03750\end{array}$ & $\begin{array}{r}-1.75370 \\
3.03750 \\
2.73577\end{array}$ & CROS \\
\hline & 4 & $\begin{array}{r}18.03000 \\
0.05000 \\
4.44000\end{array}$ & $\begin{array}{r}18.09000 \\
0.05000 \\
5.22000\end{array}$ & $\begin{array}{r}18.00000 \\
-4.52065 \\
2.61000\end{array}$ & $\begin{array}{r}18.00000 \\
-3.84515 \\
-2.22000\end{array}$ & $\begin{array}{l}0.0 \\
-4.52065 \\
-1.83000\end{array}$ & $\begin{array}{l}0.9 \\
-3.84516 \\
-3.00000\end{array}$ & $\begin{array}{r}18.00000 \\
-2.09145 \\
3.62250\end{array}$ & $\begin{array}{r}-2.09145 \\
3.62250 \\
3.26266\end{array}$ & CROS \\
\hline & 5 & $\begin{array}{r}18.00000 \\
0.00000 \\
.5 .22000\end{array}$ & $\begin{array}{r}18.00000 \\
0.00001 \\
6.00000\end{array}$ & $\begin{array}{r}18.00000 \\
-5.19615 \\
3.00000\end{array}$ & $\begin{array}{r}18.00000 \\
-4.52065 \\
2.61000\end{array}$ & $\begin{array}{l}0.0 \\
-5: 19615 \\
-2.22000\end{array}$ & $\begin{array}{l}0.0 \\
-4: 52066 \\
-3.391000\end{array}$ & $\begin{array}{r}18.00000 \\
-2.42920 \\
4.20750\end{array}$ & $\begin{array}{r}-2.42920 \\
4.20750 \\
3.78955\end{array}$ & CROS \\
\hline 2 & 1 & $\begin{array}{r}18.02000 \\
-1.81065 \\
1.05000\end{array}$ & $\begin{array}{r}18.00900 \\
-2.49415 \\
1.44000\end{array}$ & $\begin{array}{l}18.00000 \\
-2.49415 \\
-1.44000\end{array}$ & $\begin{array}{l}18.00000 \\
-1.81865 \\
-1.05000\end{array}$ & $\begin{array}{r}0.0 \\
-0.67550 \\
-2.49000\end{array}$ & $\begin{array}{r}0.07550 \\
0.67550 \\
-2.49000\end{array}$ & $\begin{array}{rl}18 & 09000 \\
-2 & 15640 \\
0.0 & \end{array}$ & $\begin{array}{r}-2.15640 \\
1.68199\end{array}$ & CROS \\
\hline & 2 & $\begin{array}{r}18.00000 \\
-2.49415 \\
1.44000\end{array}$ & $\begin{array}{r}18.00009 \\
-3.16965 \\
1.83000\end{array}$ & $\begin{array}{l}18.00000 \\
-3.16965 \\
-1.83000\end{array}$ & $\begin{array}{l}18.00000 \\
-2.49415 \\
-1.44000\end{array}$ & $\begin{array}{l}0.0 \\
-0.67550 \\
-3.27000\end{array}$ & $\begin{array}{r}0.0 \\
0.67550 \\
-3.27000\end{array}$ & $\begin{array}{l}18.00000 \\
-2.83190 \\
0.0\end{array}$ & $\begin{array}{r}-2.83190 \\
0.80 \\
2.20888\end{array}$ & CROS \\
\hline & 3 & $\begin{array}{r}18.00000 \\
-3.16965 \\
1.83000\end{array}$ & $\begin{array}{r}18.00000 \\
-3.84515 \\
2.22000\end{array}$ & $\begin{array}{l}13.00000 \\
-3.84515 \\
-2.22000\end{array}$ & $\begin{array}{l}18.00000 \\
-3.16965 \\
-1.83000\end{array}$ & $\begin{array}{r}0.0 \\
-0.67550 \\
-4.05000\end{array}$ & $\begin{array}{r}0.0 \\
0.67550 \\
-4.05000\end{array}$ & $\begin{array}{c}18.00009 \\
-3: 50749 \\
0.0\end{array}$ & $\begin{array}{r}-3.50740 \\
0: 0 \\
2.73577\end{array}$ & CROS \\
\hline & 4 & $\begin{array}{r}18.03000 \\
-3.84515 \\
2.22000\end{array}$ & $\begin{array}{r}18.00000 \\
-4.52065 \\
2.01000\end{array}$ & $\begin{array}{l}18.00000 \\
-4.52065 \\
-2.61000\end{array}$ & $\begin{array}{l}18.00000 \\
-3.84515 \\
-2.22000\end{array}$ & $\begin{array}{l}0.0 \\
-0.87550 \\
-4.83000\end{array}$ & $\begin{array}{l}0.0 \\
0.67550 \\
-4.83000\end{array}$ & $\begin{array}{c}18.00000 \\
-4.18290 \\
0.0\end{array}$ & $\begin{array}{r}-4.18290 \\
0: 0 \\
3: 26266\end{array}$ & CROS \\
\hline & 5 & $\begin{array}{r}18.00000 \\
-4.52065 \\
2.61000\end{array}$ & $\begin{array}{r}18.00000 \\
-5.19615 \\
3.010000\end{array}$ & $\begin{array}{l}18.00000 \\
-5.19615 \\
-3.00000\end{array}$ & $\begin{array}{l}18.80909 \\
-4.52065 \\
-2.61000\end{array}$ & $\begin{array}{l}0.0 \\
-0.67550 \\
-5.61000\end{array}$ & $\begin{array}{r}0.9 \\
0.67550 \\
-5.61000\end{array}$ & $\begin{array}{l}18.00000 \\
-4.85840 \\
0.0\end{array}$ & $\begin{array}{r}-4.85840 \\
0: 0 \\
3.78955\end{array}$ & CROS \\
\hline 3 & & $\begin{array}{r}18.0 j 000 \\
-1.81865 \\
-1.05000\end{array}$ & $\begin{array}{l}18.00000 \\
=2.49415 \\
-1.44000\end{array}$ & $\begin{array}{r}18.00000 \\
0.0 \\
-2.88000\end{array}$ & $\begin{array}{r}00030 \\
\text { ¿. } \\
-2.10000\end{array}$ & $\begin{array}{l}0.0 \\
1.81865 \\
-1.83000\end{array}$ & $\begin{array}{r}0.0 \\
2.49415 \\
-0.66000\end{array}$ & $\begin{array}{l}18.0000 \\
-1.07820 \\
-1.86750\end{array}$ & $\begin{array}{r}-1.07820 \\
-1.86750 \\
1.68199\end{array}$ & CROS \\
\hline
\end{tabular}


CROSS SECTION ANO CONTRCL STATION PROGRAM
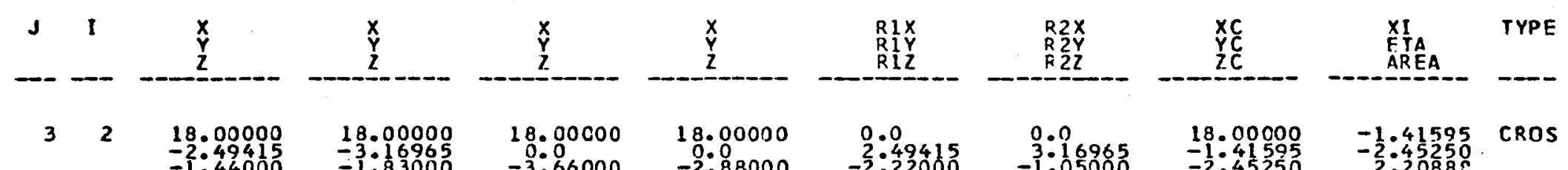

$3 \quad 2 \quad 18.00000$

18.00000
$=3.16965$
-1.83000

18.00000

18.00000

0.0

$\begin{array}{cc}0.0 & 0.0 \\ 2.49415 & 3.16965 \\ -2.22000 & -1.05000 \\ 0.0 & 0.0 \\ 3.16965 & 3.84515 \\ -2.61000 & -1.44000 \\ 0.0 & 0.0 \\ 3.84515 & 4.52065 \\ -3.00000 & -1.83000 \\ 0.0 & 0.0 \\ 4.52065 & 5.19615 \\ -3.39000 & -2.22000\end{array}$

18. 00000

0.0
-4.44000

18.00000

0.0
-3.66000

18. 00000

0.0
-5.22000

18.00000

0.0
-4.44000

18. 00000

$-6.00000$

18.00000

$-5.22000$

18.00000
-1.41595
-2.45250

-2.45250
2.2088

CROS

18.00000
-1.75370
-3.03750

-1.75370
-3.03750
2.73577

CROS

18.00000

18.009
-2.092250

$-2.09145$

-3.62250
3.26266

18.00000

-2.42920 CROS

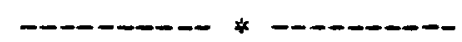

FINISHED COMPUTATION FOR CROSS SECTION

TOTAL NUMBER OF OFF-BODY POINTS GENERATED =

15

CASE NO. TEST

PROGRAM JIHP, DOUGLAS AIRCRAFT COMPANY
LONG PHURSOAYFACHAPR DIVISION

PAGE

ONE

INLET TEST CASE WITH CENTERBODY 1 hAKE 1 PL. SYM. TYPE C

NO. OF STRIPS $=3$

BODY SECTION NO. $=2$

TYPE $=1$

TOTAL NO. OF POINTS = 21

NO. OF SCURCE ELEMENTS

No. DF HAKE ELEMENTS 1 TOTAL NO. OF ELEMENTS PER STRIP

TOTAL NO. OF CONTRDL POINTS I INCL. OFF BODY PUINTS $1=15$

TOTAL NO. OF ELEMENTS IN THE LIFTING SECTION = 21

NO. UF FAR ELEMENTS =

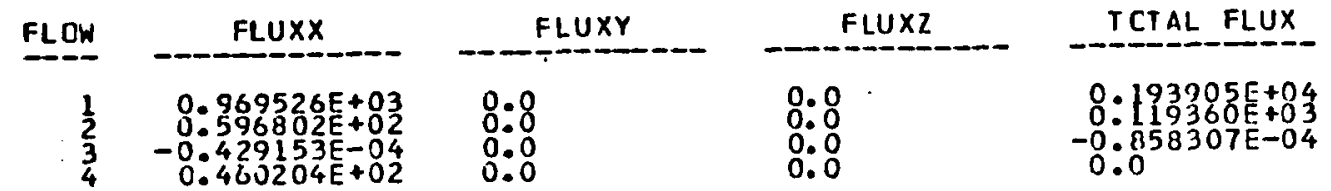

CAL CULATION OF CROSS SECTION NO. IHAS BEEN COMPLETED. 


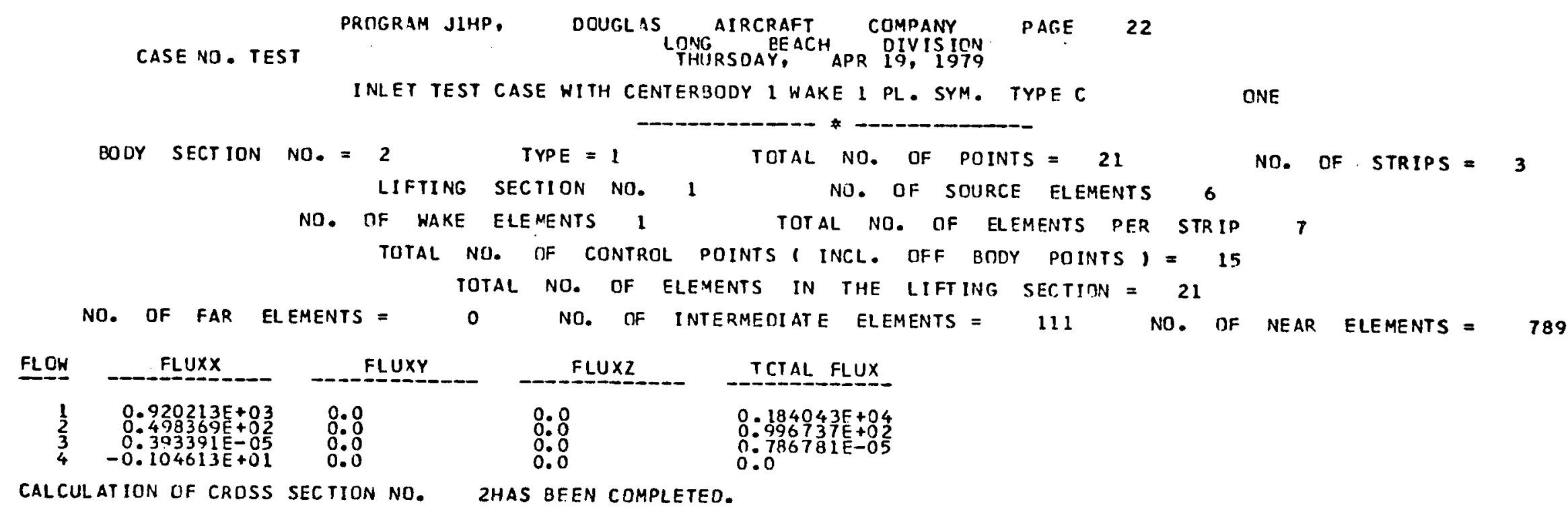

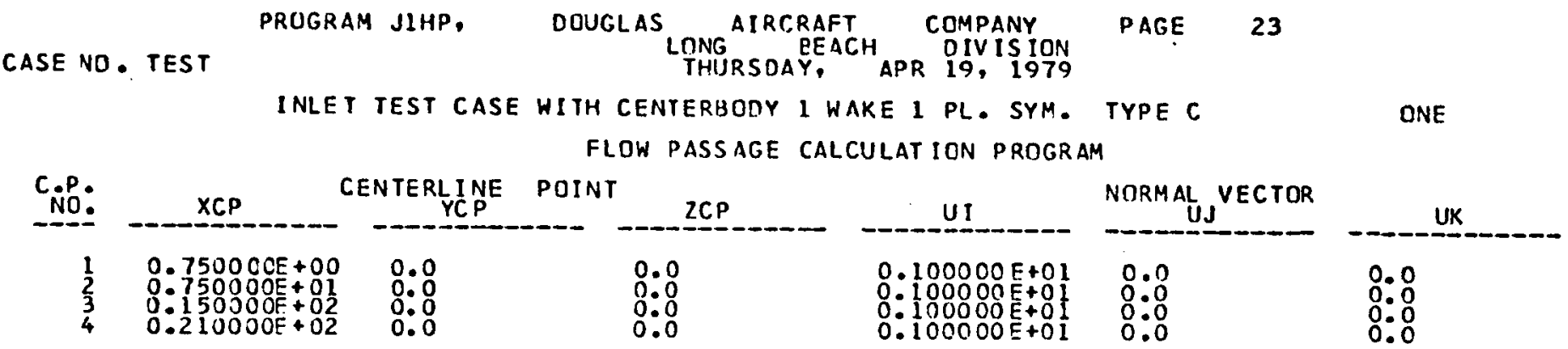




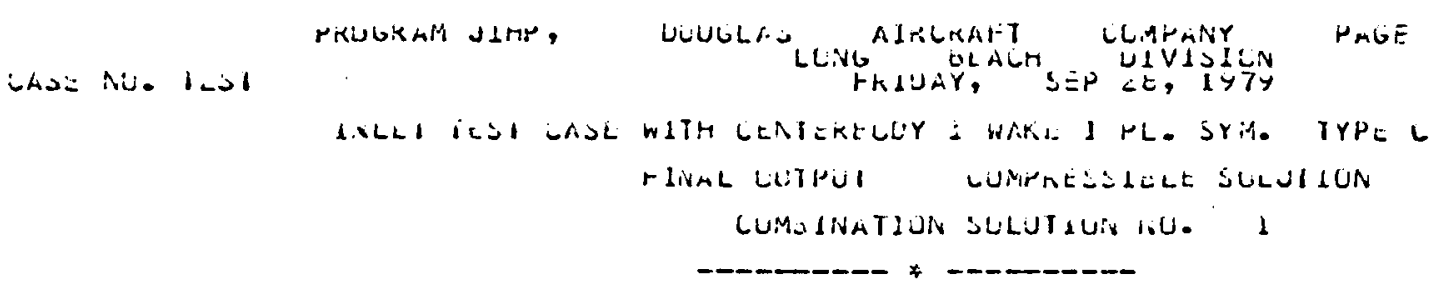

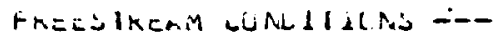

rntijunc nalid

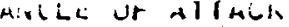

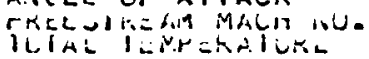

lital LeNolly

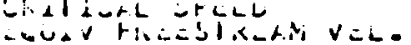

V.e. AIVLLE Óf Yain

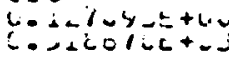

U.Sill $<4=-U$

cyctictu

coxulus

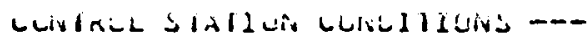

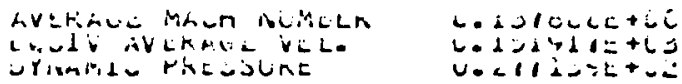

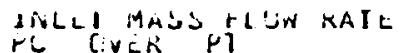

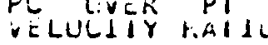

4.6 u.elruvetus U. $3=416=-02$ $\forall \rightarrow 2 \rightarrow 5$, U.

STATIL WEISITY IEFPYSSA-LEJLL KAIIO EGLIV CHATLLAL VEL.

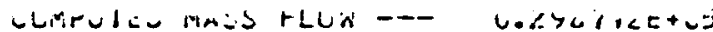
$\therefore-2110<3 E+U$ $\angle 0$

one
THEESTRLAM VLLOLITY O.141600E+U3 CYAATIL PKLSSURE L.ENDIIY KATIU U.YS1Y?IE+CO

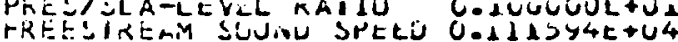

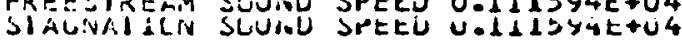

LikK. MASD FLUn RATE

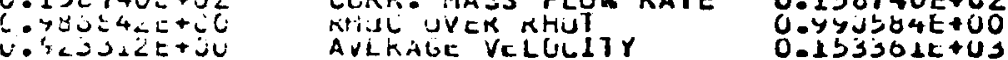

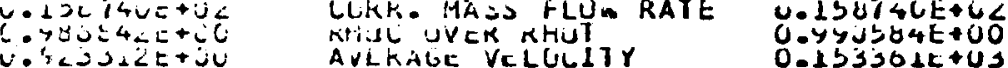


PRIGRAM JLHP, DNUGLAS AIRCRAFT COMPANY PAGE 27

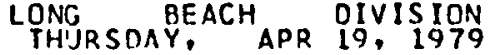

INLET TEST CASE WITH CEHTERBODY 1 WAKE 1 PL. SYM. TYPE C ONE FINAL DUTPUT COMPRESSIBLE SOLUTION NON-SYMMETRY PRINT DSTPUT SOLUTION FOR THE ON-BIOY ELEMENTS

\begin{tabular}{|c|c|c|c|c|c|}
\hline$N$ & M & \multicolumn{2}{|c|}{$\begin{array}{r}v X \\
v Y \\
V Z \\
\end{array}$} & $\begin{array}{l}\text { VMAC } \\
\text { MACH } \\
\text { P }\end{array}$ & $\begin{array}{c}\text { VBAR } \\
\text { EPSLON } \\
\text { AR EAIFP I }\end{array}$ \\
\hline \multirow[t]{3}{*}{1} & 1 & $\begin{array}{r}7.999998 \\
-0.346410 \\
0.600000\end{array}$ & $\begin{array}{r}255.825241 \\
-44.310364 \\
43.679840\end{array}$ & $\begin{array}{r}263.282959 \\
0.237253 \\
0.961577\end{array}$ & $\begin{array}{r}266.170654 \\
C .970045 \\
112.236832\end{array}$ \\
\hline & 2 & $\begin{array}{r}10.636363 \\
-0.732185 \\
1.268181\end{array}$ & $\begin{array}{r}337.686768 \\
-43.867065 \\
42.717133\end{array}$ & $\begin{array}{r}343.193115 \\
0.310487 \\
0.935346\end{array}$ & $\begin{array}{r}321.380371 \\
C .955167 \\
92.955750\end{array}$ \\
\hline & 3 & $\begin{array}{r}18.000000 \\
-0.909327 \\
1.574998\end{array}$ & $\begin{array}{r}342.087402 \\
-0.000198 \\
2.538933\end{array}$ & $\begin{array}{r}342.096924 \\
0: 309476 \\
0.935750\end{array}$ & $\begin{array}{r}364.895664 \\
0.947721 \\
81.890594\end{array}$ \\
\hline \multicolumn{2}{|c|}{$* * * * * * * * * * * *$} & & 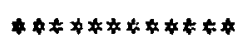 & & 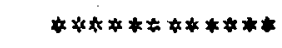 \\
\hline \multirow[t]{3}{*}{2} & 1 & $\begin{array}{r}7.999998 \\
-0.692819 \\
0.300000\end{array}$ & $\begin{array}{r}256.037109 \\
-88.693588 \\
-0.000158\end{array}$ & $\begin{array}{r}270.964355 \\
0.244257 \\
0.959337\end{array}$ & $\begin{array}{l}266.179654 \\
11: 970045 \\
112.236832\end{array}$ \\
\hline & 2 & $\begin{array}{l}10.636362 \\
-1.464368 \\
-0.050000\end{array}$ & $\begin{array}{r}337.948975 \\
-87.801758 \\
0.000023\end{array}$ & $\begin{array}{r}349.168701 \\
0: 316000 \\
0.933132\end{array}$ & $\begin{array}{r}321.382371 \\
0.955167 \\
92.955750\end{array}$ \\
\hline & 3 & $\begin{array}{l}18.000000 \\
-1.818653 \\
0.0\end{array}$ & $\begin{array}{r}342.091553 \\
0.000015 \\
0.000036\end{array}$ & $\begin{array}{r}342.091797 \\
0.309472 \\
0.935750\end{array}$ & $\begin{array}{r}364.373535 \\
C: 947696 \\
81.975381\end{array}$ \\
\hline \multicolumn{2}{|c|}{$\star \star * * * * * * * * * *$} & & 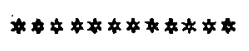 & & 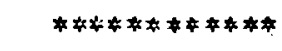 \\
\hline \multirow[t]{3}{*}{3} & 1 & $\begin{array}{r}7.999998 \\
-0.346410 \\
-0.600000\end{array}$ & $\begin{array}{l}255.825653 \\
-44.309662 \\
-43.679916\end{array}$ & $\begin{array}{r}263.283447 \\
0.237254 \\
0.961577\end{array}$ & $\begin{array}{r}266.170654 \\
0.970045 \\
112.236832\end{array}$ \\
\hline & 2 & $\begin{array}{l}10.636363 \\
-0.732185 \\
-1.268180\end{array}$ & $\begin{array}{l}337.686768 \\
-43.866455 \\
-42.717224\end{array}$ & $\begin{array}{r}343.193115 \\
0: 310487 \\
0.935346\end{array}$ & $\begin{array}{r}321.380371 \\
0.955167 \\
92.955750\end{array}$ \\
\hline & 3 & $\begin{array}{l}18.000000 \\
-0.909326 \\
-1.574998\end{array}$ & $\begin{array}{r}342.090820 \\
0.000073 \\
-2.538962\end{array}$ & $\begin{array}{r}342.100342 \\
0.309480 \\
0.935747\end{array}$ & $\begin{array}{r}364.856445 \\
0.940703 \\
81.879181\end{array}$ \\
\hline \multicolumn{2}{|c|}{ 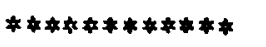 } & & $\star * * * \neq * \neq * \forall * * *$ & & $\forall * \neq * * \neq * \neq * * *$ \\
\hline \multirow[t]{6}{*}{4} & 1 & $\begin{array}{r}18.000000 \\
-2.598071 \\
4.500000\end{array}$ & $\begin{array}{r}337.698975 \\
-0.000143 \\
2.423266\end{array}$ & $\begin{array}{r}337.707764 \\
0: 305431 \\
0.937352\end{array}$ & $\begin{array}{r}365.448975 \\
0.940487 \\
81.746475\end{array}$ \\
\hline & 2 & $\begin{array}{r}7.500000 \\
-2.857880 \\
4.949999\end{array}$ & $\begin{array}{r}305.916016 \\
17.601087 \\
-14.202207\end{array}$ & $\begin{array}{r}306.754395 \\
0: 276985 \\
0.948100\end{array}$ & $\begin{array}{r}266.170654 \\
0.970045 \\
112.736816\end{array}$ \\
\hline & 3 & $\begin{array}{r}1.500000 \\
-3.767204 \\
6.524998\end{array}$ & $\begin{array}{r}102.800751 \\
44.513550 \\
-36.211075\end{array}$ & $\begin{array}{r}117.731537 \\
0: 105617 \\
0.992232\end{array}$ & $\begin{array}{l}143.946915 \\
207.5315601\end{array}$ \\
\hline & 4 & $\begin{array}{r}1.500000 \\
-5.066241 \\
8.774994\end{array}$ & $\begin{array}{r}121.370392 \\
-52.554932 \\
97.876053\end{array}$ & $\begin{array}{r}164.537415 \\
0: 147764 \\
0.984868\end{array}$ & $\begin{array}{r}56.035858 \\
0.998737 \\
533.125732\end{array}$ \\
\hline & 5 & $\begin{array}{r}7.500000 \\
-5: 775566 \\
10.349991\end{array}$ & $\begin{array}{r}165.750153 \\
-9.569506 \\
20.959061\end{array}$ & $\begin{array}{r}167.344025 \\
0: 150296 \\
0.984348\end{array}$ & $\begin{array}{r}16.709252 \\
0.999888 \\
1787.99730\end{array}$ \\
\hline & 6 & $\begin{array}{l}18.000000 \\
-6.235375 \\
10.799988\end{array}$ & $\begin{array}{r}135.253372 \\
-0.000207 \\
4.279458\end{array}$ & $\begin{array}{r}135.321167 \\
0.121441 \\
0.989747\end{array}$ & $\begin{array}{r}5.673552 \\
0.999987 \\
5265.51562\end{array}$ \\
\hline \multicolumn{2}{|c|}{ 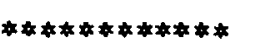 } & & 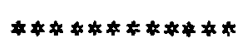 & & 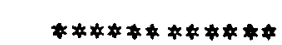 \\
\hline
\end{tabular}




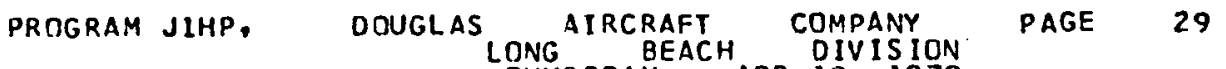
THURSDAY, APR 19, 1979

INLET TEST CASE WITH CENTERBDOY 1 WAKE 1 PL. SYM. TYPE C

CNE

FINAL DUTPUT COMPRESSIBLE SOLUTION NON-SYMMETRY PRINT DUTPUT

SOLUTION FOR THE ON-BOOY ELEMENTS

\begin{tabular}{|c|c|c|c|c|c|}
\hline $\mathbf{N}$ & & $\begin{array}{l}X C \\
Y C \\
Z C\end{array}$ & $\begin{array}{l}V X \\
V Y \\
V Z \\
V Z\end{array}$ & $\begin{array}{l}\text { VMAG } \\
\text { MACH } \\
P \quad 1 P T\end{array}$ & $\begin{array}{r}\text { VBAR } \\
\text { EPSLO } \\
\text { AREA IFP । }\end{array}$ \\
\hline \multirow[t]{6}{*}{5} & 1 & $\begin{array}{l}18.000000 \\
-5.196150 \\
0.0\end{array}$ & $\begin{array}{r}337.698486 \\
-0.000251 \\
0.000008\end{array}$ & $\begin{array}{r}337.698730 \\
0: 305423 \\
0.937355\end{array}$ & $\begin{array}{r}365.448975 \\
0.940487 \\
81.746475\end{array}$ \\
\hline & 2 & $\begin{array}{r}7.500000 \\
-5: 715766 \\
0.0\end{array}$ & $\begin{array}{r}305.956543 \\
35: 328491 \\
0.000058\end{array}$ & $\begin{array}{r}307.989746 \\
0: 278117 \\
0.947689\end{array}$ & $\begin{array}{r}266.170654 \\
112.970045 \\
236816\end{array}$ \\
\hline & 3 & $\begin{array}{r}1.500000 \\
-7.534418 \\
0.0\end{array}$ & $\begin{array}{r}102.910522 \\
89: 123047 \\
0.000048\end{array}$ & $\begin{array}{r}136.137894 \\
0: 122176 \\
0.939622\end{array}$ & $\begin{array}{l}143.946915 \\
207.991560 \\
2075011\end{array}$ \\
\hline & 4 & $\begin{aligned} 1.500000 \\
-10.132492 \\
0.0\end{aligned}$ & $\begin{array}{r}121.359207 \\
-1050100464 \\
0.000050\end{array}$ & $\begin{array}{r}160.543488 \\
0: 144162 \\
0.9851589\end{array}$ & $\begin{array}{r}56.035858 \\
0.998737 \\
533.125732\end{array}$ \\
\hline & 5 & $\begin{aligned} & 7.500000 \\
&-11: 951141 \\
& 0.0\end{aligned}$ & $\begin{array}{r}165.749908 \\
-19.134160 \\
0.000033\end{array}$ & $\begin{array}{r}166.851410 \\
0.149852 \\
0.984440\end{array}$ & $\begin{array}{r}16.708252 \\
0.999888 \\
1787.98730\end{array}$ \\
\hline & 6 & $\begin{array}{r}18.070000 \\
-12: 470764 \\
0.0\end{array}$ & $\begin{array}{r}135.253296 \\
-0.000963 \\
0.000012\end{array}$ & $\begin{array}{r}135.253403 \\
0: 121379 \\
0.989758\end{array}$ & $\begin{array}{r}5.673552 \\
0.997987 \\
5265.51562\end{array}$ \\
\hline \multicolumn{2}{|c|}{$\star * * * * * * * \neq * \star *$} & & 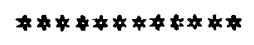 & & 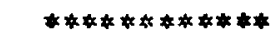 \\
\hline \multirow[t]{6}{*}{6} & 1 & $\begin{array}{l}18.000000 \\
-2.598075 \\
-4.500000\end{array}$ & $\begin{array}{r}337.698730 \\
-0.000025 \\
-2.423203\end{array}$ & $\begin{array}{r}337.707764 \\
0: 305431 \\
0.937352\end{array}$ & $\begin{array}{r}365.448975 \\
0.940487 \\
81.746475\end{array}$ \\
\hline & 2 & $\begin{array}{r}7.500000 \\
-2.857882 \\
-4.949999\end{array}$ & $\begin{array}{r}305.916016 \\
17.661621 \\
14.202299\end{array}$ & $\begin{array}{r}306.754395 \\
0: 276985 \\
0.948100\end{array}$ & $\begin{array}{r}266.170654 \\
0.970045 \\
112.236816\end{array}$ \\
\hline & 3 & $\begin{array}{r}1.500000 \\
-3: 767209 \\
-6.524998\end{array}$ & $\begin{array}{r}102.800186 \\
44.513626 \\
36.211151\end{array}$ & $\begin{array}{r}117.731094 \\
0: 105617 \\
0.992232\end{array}$ & $\begin{array}{l}143.946915 \\
207.991560 \\
2073611\end{array}$ \\
\hline & 4 & $\begin{array}{r}1.500000 \\
-5.066248 \\
-8.774994\end{array}$ & $\begin{array}{l}121.370255 \\
-52: 55486 \\
-97.876068\end{array}$ & $\begin{array}{r}164.537323 \\
0: 147764 \\
0.984868\end{array}$ & $\begin{array}{r}56.035858 \\
0.998737 \\
533.125732\end{array}$ \\
\hline & 5 & $\begin{array}{r}7.590000 \\
-5.975574 \\
-10.349991\end{array}$ & $\begin{array}{r}165.750320 \\
-29.569611 \\
-20.959091\end{array}$ & $\begin{array}{r}167.344193 \\
0: 150296 \\
0.984348\end{array}$ & $\begin{array}{r}16.708252 \\
1787997888930\end{array}$ \\
\hline & 6 & $\begin{array}{r}18.000000 \\
-6.235385 \\
-10.799988\end{array}$ & $\begin{array}{r}135.253418 \\
-0.000322 \\
-4.279426\end{array}$ & $\begin{array}{r}135.321228 \\
0: 121441 \\
0.989747\end{array}$ & $\begin{array}{r}5.673552 \\
0.999987 \\
5265.51562\end{array}$ \\
\hline \multicolumn{2}{|c|}{$* * * * * * * * * * * *$} & & 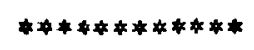 & & $k * * *$ \\
\hline
\end{tabular}


PROGRAM JLHP, DOUGLAS AIRCRAFT COMPANY PATE 31

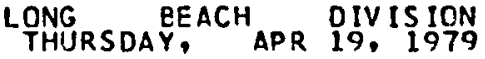

INLET TEST CASE WITH CENTERBOOY I WAKE 1 PL. SYM. TYPE C ONE

FINAL OUTPUT COMPRESSIBLE SOLUTION SYMMETRY PRINT OUTPUT -- REFLECTED ELEMENTS

SOLUTION FOR THE ON-BDDY ELEMENTS

\begin{tabular}{|c|c|c|c|c|c|}
\hline \multicolumn{2}{|l|}{$N$} & $\begin{array}{l}X C \\
Y C \\
Z C \\
-\end{array}$ & $\begin{array}{l}V X \\
V Y \\
V Z \\
-1\end{array}$ & $\begin{array}{l}\text { VMAG } \\
\text { MACH } \\
P\end{array}$ & $\begin{array}{r}\text { VBAR } \\
\text { EPSLON } \\
\text { AREA } \\
\end{array}$ \\
\hline \multirow[t]{3}{*}{$1 R$} & 1 & $\begin{array}{l}7.999998 \\
0.346410 \\
0.600000\end{array}$ & $\begin{array}{r}255.805099 \\
44: 306885 \\
39.166000\end{array}$ & $\begin{array}{r}262.551758 \\
0: 236587 \\
0.961787\end{array}$ & $\begin{array}{l}266.170654 \\
112: 970045 \\
236832\end{array}$ \\
\hline & 2 & $\begin{array}{r}10.636363 \\
0: 732185 \\
1.268181\end{array}$ & $\begin{array}{r}337.664795 \\
43.864227 \\
38.705170\end{array}$ & $\begin{array}{r}342.695068 \\
0: 310028 \\
0.935529\end{array}$ & $\begin{array}{r}321.380371 \\
0.955167 \\
92.955750\end{array}$ \\
\hline & 3 & $\begin{array}{r}18.000000 \\
0.909327 \\
1.574998\end{array}$ & $\begin{array}{r}342.087402 \\
0.000198 \\
-2.538939\end{array}$ & $\begin{array}{r}342.096924 \\
0.309476 \\
0.935750\end{array}$ & $\begin{array}{r}364.805664 \\
C .940721 \\
81.890594\end{array}$ \\
\hline \multicolumn{2}{|c|}{$* * * * * * * * * * * *$} & & 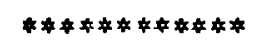 & & 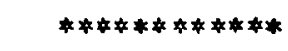 \\
\hline \multirow[t]{3}{*}{$2 R$} & 1 & $\begin{array}{l}7.999998 \\
0.692819 \\
0.000000\end{array}$ & $\begin{array}{r}256.037109 \\
88.69358 \\
-0.000133\end{array}$ & $\begin{array}{r}270.964355 \\
0.244257 \\
0.959337\end{array}$ & $\begin{array}{r}266.170654 \\
0.970045 \\
112.236832\end{array}$ \\
\hline & 2 & $\begin{array}{r}10.636362 \\
1.464368 \\
-0.000000\end{array}$ & $\begin{array}{r}337.948975 \\
87.801758 \\
0.000021\end{array}$ & $\begin{array}{r}349.168701 \\
0: 316000 \\
0.933132\end{array}$ & $\begin{array}{r}321.380371 \\
0.955167 \\
92.955750\end{array}$ \\
\hline & 3 & $\begin{array}{l}18.000000 \\
1.818653 \\
0.0\end{array}$ & $\begin{array}{r}342.091553 \\
-0.000015 \\
0.000042\end{array}$ & $\begin{array}{r}342.091797 \\
0.309472 \\
0.935750\end{array}$ & $\begin{array}{r}364.873535 \\
0.940696 \\
81.875381\end{array}$ \\
\hline \multicolumn{2}{|c|}{$* * * * * * * * * \neq * *$} & & 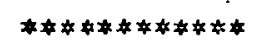 & & 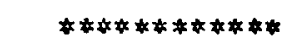 \\
\hline $3 R$ & 1 & $\begin{array}{r}7.999998 \\
0.346410 \\
-0.600000\end{array}$ & $\begin{array}{r}255.805511 \\
44.306168 \\
-39.166046\end{array}$ & $\begin{array}{r}262.552002 \\
0.236587 \\
0.961787\end{array}$ & $\begin{array}{r}266.170554 \\
0.970045 \\
112.236832\end{array}$ \\
\hline & 2 & $\begin{array}{r}10.636363 \\
0.732185 \\
-1.268180\end{array}$ & $\begin{array}{r}337.664795 \\
43.863617 \\
-38.705215\end{array}$ & $\begin{array}{r}342.694824 \\
0: 310028 \\
0.935529\end{array}$ & $\begin{array}{r}321.380371 \\
92.955167 \\
92.955750\end{array}$ \\
\hline & 3 & $\begin{array}{r}18.000000 \\
0.909326 \\
-1.574998\end{array}$ & $\begin{array}{r}342.090820 \\
-0.050070 \\
2.538970\end{array}$ & $\begin{array}{r}342 \cdot 100342 \\
0.309489 \\
0.935747\end{array}$ & $\begin{array}{r}364.856445 \\
0.940703 \\
81.879181\end{array}$ \\
\hline \multicolumn{2}{|c|}{$\star * * \star * \neq * * * * * *$} & & 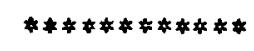 & & 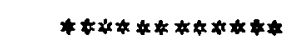 \\
\hline \multirow[t]{6}{*}{$4 R$} & 1 & $\begin{array}{r}18.000000 \\
2.598071 \\
4.500000\end{array}$ & $\begin{array}{r}337.698975 \\
0.000143 \\
-2.423064\end{array}$ & $\begin{array}{r}337.707764 \\
0: 305431 \\
0.937352\end{array}$ & $\begin{array}{r}365.448975 \\
0.940487 \\
81.746475\end{array}$ \\
\hline & 2 & $\begin{array}{l}7.590000 \\
2: 857880 \\
4.949999\end{array}$ & $\begin{array}{l}305.924072 \\
-17.661560 \\
-18.716019\end{array}$ & $\begin{array}{r}307.004639 \\
0.277214 \\
0.948016\end{array}$ & $\begin{array}{l}266.170654 \\
112.236816\end{array}$ \\
\hline & 3 & $\begin{array}{l}1.500000 \\
3.767204 \\
6.524998\end{array}$ & $\begin{array}{l}102.799973 \\
-44.513214 \\
-35.814575\end{array}$ & $\begin{array}{r}117.609390 \\
0.105507 \\
0.992248\end{array}$ & $\begin{array}{l}143.946915 \\
207.991560 \\
207.56011\end{array}$ \\
\hline & 4 & $\begin{array}{l}1.500000 \\
5.066241 \\
8.774994\end{array}$ & $\begin{array}{r}121.370621 \\
52.555023 \\
98.019104\end{array}$ & $\begin{array}{r}164.627757 \\
0: 147841 \\
0.984852\end{array}$ & $\begin{array}{r}56.035858 \\
0.998737 \\
533.125732\end{array}$ \\
\hline & 5 & $\begin{array}{r}7.500000 \\
5: 975566 \\
10.349991\end{array}$ & $\begin{array}{r}165.749207 \\
9.569451 \\
12.674822\end{array}$ & $\begin{array}{r}166.508484 \\
0: 149542 \\
0.984505\end{array}$ & $\begin{array}{r}16.708252 \\
0.799888 \\
1787.98730\end{array}$ \\
\hline & 6 & $\begin{array}{r}18.000000 \\
6.235375 \\
10.799988\end{array}$ & $\begin{array}{r}135.253372 \\
0.000207 \\
-4.279350\end{array}$ & $\begin{array}{r}135.321167 \\
0.121441 \\
0.989747\end{array}$ & $\begin{array}{r}5.673552 \\
0.999987 \\
5265.51562\end{array}$ \\
\hline \multicolumn{2}{|c|}{$\star * * * * * * * * * * *$} & & 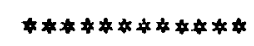 & & 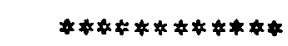 \\
\hline
\end{tabular}


PROGRAM JIHP, DOUGLAS AIRCRAFT COMPANY PAGE 33 LONG PHURSDAY, ACACH OPR I9, 1979

ONE

INLET TEST CASE WITH CENTERBODY 1 WAKE 1 PL. SYM. TYPE C FINAL OUTPUT COMPRESSIBLE SOLUTION SYMMETRY PRINT OUTPUT -- REFLECTED ELEMENTS SOLUTION FOR THE ON-BOOY ELEMENTS

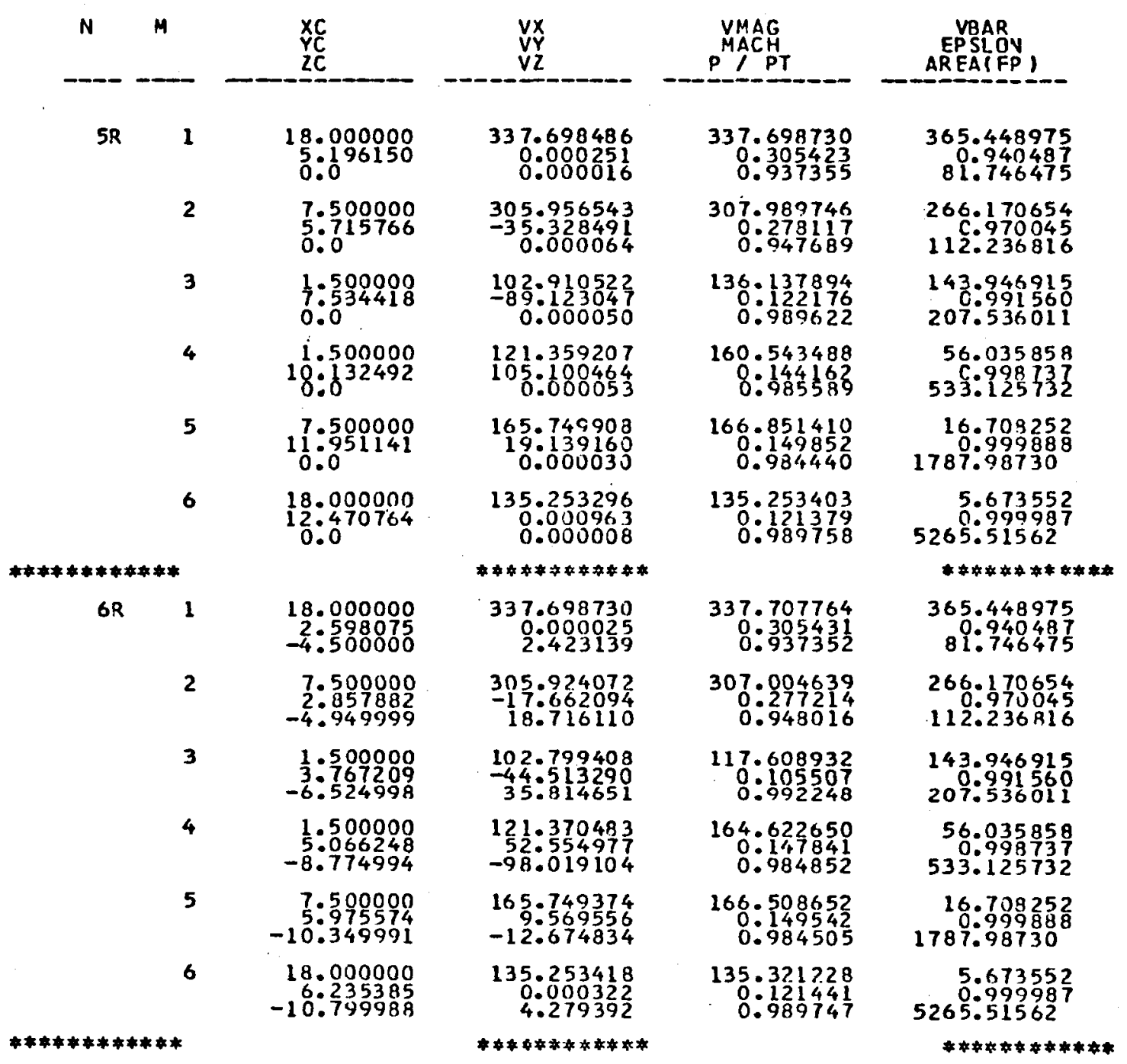




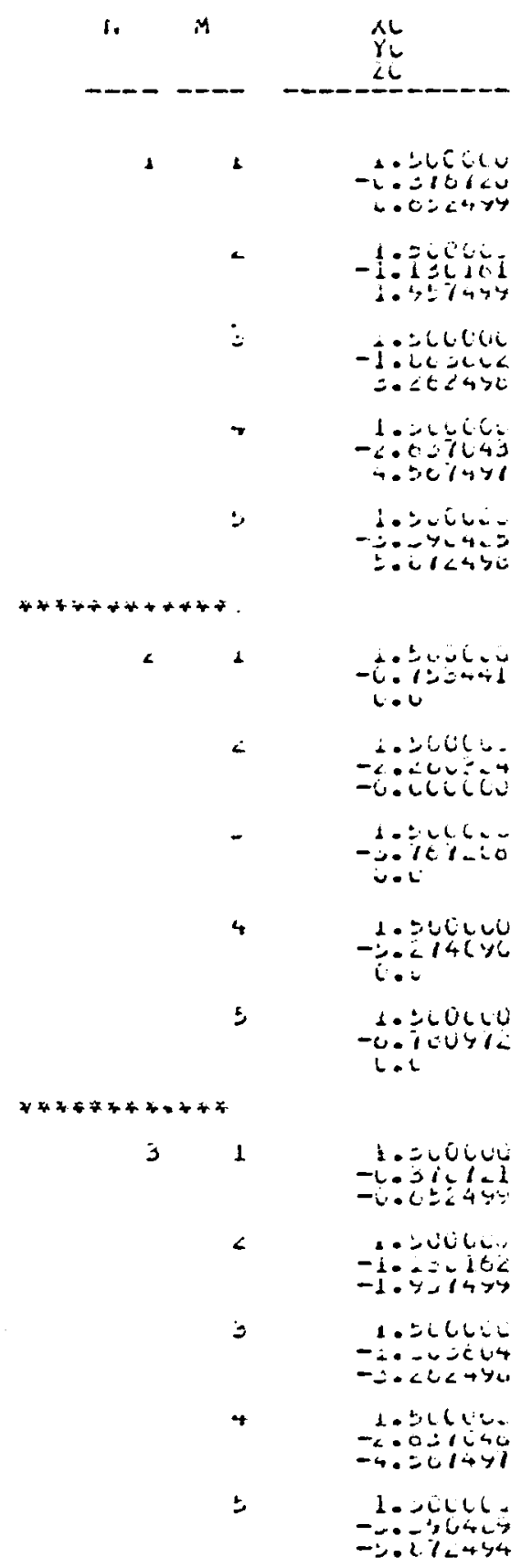

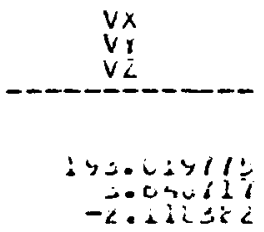

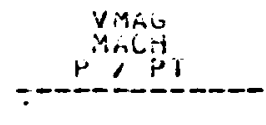

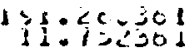
-citis

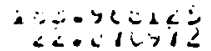

$-120,2+i L 5$

$\Delta-4 \cdot c+1<3$

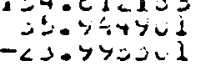

$1<-0.51-7 c$

$-1.52455$

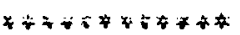

$+90064-7=$

i. . vilus

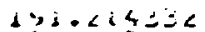

2.0

1.4. $-2 .+1,10$

a. 1CU4C

avivio

$134-1+10<$

11.42 .3944

C.. $2 i c i s$

2.0.5603

i. $i$ i i $t$

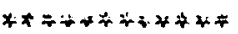

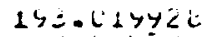
a.t4isic

1) 21.20045 11. $12<015$ t... 54.05

1E3.) C.til

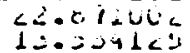

$154.51170 y$ ーシ・ターニニ

1230 -2.2दो.

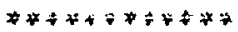

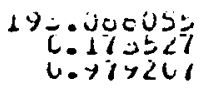

$1>1 \cdot 7+3726$ i.

16.

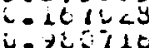

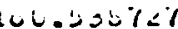
U.

三.

C. $11>4=4$

: प Yर:CEs

142.

L. $11-013$

. I Y YES

14:-1 1455 $U .17 \equiv 216$
U. $47 \div 278$

$10 j \cdot 0 \div-2+4$ C. 110448 U⿺⿻⿻一𠃋十⿺⿻一𠃋

114.12132

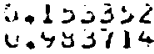

$144.10>02=$ U. $1<\because 441$
l. 40.70

$1 Y 5.606143$ i. $17 ?+304$

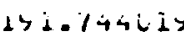
c. $11-3=5$ 6.9748

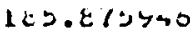
L. 10 ivis

lti.jssto .144134

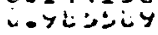

$1=\dot{A}<\leq<0<1$ i. $\begin{aligned} & 1 \\ & \text { i. }>\text { y }\end{aligned}$
VEAK AKEA (FP) -

$د C=-5 \dot{0}=5<$ U.SCl
Yu. $3<4$ iU⿺

$30 \mathrm{j} \cdot 3 \mathbf{3}<25$ $>\varepsilon \cdot 324108$

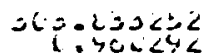
YA. $-2<4$ ite

sن3. 33232 C. $>0$ C 45

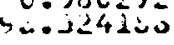

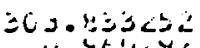
U. StUCYL X.josile

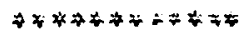

ง $40.3 \angle+18 b$

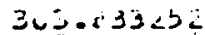

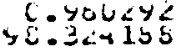

- $200=3-0 \leq$ C. You $<y<$ 40.324108

al $-205<2$ $(0.70)<y 2$ Y $6.3<+162$

301.003202 U. $400<5<$

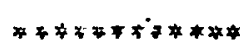

كان L. you:4. $\checkmark \mathrm{y} \cdot 3<+10 \dot{0}$

si. $2.20: 20$ 1.2Cl 42 >i. उदि1दu

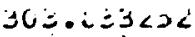
$6 .>t 264<$
$4-0.324200$

उट L. $>4<y<$ $x: 3<4<6$

ग $20.0334 \%$ पi. उ

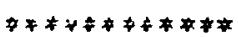

LKLSS-SELTLLA PLAIVE NC.

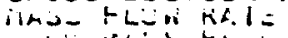

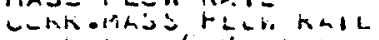

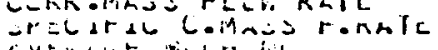
Fvenale incm ivi.e
1

- $2440=1 L+U C$

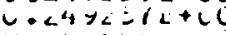
U.<i-jue L-U L. LCS 


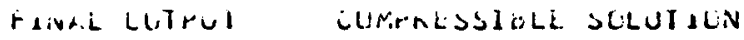

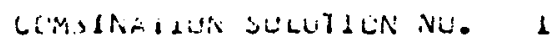$$
\text { SYMVILIRY RKLIVI UUTHUI - REFLLCTEO ELEMENTS }
$$

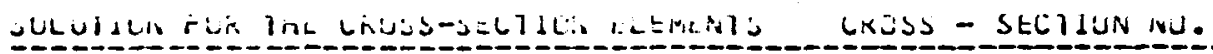

\begin{tabular}{|c|c|c|}
\hline iv & & $\begin{array}{l}x L \\
y L \\
L C\end{array}$ \\
\hline $1 \mathrm{k}$ & 1 & 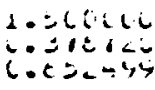 \\
\hline & $\dot{2}$ & 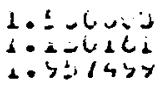 \\
\hline & $\dot{\Xi}$ & 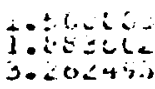 \\
\hline & 4 & 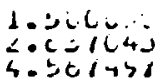 \\
\hline & $\dot{ }$ & 1. \\
\hline $4+++\infty=2+4$ & & \\
\hline$\angle K$ & 1 & 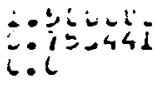 \\
\hline & $c$ & $\frac{1}{2} \cdot 2<u$ \\
\hline & $=$ & 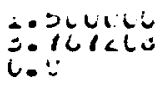 \\
\hline & 4 & $\begin{array}{l}-306 \\
-2146\end{array}$ \\
\hline & $=$ & 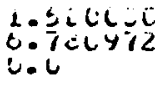 \\
\hline $4 * 4 * * 4 * 4$ & & \\
\hline $2 k$ & $i$ & $1.3 \leq 6 \leq$ \\
\hline & c & $-3-c c c$ \\
\hline & ت & $1-20 \mathrm{COC}$ \\
\hline & 4 & 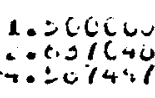 \\
\hline & ג & $\begin{array}{l}3<x y \\
1<4>4\end{array}$ \\
\hline
\end{tabular}

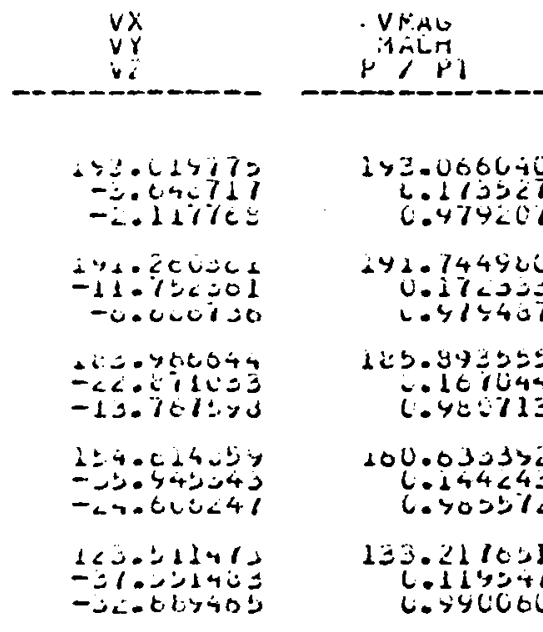

*⿻一𠃋十

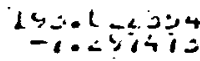
i.civut4

$1 \because 1.05235$

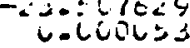

145.105980 4. iviluta

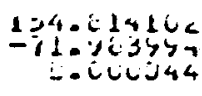

$1<=-6 y 0 e$

-19.01919

L.CCECa

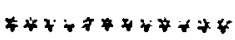

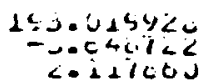

111006400 $c 0$ cos 06

Itisycoes i.oilles

190.019040
-39.4906 anove-5:

$1<3011414$ $=-10501+4 y$

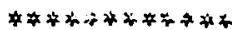
493016416 i. $11 \leq t<5$
i.y

$142.7232=?$ colisis C. $>7 y<10$

io ?. 559210 0.116441
0.474528
$116 \cdot 92123<$ c. 03354
0.405714
$144.70>040$ ‥ $12>y+1$ i.tex

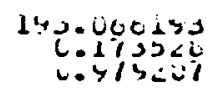

$1>1.94=0$ ㄴ. 1 1 433

105.0y-c10 단

100.030216 l.144251

$135-211743$ i.114097

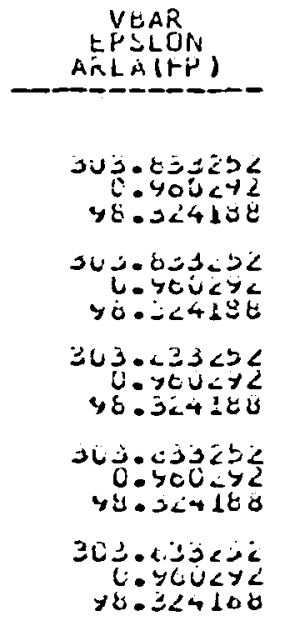

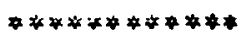

303.033252

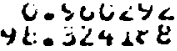

उ०3.8j3<2 $0.50<42$ Yن.-ं<4lic

2030102052 98.344198

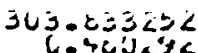
corcjustc

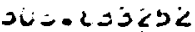

cosuctic $>$ >.

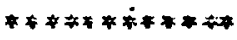

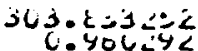
पष्ठ $044 \mathrm{ib}$

シง $0 .>0(1<y<$ >c.

كان C.>CC.'L

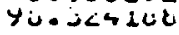

$363.253 \times 52$

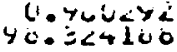

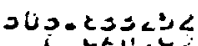
i. bed 4 y

YL. $2 \angle 410 \mathrm{C}$

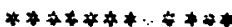
LRUSS-itinilir r LANR Nu.

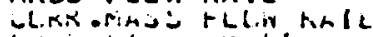
Sractle vekinsts rekati mulnmete inalt: trie.

il Lisal tivir
1

U. $43 c+25 t+v i$ $\because A S C D \angle S L+U C$ $\therefore-u l i d z-i c$

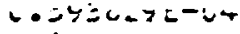


LASt Nu. I ISI

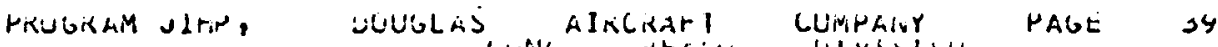

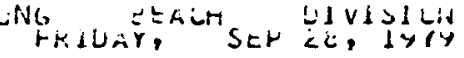

IVIET leSI LASE WITH CERTERECLY I WAKE 1 HL. SYM. IYPE $C$

UNE

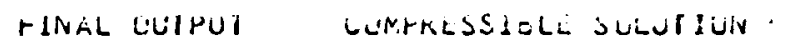

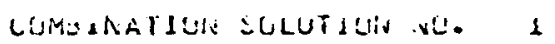

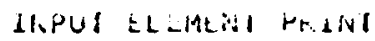

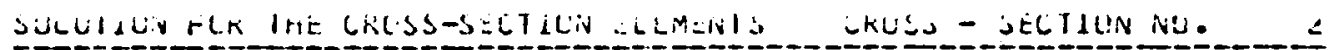

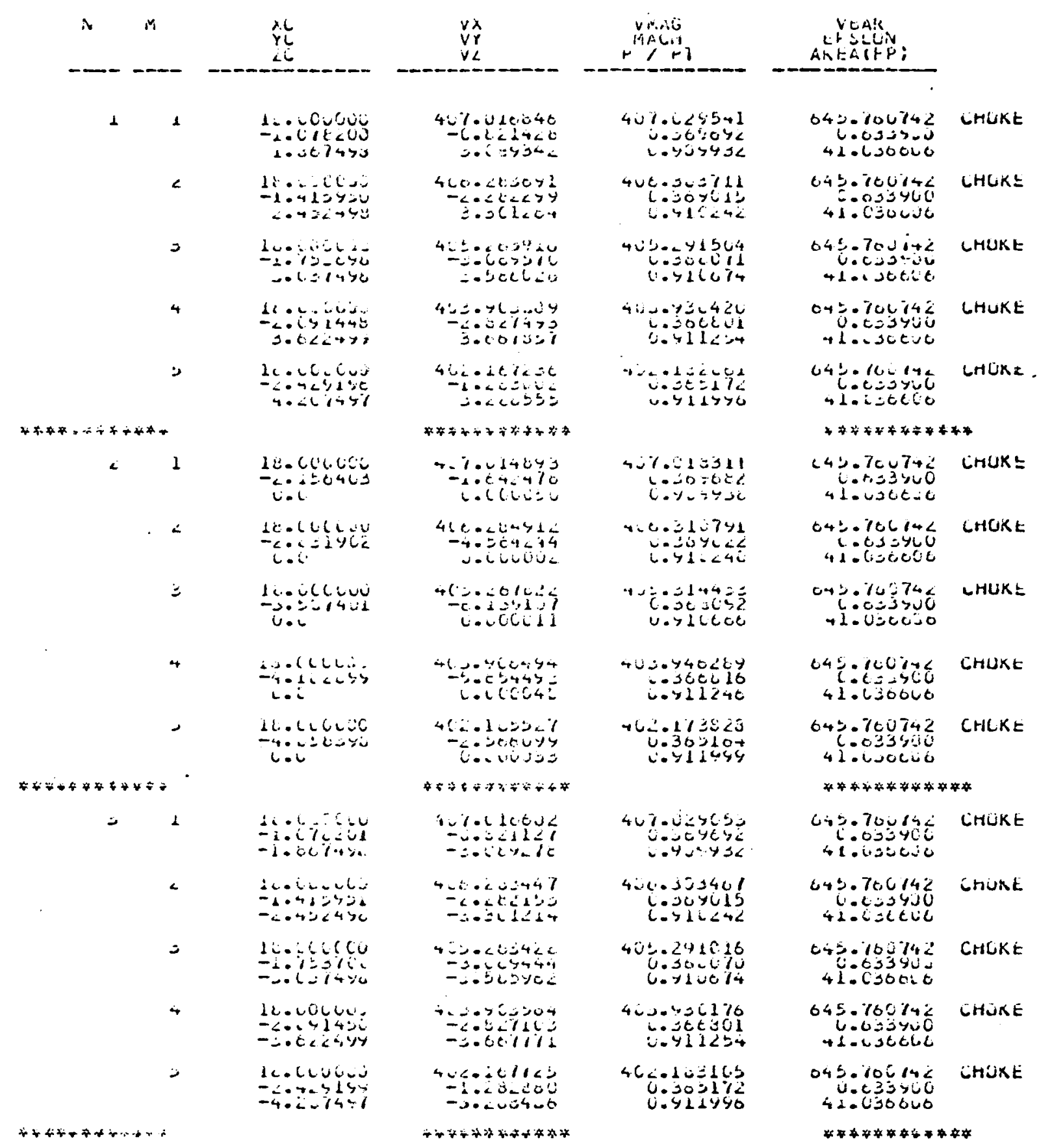

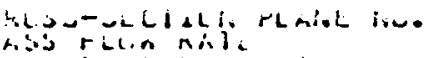

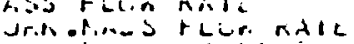

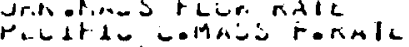

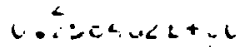

vermice Nauri ki.

lexnoiviv

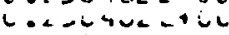

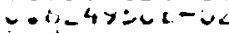

U.

1 
PKUGKAM JIHY, ULUGLAS

GASE NU. TESI

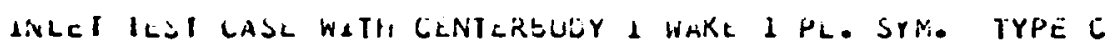

UNE

FIPIML UUIRUI CUMFHESEILLE SULUTIUN

CLMELNAIIL.N SLLUIILN NL. 1

SYMMLIKY FRLNT WUTRUT - REFLECTEO ELEMENTS

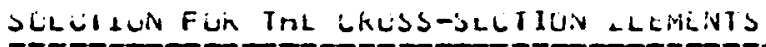
LXUSS - SELTIUN NO. $\therefore$

\begin{tabular}{|c|c|c|}
\hline w & i & $\begin{array}{l}x c \\
y \\
L E\end{array}$ \\
\hline ik & 1 & 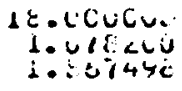 \\
\hline & 2 & 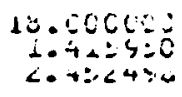 \\
\hline & $=$ & 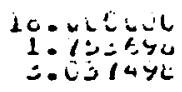 \\
\hline & 4 & 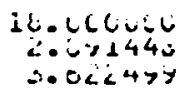 \\
\hline & $=$ & $\begin{array}{r}10.2046 \\
34<y 1 \% 0 \\
40074 y 0\end{array}$ \\
\hline \multicolumn{3}{|c|}{$+4+7 * *+4+4+*$} \\
\hline$<k$ & $i$ & 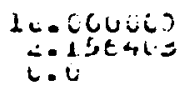 \\
\hline & $c$ & $\begin{array}{l}\text { 1E. } \\
\text { c. }\end{array}$ \\
\hline & 2 & 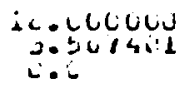 \\
\hline$\cdot$ & 4 & $1=0 \operatorname{cicc}$ \\
\hline & $=$ & 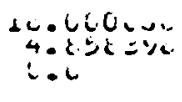 \\
\hline \multicolumn{3}{|c|}{ 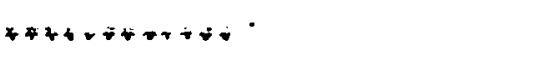 } \\
\hline sn & 1 & 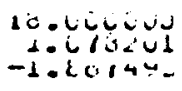 \\
\hline & - & 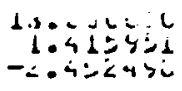 \\
\hline & 3 & 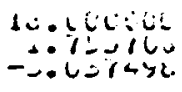 \\
\hline & 4 & 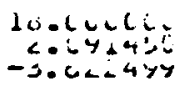 \\
\hline & $=$ & 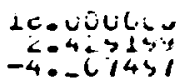 \\
\hline
\end{tabular}

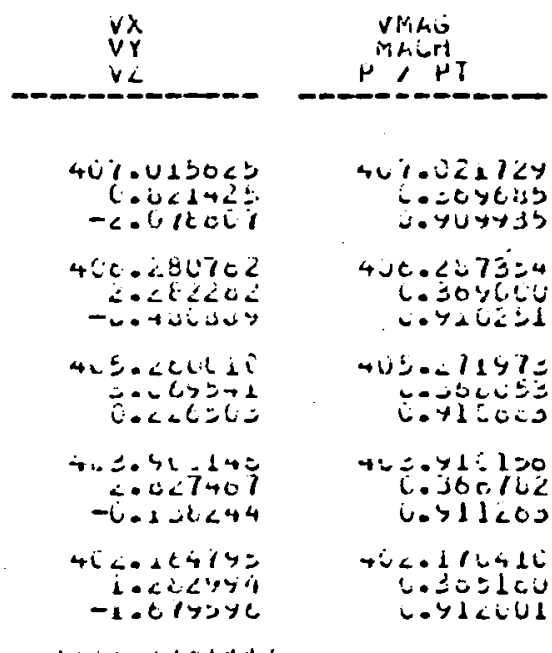

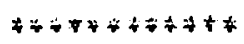

$+67.214 \div 3$
$1.64-4 \% 3$

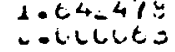

$4 . t \cdot c i+>1<$

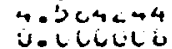

$4-3 \cdot 0<13<$

cosedit

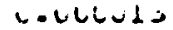

$423.5604 y 4$ cocicistio

$4+2 \cdot 16=207$ $<\cdot \div \cos 49$

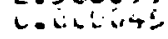

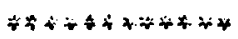

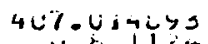
$u \cdot i-11 z$ i. C C t e r

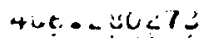
$4.4 \div 2=0$
6.3154

$4330 \pm 5100$

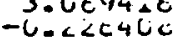

4.: - Eบyo: $\therefore-2<1010$

U. $10=0<8$ 1.202513
$1-014021$

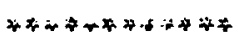

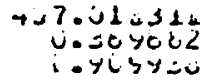

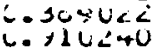

400024452

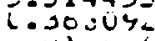
.4lucoó

$40 \div 07462 C Y$

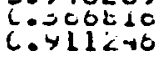

$40<.27020$ 0.504104
$1.411>49$

$40.0<1240$ $0.00=0$
$0.50 \div+55$

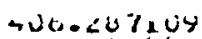
U. 0 -

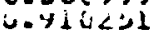

412.71484 U. Yil 100

4Cj-yûy $1:$ U. $300 \% 24$
U. $411<63$

$4 \div 217135 ?$ 0.305161
U.

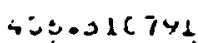

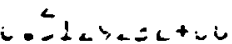
U. U-1L4>>L-U1 c. $+4 t<9+5-5$ liber teig kal ariclirai lonats ronal r.visani mincin ine ligron I L is 


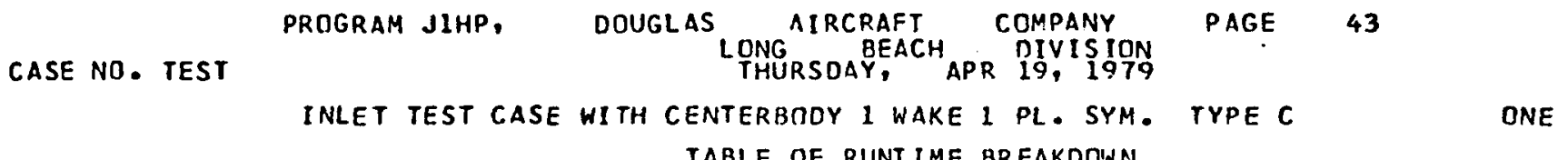

TABLE OF RUNT IME BREAKDONN

\begin{tabular}{ccc} 
SUBROUTINES & $\begin{array}{c}\text { CPUTIME } \\
\text { ATI CALL } \\
\text { STAIEMENT }\end{array}$ & $\begin{array}{c}\text { CPU TIME } \\
\text { AFTER RETURN } \\
\text { IOCALLPROG }\end{array}$ \\
\hline MAIN & 0.000 & 16.590 \\
REPAN & 0.0 & 0.0 \\
INPUT & 0.035 & 0.632 \\
VFORM & 0.632 & 2.194 \\
PSWISE & 0.0 & 0.0 \\
AFORM & 2.194 & 2.564 \\
COLSOL & 2.564 & 3.233 \\
FSLUTN & 4.100 & 4.824 \\
CROSEC & 4.895 & 7.853 \\
FLPASG & 7.886 & 8.501 \\
COMPRO & 0.0 & 0.0. \\
ICMPRS & 8.501 & 16.590 \\
& & \\
\hline
\end{tabular}

\begin{tabular}{cc} 
CPU TIME & \multicolumn{1}{c}{ IN TIME } \\
\hline AT CALD & STATEMENT \\
\hline 16.590 & 0.0 \\
0.0 & 0.0 \\
0.597 & 0.068 \\
1.562 & 1.386 \\
0.0 & 0.0 \\
0.370 & 2.286 \\
0.668 & 2.566 \\
0.724 & 3.376 \\
2.958 & 4.186 \\
0.615 & 7.488 \\
0.0 & 0.0 \\
8.088 & 8.804 \\
\hline
\end{tabular}

\begin{tabular}{|c|c|}
\hline $\begin{array}{l}\text { AFT'O TIMER } \\
\text { TI RALTURN } \\
\end{array}$ & I/ O TIMED \\
\hline 13.244 & 13.244 \\
\hline 0.0 & 0.0 \\
\hline 1.386 & 1.318 \\
\hline 2.286 & 0.900 \\
\hline 0.0 & 0.0 \\
\hline 2.566 & 0.280 \\
\hline 3.578 & 1.012 \\
\hline 4.066 & 0.690 \\
\hline 7.488 & 3.302 \\
\hline 8.804 & 1.316 \\
\hline 0.0 & 0.0 \\
\hline 13.244 & 4.440 \\
\hline
\end{tabular}

( UNIT IN SECONDS )

*** end of input data. nORmal program termination. 

4. Title and Subtitle

An Efficient User-Oriented Method for Calculating

Compressible Flow In and About Three-Dimensional Inlets

9. Performing Organization Name and Address Douglas Aircraft Company

McDonnel1 Douglas Corporation

o. Work Unit No.

3855 Lakewood Blvd.

Long Beach, CA. 90846

11. Contract or Grant No.

NAS3-21135

13. Type of Report and Period Covered

Contractor Report

Nov. 1977

14. Sponsoring Agency Code

National Aeronautics and Space Administration

Washington, D.C.

15. Supplementary Notes

Final Report. Project Manager:

H.C. Kao, Wind Tunnel and Flight Division,

NASA-Lewis Research Center

Cleveland, Ohio

16. Abstract

This method uses a panel method to calculate incompressible flow about arbitrary three-dimensional inlets with or without centerbodies for four fundamental flow conditions: unit onset flows parallel to each of the coordinate axes plus static operation. The computing time is scarcely longer than for a single solution. A linear superposition of these solutions quite rigorously gives incompressible flow about the inlet for any angle of attack, angle of yaw, and mass flow rate. Compressibility is accounted for by applying a well-proven correction to the incompressible flow. Since the computing times for the combination and the compressibility correction are small, flows at a large number of inlet operating conditions are obtained rather cheaply. Geometric input is aided by an automatic generating program. A number of graphical output features are provided to aid the user, including surface streamline tracing and automatic generation of curves of constant pressure, Mach number, and flow inclination at selected inlet cross sections. This report describes the inlet method, including the use of the program and presents illustrative results.

17. Key Words (Suggested by Author(s)) Aerodynamics Computer Program Panel Method Flow Field Graphical Display Inlets
18. Distribution Statement

Unclassified - Distribution UnTimited
19. Security Classif. (of this report)

Unclassified
20. Security Classif. (of this page) Unclassified
21. No. of Pages

115
22. Price 
Copy number

Report number

ADC J8497

AN EFFICIENT USER-ORIENTED METHOD

FOR CALCULATING COMPRESSIBLE FLOW IN

AND ABOUT THREE-DIMENSIONAL INLETS

Revision date

Issue date

July 1979

Contract number

NAS3-21135

Prepared by: John L. Hess

Dun-Pok Mack

Norbert 0. Stockman (NASA Lewis Research Center)

Approved by :

Hence Geber

Tuncer Cebeci

Chief Technology Engineer

Research

Frank T. Lynch

Branch Chief

Research and Development

Aerodynamics Subdivision

Aerodynamics Subdivision

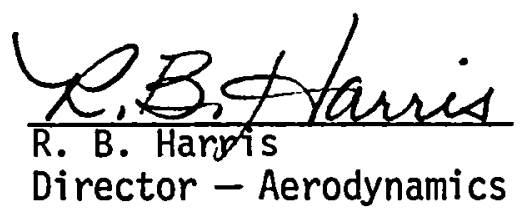

DOUGLAS AIrcRAFt COMPANY

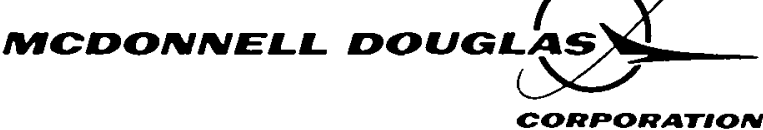





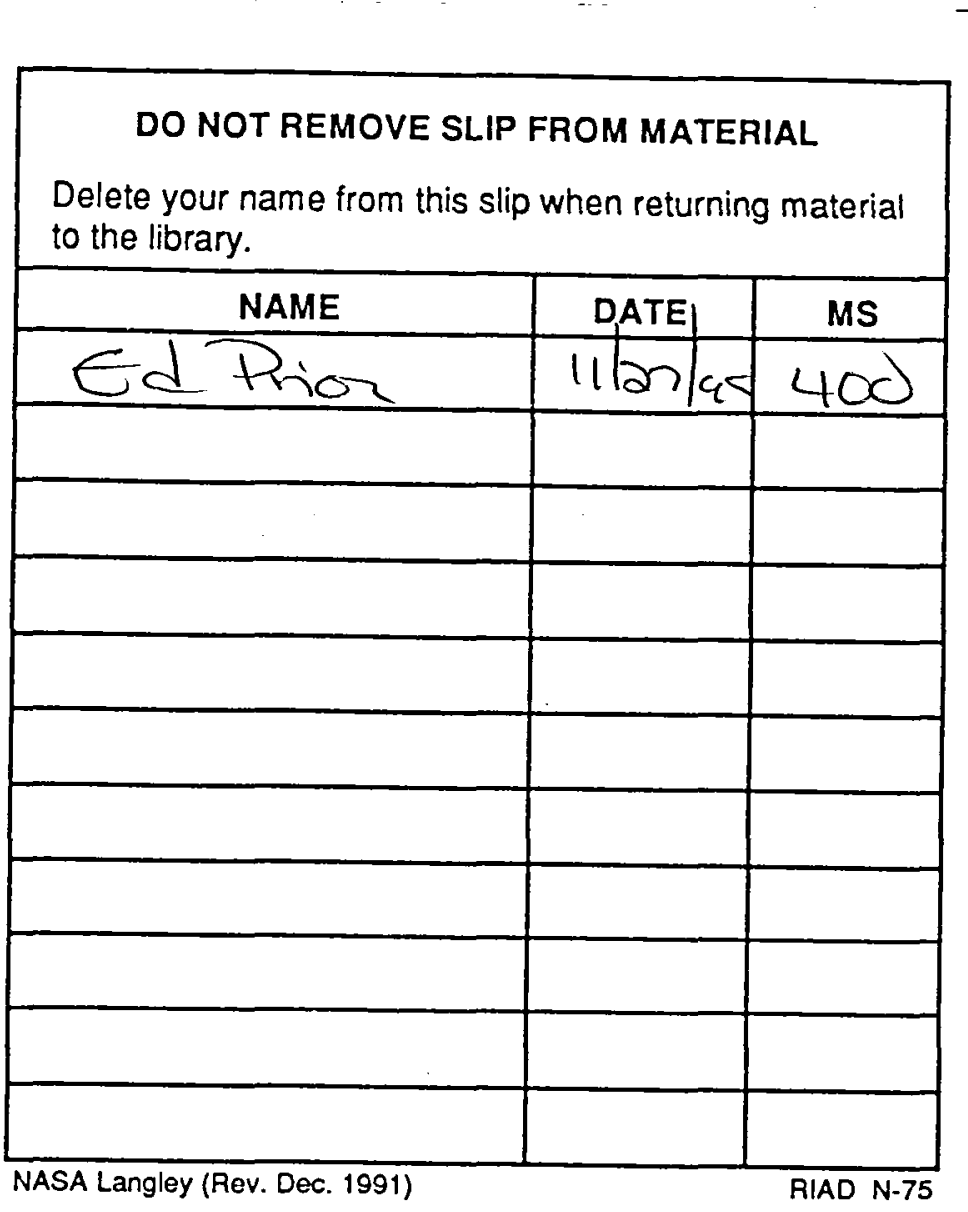

